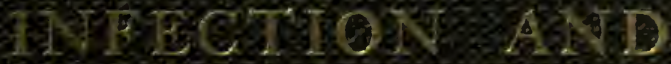

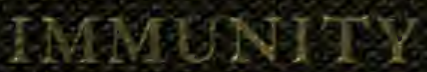

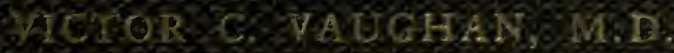




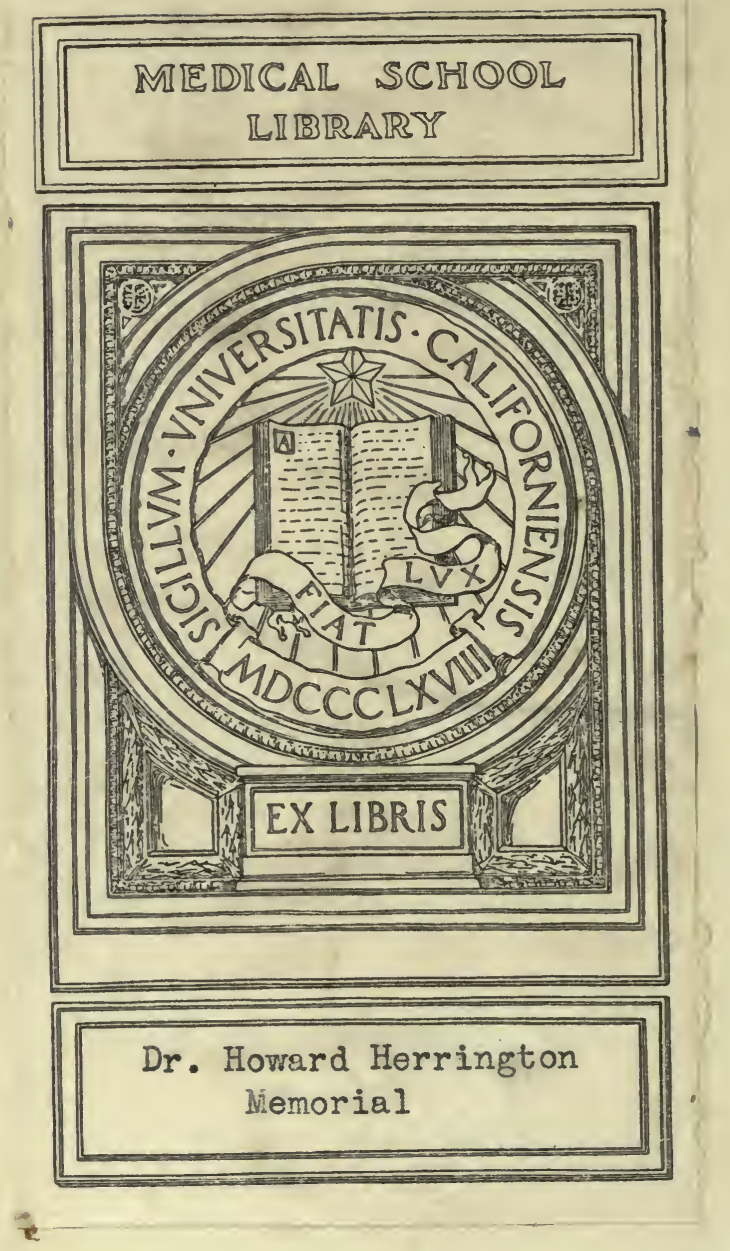


Io He Herringtons in

imonery of an charmin?

ony fine thain oes

Inoter. The Guthin 
Digitized by the Internet Archive in 2007 with funding from Microsoft Corporation 



\title{
INFECTION AND IMMUNITY
}

\author{
By
}

VICTOR C. VAUGHAN, M.D.

ANN ARBOR, MICH.

CHICAGO

AMERICAN MEDICAL ASSOCIATION

1915

R 
Copyright, 1915

BY THE

American Medical Association

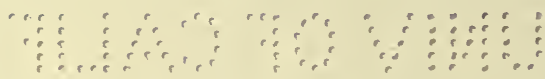

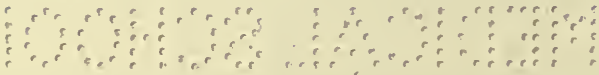




\section{QR175 \\ $\vee 36$ \\ 1915}

This monograph is a part of the Commemoration Volume, issued by the American Medical Association at its meeting in San Francisco, June 22 to 26, 1915, as a tribute to the medical sciences, which made possible the building of the Panama Canal and the Panama Pacific Exposition. 



\section{FOREWORD}

The development of modern medicine, its influence on civilization, and its rôle in the advancement of the welfare of the nation are matters which concern us all. While our lives are short and we are soon to pass away, our children and their descendants will possess and occupy the land,- - at least we hope that this may be true. No nation can be great so long as disease prevails widely among any classes. Modern medicine has become largely a social service. Preventive medicine is the keystone of the triumphal arch of modern civilization. Displace it and the whole structure will fall. Widespread epidemics lead to national decay. Infection has overthrown nations and has blotted out civilizations in the past. We are aware of the fact that the future of this country does not depend wholly on the medical man, but he should be ready at all times to do his part in assisting in the progress of the nation. Medicine consists of those facts, gathered from the various sciences, which can be utilized in the prevention or cure of disease. That nation which does not encourage scientific investigation, must fall into the rear. It is, therefore, the duty of the state to favor research medicine. Every physician who treats an infectious disease renders a service to the individual under his treatment, and at the same time he renders a greater service to the community in preventing the spread of the disease.

The present volume is an incomplete and imperfect statement of what medicine has done, is doing, and an indication of what it may do for the common good. The attempt has been made to present these facts in non-technical verbiage so that any intelligent citizen may read, comprehend, and appreciate them. The medical profession feels that it has a patriotic duty to perform in the advancement of the best interests of the people. It offers its services, and begs an intelligent appreciation of what it has done, is doing, and may do. 



\section{CONTENTS}

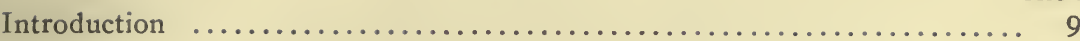

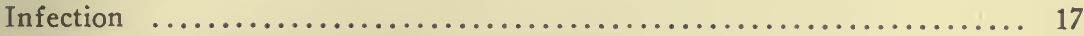

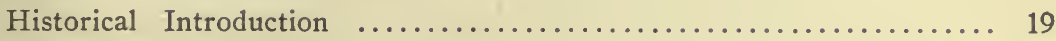

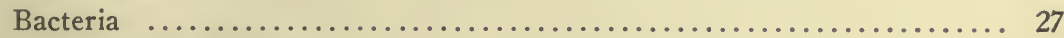

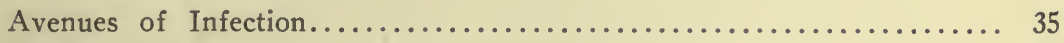

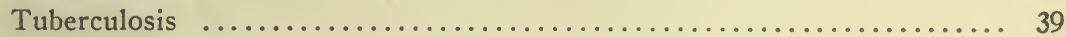

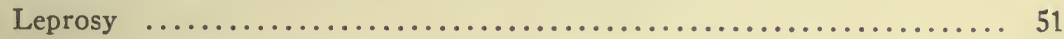

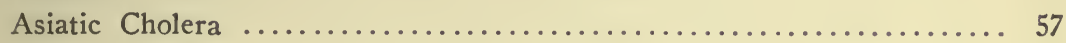

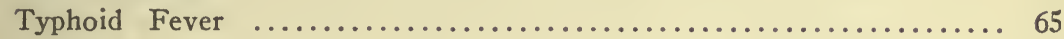

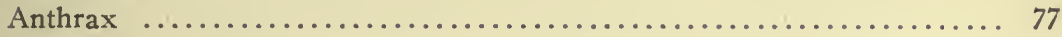

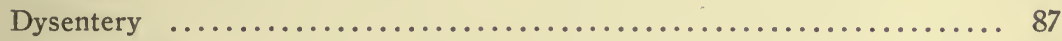

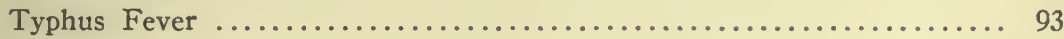

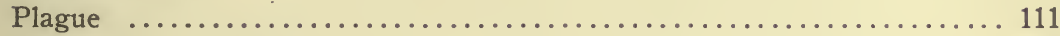

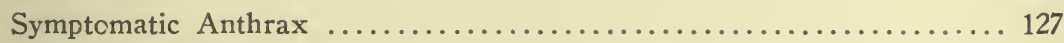

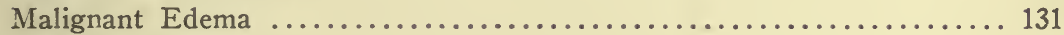

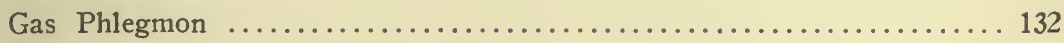

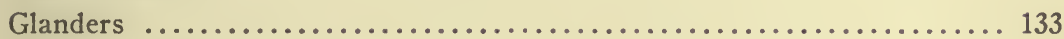

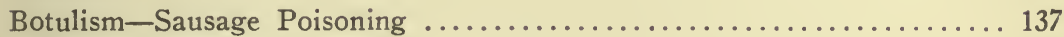

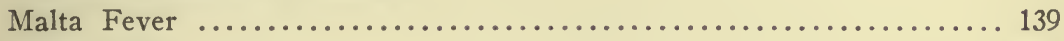

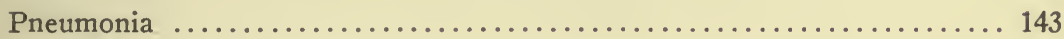

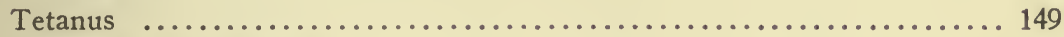

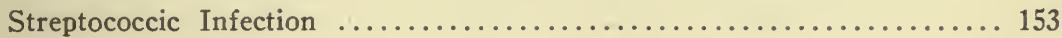

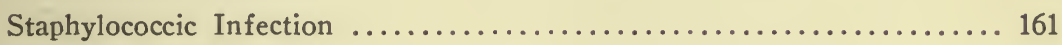

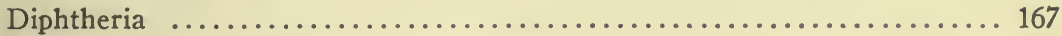

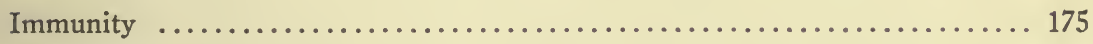

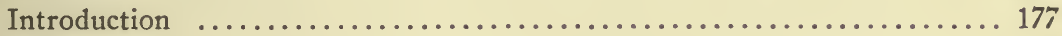

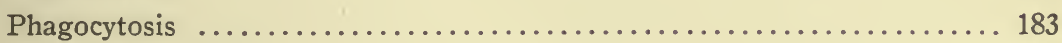

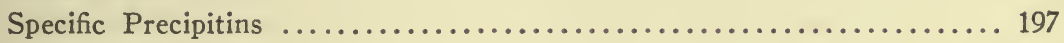

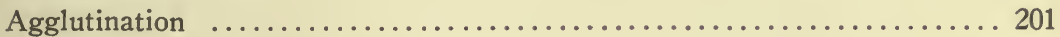

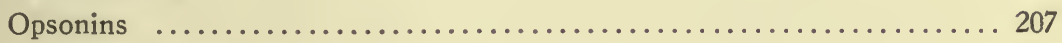

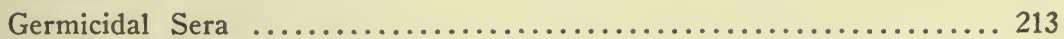

The General Principles and Mechanism of Infection and Immunity....... 223

The Index 



\section{CHAPTER I}

\section{INTRODUCTION}

The purpose of this writing is to state the essential facts of infection and immunity accurately and simply, so that they may be understood by the intelligent, non-professional man. The reduction and ultimate eradication of unnecessary disease and the consequent prolongation of life with improved health constitute a patriotic obligation which every citizen should strive to appreciate and to do his part in its performance.

The further developments of medicine, both curative and preventive, depend on scientific investigations. The public is the beneficiary and should in every way encourage medical research. By the application of discoveries already made, the burden of disease has been lightened, sickness has become less frequent and less prolonged, a greater degree of health has been secured, the efficiency of the individual and of the nation has been increased, and life has been lengthened and made more enjoyable. The Federal government and the states should sustain and promote scientific research. That government is the best which secures for its citizens the greatest freedom from disease, the highest degree of health and the longest life, and that people which most fully secures the enjoyment of these blessings will dominate the world.

Medicine consists of the application of scientific discovery to the prevention and cure of disease. All else which may go under the name of medicine is sham and fraud. Without advancement in the physical, chemical, and biologic sciences, there can be no progressive movement in medicine. Scientific knowledge is gained only by observation and experiment. Before the time of Jenner, we are told by the historian, it was unusual to meet in London one whose face was not marked by smallpox. There was a popular belief that one who had cowpox was immune to smallpox. Jenner put this belief to a scientific test. The result was the discovery of vaccination, and this secured the abolition of this disfigurement and a marked reduction in mortality. In 1849, a village doctor, with a crude microscope, 
studied the blood of animals sick with anthrax and compared it with that of healthy ones. He discovered the anthrax bacillus. This work was extended by Davaine, Pasteur, Koch, and others, and from this, the science of bacteriology has been developed. The particulate causes of many infectious diseases have been recognized, isolated, and their effects on animals demonstrated. Many of the mysteries of contagion have been revealed and the conditions of the transmission of disease made known. The fundamental principles of preventive medicine have been developed into a science which is to-day the most potent factor in the progress of civilization. Finlay suspected a certain mosquito to be the carrier of the virus of yellow fever. Reed and his co-workers demonstrated the truth of this theory, the work of Gorgas has freed Havana from the pestilence, and the construction of the Panama Canal is an accomplished fact.

Laveran discovered Plasmodium malariae. Ross studied its life history, and the fetters of a disease that has so long retarded the progress of man, have been broken. Mitchell and Reichert investigated the poisonous properties of snake venom. Sewall immunized animals with it. Ehrlich studied the similar bodies, abrin, ricin and diphtheria toxin, and von Behring and Roux gave the world antitoxin, the magical curative value of which has greatly reduced the mortality from diphtheria. The experiments of Villemin demonstrated the contagious nature of tuberculosis, long suspected and frequently denied. The diligent research of Koch resulted in the recognition and isolation of the causative agent, and since this discovery the mortality of the Great White Plague in Europe and the United States has been diminished more than half. It is, then, within the range of sanity to look forward to the time when the former "Captain of the hosts of death" will be known only by the fearful records he once made in the history of man's struggle to be relieved from the heavy tribute paid to infection.

We boast of a great civilization, but this is justified only within limits. Science more nearly dominates the world than at any time in the past. Learning permeates the masses more deeply, but credulity and ignorance are widely prevalent. In this country of nearly one hundred millions, there are thousands whose greed impedes the progress of the whole, tens of thousands whose ignorance retards their 
own growth, and other thousands who live by crime and procreate their kind to feed on generations to come. We have our schools, colleges, and universities, while our almshouses, insane asylums, and penal institutions are full. In our cities we see the palatial homes of the very rich, the splendid temples of trade and commerce, the slums of want and poverty, and the homes, both rich and squalid, of vice and crime. No nation in this condition can be given a clean bill of health. Our hilltops are illuminated by the light of knowledge, but our valleys are covered by the clouds of ignorance. We have not emerged from the shadows of the dark ages. The historian of the future will have no difficulty in convincing his readers that those who lived at the beginning of the twentieth century were but slightly removed from barbarism, as he will tell that the school, saloon, and house of prostitution flourished in close proximity; that the capitalist worked his employees under conditions which precluded soundness of body; that the labor union man dynamited buildings; that while we sent missionaries to convert the Moslem and the Buddhist, ten thousand murders were committed annually in the midst of us, and that a large percentage of our mortality was due to preventable disease.

Evidently there is much to be done before we pass out from the shadows of ignorance into the full light of knowledge. In this great work for the betterment of the race the medical profession has important duties to perform. I do not mean to imply that the uplift of mankind devolves wholly on the medical man. The burdens are too many and too diversified, the ascent is too steep and the pathways are too rough for one profession to hope to reach unaided the high plateau we seek. Moreover, other callings have no right, and should have no desire to shirk the moral responsibilities which rest alike on all. But in past ages, medical men have been the chief torch bearers of science, whose light is the only one in which man may safely walk, and we must keep and transmit this trust and honor to those who follow us. I know of no scientific discovery, from the ignition of wood by friction to the demonstration of the causes of infection and the restriction of disease, which has not sooner or later assisted in the betterment of the race. It may be added that nothing else has so aided man in his slow and halting progress from the pestilential marshes of ignorance to the open uplands of intelligence. 
In so great a work as the eradication of preventable disease, all intelligent people must cooperate. The law must support by proper enactments, and these must be enforced with justice and intelligence; it must recognize that the right to enjoy health is quite as sacred as that to possess property; that to poison men in factories and mines, to pollute drinking-water supplies, to adulterate foods, and to drug with nostrums, is manslaughter. Religion must teach the sanctity of the body as well as that of the soul, that ignorance is sin and knowledge virtue, that parenthood is the holiest function performed by man, and that to transmit disease is an unpardonable sin. The teacher must know hygiene as well as mathematics. The capitalist must recognize that improvement in health and growth in intelligence increase the efficiency of labor. There never has been a time when scientific medicine has had so many and such efficient and appreciative helpers as it has to-day. Our sanitary laws are for the most part good, but their administration is weak, on account of ignorance. The pulpits of the land are open, for the most part, to the sanitarian. The respectable newspapers are most effective in the crusade against quackery and disease. The philanthropist has learned that the advancement of science confers the greatest and most lasting benefits on man.

There is a moral obligation to be intelligent. Ignorance is a vice and when it results in injury to anyone, it becomes a crime, a moral, if not a statutory one. To infect another with disease, either directly or indirectly, as a result of ignorance, is an immoral act. The purpose of government is to protect its citizens, and a government which fails to shelter its citizens against infection is neither intelligent nor moral. To transmit disease of body or mind to offspring is an unpardonable sin. In a reasonable sense it is worse than murder, because it projects suffering into the future indefinitely.

That medicine has become a fundamental social service must be evident. To return one incapacitated by illness or injury to the condition of self-support, benefits not only the individual, but the community, inasmuch as it increases its productive capacity. Infirmity is a direct burden on the individual and scarcely less direct on the community. Weakness in any part diminishes the strength of the whole. It is a fully established principle in social economy that widespread intelligence and growth in knowledge are beneficial to the state. It 
was in full recognition of this that the framers of the ordinance of 1787 wrote into that immortal document: "Religion, morality and knowledge being necessary to good government and the happiness of mankind, schools and the means of education shall forever be encouraged." The territory of the Northwest, the government of which was created in this ordinance, was at that time a vast waste of forest and prairie, furnishing a scant and precarious subsistence for savage tribes and attracting to its borders a few of the most hardy sons of civilization. The knowledge, for whose growth and diffusion the wise provision was made, has drained the malarial marshes, converted wild prairie and tangled wood into fruitful orchards and fertile fields, dotted the whole area with neat villages, reared great cities, linked all parts with steam and electric roads, and provided comfortable homes and abundant food for millions. The men who wrote the ordinance of 1787 left a great inheritance which is temporarily in our possession. Let us write into this great document: "Every ill which can be relieved shall be removed, and every preventable disease shall be prevented." The wisdom of our fathers has secured for us a greater measure of health and a longer term of life; let us do as well for those who are to possess this fair land in the next generation. Let us live not only for ourselves and the present, but for the greater and more intelligent life of the future.

Not myself, but the truth that in life I have spoken,

Not myself, but the seed that in life I have sown

Shall pass into ages - all about me forgotten

Save the truth I have spoken, the things I have done.

All things are relative and health is no exception. With a greater degree of health among all, religion will become more effective for good, morality will have a deeper significance and a wider application, and knowledge will multiply and distribute its blessings more widely.

After the last epidemic of the plague in London, in 1665, the deathrate, so far as it can be ascertained, fell to between seventy and eighty per 1,000. During the next century it fell as low as fifty, but fluctuated greatly with recurring epidemics of typhus and smallpox. In the nineteenth, it gradually and quite constantly decreased and is now about fourteeen. In $1879-80$, the first year in which the mortality 
statistics of the United States possess sufficient accuracy to be of any value, the death-rate in the registered area was 19.8; in 1912 it was 13.9 - a decrease of 30 per cent. During the same time the mortality from typhoid fever has decreased 50 per cent.; that from scarlet fever 89 per cent.; that from diphtheria 84 per cent.; that from tuberculosis 54 per cent. Hoffman states that had the death-rate for tuberculosis in 1901 continued, there would have been 200,000 more deaths from this cause from that date to 1911 than actually did occur, so that the actual saving of lives from death by tuberculosis accomplished in that decennium averaged 20,000 a year. Preventive medicine measures its successes by the number of lives saved, and 20,000 a year preserved from death from one disease is no small triumph. In the last century the average of human life has been increased fifteen years and this increase could be duplicated in the next twenty years if the facts we now possess were effectively employed. Hoffman further states that the addition to the material wealth of this country secured by the reduction of deaths from tuberculosis within ten years amounts approximately to $6,200,000$ years of human life, covering its most productive period. Medicine discovered the facts which have made this great work possible and has directed their application. With evidence of this kind before them, will our lawmakers listen to those who demand recognition as practitioners of medicine without proper qualifications?

The following figures give the death-rates from all causes and from each of certain infectious diseases in the registered area of the United States since the census of the year of 1879-80:

\begin{tabular}{|c|c|c|c|c|c|}
\hline \multirow[b]{2}{*}{ Year } & \multirow{2}{*}{$\begin{array}{l}\text { Deaths per } \\
1,000 \text { from } \\
\text { all causes }\end{array}$} & \multirow{2}{*}{$\overbrace{\text { Scarlet fever }}$} & \multicolumn{2}{|c|}{-Deaths per 100,000 from- } & \multirow[b]{2}{*}{$\begin{array}{l}\text { Tuberculosis } \\
\text { (all forms) }\end{array}$} \\
\hline & & & Typhoid fever & Diphtheria & \\
\hline $1879-80$ & 19.8 & 54.0 & 34.0 & 112.6 & 326.2 \\
\hline 1889-90 & 19.6 & 13.6 & 46.3 & 97.8 & 267.4 \\
\hline 1899 & 17.8 & 11.6 & 33.8 & 45.2 & 205.2 \\
\hline 1900 & 17.6 & 10.2 & 35.9 & 43.3 & 201.9 \\
\hline 1901 & 16.5 & 13.1 & 32.3 & 34.0 & 196.9 \\
\hline 1902 & 15.9 & 12.6 & 34.3 & 30.8 & 184.5 \\
\hline 1903 & 16.0 & 12.2 & 34.1 & 31.7 & 188.5 \\
\hline 1904 & 16.5 & 10.8 & 31.7 & 28.3 & 200.7 \\
\hline 1905 & 16.0 & 6.7 & 27.8 & 23.6 & 192.3 \\
\hline 1906 & 15.7 & 7.7 & 31.3 & 25.7 & 180.2 \\
\hline 1907 & 16.0 & 10.0 & 29.5 & 23.6 & 178.5 \\
\hline 1908 & 14.8 & 11.9 & 24.3 & 21.5 & 167.6 \\
\hline 1909 & 14.4 & 11.4 & 21.1 & 20.4 & 160.8 \\
\hline 1910 & 15.0 & 11.6 & 23.5 & 21.4 & 160.3 \\
\hline 1911 & 14.2 & 8.8 & 21.0 & 18.9 & 158.9 \\
\hline 1912 & 13.9 & 6.7 & 16.5 & 18.2 & 149.5 \\
\hline 1913 & $: 4.1$ & 8.7 & 17.9 & 18.8 & 147.6 \\
\hline
\end{tabular}


Preventive medicine, still in its youth, has accomplished great things. As I have stated, within the past thirty years in this country the mortality from tuberculosis has been reduced more than half, and with scarlet fever and diphtheria, the results have been more striking. Within the past ten years, the average life has been increased four years. Great epidemics which once devasted continents are no longer known in the more intelligent parts of the world. In fact, it may be said that the death-rate is now an excellent measure of intelligence. In 1911 the death-rate in London was 15 per thousand, while that of Moscow was 27.3. Preventive medicine is the keystone of the triumFhal arch of modern civilization and its displacement would precipitate mankind into relative barbarism. Should the health administrators of any great commercial center fail, for even a few months, to exercise the function of restricting disease, the history of the epidemics of the middle ages might be repeated. Great things have been done, but greater tasks lie before us, and their accomplishment depends on the scientific wisdom of the medical profession and the intelligence of the people. Without the harmonious adjustment of these forces the greatest efficiency cannot be secured. While the mortality from tuberculosis has been reduced half in the past thirty-five years, we must not assume that the total eradication of this disease will be accomplished in the same number of years. Only the more progressive members of the profession have taken the initiative, and only the more intelligent members of the community have responded. Intelligence and the sense of moral responsibility must grow as the work proceeds. It remains for all who have the welfare of the race at heart to plan wisely and carry forward courageously the campaign against greed, ignorance and disease. 



\section{PART I}

I N F ECTION 



\section{CHAPTER II}

\section{HISTORICAL INTRODUCTION}

The oldest and most persistent belief holds that disease is an infliction imposed on man by some supernatural power. This doctrine was handed down by tradition to the earliest civilizations, was incorporated in their records and is held by many to-day. Some have attributed disease to evil spirits and others have regarded it as a dispensation of their gods. The Babylonians regarded disease "as the work of demons which swarmed in the earth, air and water, and against which long litanies and incantations were recited." In the hand of the Jehovah of the Jews disease was a whip of chastisement which fell at will on the chosen people or their enemies. "I will put none of those diseases upon thee which I have brought upon the Egyptians; for I am the Lord that healeth thee." There is no book of the middle ages down to the eighteenth century, describing an epidemic which does not attribute it to the wrath of God. Job ascribed his own pains to the "arrows of the Almighty." Luther wrote that "pestilence, fever and other severe diseases are naught else than the devil's work." Cotton Mather described disease as "flagellum Dei pro pecatis mundi."

"The American Indian medicine man or the Asiatic Samoyed does his best to frighten away the demons of disease by assuming a terrifying aspect, covering himself with the skins of animals so as to resemble an enormous beast walking on his hind legs, resorting to such demonstrations as shouting, raving, slapping his hands or shaking a rattle, and pretending (or endeavoring) to extract the active principle of the disease by sucking it through a hollow tube. . . . We may smile at these phases of Shamanistic procedure, but, except for the noise, they are not essentially different from the mind-medicine or faithhealing of our own day. Both rely upon psychotherapy and suggestion, and for a sick savage, the fantastic clamor made about him might be conceivably as effective as the quieter methods of Christian Science, to a modern nervous patient." (Garrison.) 
A doctrine quite as old, but with a smaller following at present, taught that all the joys and ills of man are determined by the position of the heavenly bodies. Even within the present generation there are those who believe that famine, war and pestilence are determined by the spots on the sun or by the juxtaposition of certain planets. Our great lexicographer, Noah Webster, wrote a book to prove that epidemics are due to earthquakes and other terrestrial disturbances.

Hippocrates taught that epidemics are due to a pestilential condition of the air. This theory dominated the medical profession for more than two thousand years, and still colors some of our conceptions of infection. Quite naturally, such a theory is liable to many modifications. How does the air become pestilential? This question has been answered in numberless ways. Some say it is made so by evil spirits; by an angered God; by the influence of heavenly bodies; by terrestrial disturbances; by prevailing winds; by emanations from earth or water; etc. It is natural for man to believe in the evil genius of the locality in which ills befall him. In 1898, intelligent army officers told with bated breath that the word "Chickamauga" means river of death. They believed that the epidemic of typhoid there prevalent was due in part, at least, to the miasm of the locality and the disease was called "Chickamauga fever." The word malaria (mal aria) owes its origin to this theory. In war, unburied bodies of men and animals were supposed to fill the air with deadly decomposition products. It was fear of this that secured burial of the numerous victims of the plague in the great epidemics of the middle ages. This fear had, in part at least, a religious basis, and burial was regarded not only as a necessary sanitary measure, but as a compliance with a divine command. The unburied dead became a reproach to the living; from the decomposing body noxious and fatal emanations polluted the surrounding air, and with this threatening weapon, the dead demanded the honor of Christian burial.

Lowlands and swamps were supposed to be places in which noxious vapors were generated and from which they spread, poisoning the air of the surrounding country. These localities were shunned, especially after sunset, and the fear of breathing night air became well nigh universal. We now know that the real truth in this belief was made 
plain by the discovery of the transmission of malaria by mosquitos. The latest scientific support of the theory of miasm appeared in the teachings of the great sanitarian of Munich, Pettenkoffer. When he began his work in the Bavarian capital, about the middle of the nineteenth century, that city was known as a hotbed of typhoid fever. Fecal matter was deposited in shallow vaults and the drinking-water was taken from shallow wells. The whole city was honeycombed with these privies and wells, and the people were drinking strong infusions of their own excrement. Pettenkoffer taught that the fecal matter undergoes a ripening process in the soil and thereby becomes the cause of typhoid fever. Responding to his teachings, the people of Munich introduced a complete sewerage system and brought a pure drinkingwater from a distant mountain lake. This resulted in the eradication of typhoid fever and Pettenkoffer's theory was justified by the result. We now know that the typhoid bacillus needs no ripening process during the interval which elapses from its passage from the bowels of one to its entrance into the alimentary canal of another. Pettenkoffer's theory did not assume that the noxious agent in the fecal matter is a living organism, but rather held that the ripening process consists of chemical changes. From this, there grew up the idea of the de novo origin of typhoid fever. The fecal matter of uninfected individuals was supposed to undergo ripening processes in the soil and the products of these changes, finding their way into either water or air, distributed the disease. This theory was not only plausible, but was in accord with the then known facts. It found ready support, especially among army medical officers. However healthy men appeared to be when they went into camp, even in locations which could not have been contaminated previously, after a few weeks, typhoid fever appeared and spread in proportion to the filthiness of the camp and the inefficiency of the methods of fecal disposal. Men of the highest intelligence and widest experience became firm supporters of the de novo origin of typhoid fever which they regarded as a filth disease. They believed that the disease was spread by gases generated in any kind of filth, but more especially by those developed in fecal matter.

The theory of miasm was applied not only to typhoid fever and malaria, but to all diseases, especially those appearing in epidemic 
form. With sound sense, the Greek Father of Medicine said that when a large number of people fall ill simultaneously the cause must be sought in that which is common to all, and what can that be save the air they breathe? It was observed, however, that while the whole community was breathing the same air, many remained well; some had eruptive diseases; others diarrheal disturbances; and still others, respiratory affections. This necessitated the division of men into groups according to temperament. With the same factor in the air the result would vary with the temperament of the individual.

The study of the cholera epidemics of the nineteenth century removed the last scientific support of the theory of miasm. It had long been a matter of observation and record that epidemics travel from east to west. This was noted before the Christian era. It was frequently observed in classical times, and the cholera pandemics gave opportunity for collecting exact data on this matter. It was found that cholera, which is endemic about the delta of the Ganges, becomes pandemic on the occasion of certain religious pilgrimages. The faithful followers of Mohammed from all points of the compass gather at Mecca. Some come from the home of cholera, bringing the infection in their bodies. From their discharges others become infected, and as the great concourse disperses, bands of returning pilgrims carry the infection with them, and the disease widens its area. It travels just as fast and no faster than man travels. It goes where he carries it and nowhere else. When an individual drops the infection, some one else must pick it up and carry it on or it ceases to spread. The general direction of the spread of infection has always been from east to west because the great lines of human travel have led from this point of the compass, but it was found in the study of the cholera epidemics that whenever and wherever the paths of travel deviated from the general direction, the infection showed the same deviation. In other words, it became evident that infected man carried the infection in his own body. However, when the pandemics spread over Europe it was noticed that, while no place became infected unless visited by some infected individual, the disease established itself in certain localities and failed to do so in other places. This observation gave some support to the theory of miasm. In some soils the seeds of the disease grew and multiplied while in others they did not. When the water- 
supply of a locality became infected, the disease spread among its consumers. Budd of London was probably the first to detect the rôle of infected water in the dissemination of Asiatic cholera. Finally the discovery of the specific bacteria of cholera and other diseases removed the last support of the theory of disease originating in miasmatic conditions of the atmosphere.

The "germ theory" of disease found lodgment in the brain of an occasional genius many centuries ago. Just who first suggested it and when are not easily determined, but the argument ran something as follows: Alexandria was free from the plague. A ship from a port where it prevailed came with sick on board. Those associated with the new arrivals acquired the disease and it spread in an ever widening circle until it prevailed throughout the city and extended in a similar manner to other countries. The disease must be due to a poison of some kind. It cannot be a chemical poison, like arsenic, but it must be a living thing which finds its way from the body of the sick to those of the well where it grows and multiplies and in so doing causes the symptoms of the disease and death. Thus, man's reason, stimulated by exact observation, caused him to conclude that an epidemic must be due to a contagium vivum. He might theorize concerning this living thing, but he could not demonstrate its existence. It was too small for him to see. In the first century of the Christian era Varro wrote that there are swamps in which grow animals so small that they cannot be seen. They enter the body through the mouth and nose and cause disease. Others wrote to the same effect. Probably the first to see bacteria was the Dutch scientist and lens maker, Leeuwenhoek, who near the end of the seventeenth century described the "animalculae" which he found under his microscope in the examination of tartar from the teeth and diarrheal stools. In 1849 a village doctor on the Rhine, with a crude compound microscope, saw rod-like bodies in the blood of animals sick with anthrax and failed to find them in the blood of healthy animals. The science of bacteriology may be said to owe its birth to these observations. Independently, this work was continued by Brauel, Davaine and others, but the founder of exact and systematic knowledge concerning the causal agents of disease was the great Frenchman, Louis Pasteur. 
Space permits only a brief and incomplete statement of the work of Pasteur, and in doing this the chronological order will not be followed. He overthrew the doctrine of spontaneous generation. Although Harvey, two centuries earlier, had laid down the dictum, omne vivum ex vivo, there were those who held that this does not hold for the lowest forms of life. As Abel says, "Homer wrote of autochthonus men who sprang from the soil; the sixteenth century saw recipes for the manufacture of mice and frogs, and in later days, it was claimed that lower forms of animal life must have developed spontaneously because the Bible makes no mention of their having been taken into the ark by Noah." It was essential to the development of bacteriology, which depends so largely on sterilization, to dispose of spontaneous generation and to show that lower, as well as higher, forms of life breed true. This Pasteur did with the aid of Tyndall, and others. He showed that fermentation is due to the growth of living organisms, and that each kind of fermentation, like that in beer, wine and milk, is due to specific organisms. Furthermore he showed that a temperature high enough to kill these organisms arrests fermentation. By this process, now known as pasteurization, he preserved beer, wine and milk. Among this line he went further still and demonstrated that putrefaction, like fermentation, is due to bacterial growth. Lister utilized this discovery in the development of antiseptic surgery from which aseptic surgery has come. If each kind of fermentation has its specific organism, why may not each disease have its specific bacterial cause? Exposure to smallpox does not develop typhoid fever. The answer to this question has been given by the discovery of the specific causal agents of many diseases, and when found and tested, their specificity is demonstrated. The anthrax bacillus grown through a hundred generations and then inoculated into susceptible animals induces anthrax still. Pasteur found that certain specific bacteria can be so attenuated by unfavorable conditions of growth that they will not develop the disease in susceptible animals, but do impart to them immunity to infection with virulent strains. In this way he prepared vaccines for chicken cholera, swine eryripelas and anthrax. He also developed the successful treatment of hydrophobia, now used in every part of the world. 
The great German scientist, Koch, extended and developed the work of Pasteur. His solid media and bacterial stains made the growth, indentification and separation of bacteria comparatively easy. His untiring labor led to the discovery of the specific bacteria of Asiatic cholera and tuberculosis, and has placed in man's hands the possibility of completely eradicating these and other infectious diseases.

The work so firmly established by Pasteur and Koch has been amplified by many workers in many lands and has led already to marked reduction in both morbidity and mortality from the infectious diseases. Much has been accomplished in the attempt to lift the burden of unnecessary disease from man, but greater tasks lie before us.

This article will be limited to the bacterial diseases and only the more common of these can be included. 



\section{CHAPTER III}

\section{BACTERIA}

Morphology. - Bacteria are microscopic, unicellular organisms which appear in three fundamental forms. The spherical forms are known as cocci and may be single, in chains or in bunches. The individuals may be perfectly spherical, elliptical or lancet-shaped. The individual pus coccus has a diameter of from 0.4 to 1 micron.* The cylindrical forms are known as bacilli. Some have plane and others convex or rounded ends. Bacilli differ greatly in length, the longest pathogenic bacillus, that of malignant edema, being 9 microns, and the shortest, that of influenza, being 0.5 of a micron. Growth is in the direction of the long axis and multiplication by transverse fission. The shape of the spirilla is sufficiently indicated by the name. Involution forms will not be discussed.

Spore Formation.-The only spore-forming pathogenic bacteria are those of anthrax, symptomatic anthrax, tetanus and malignant edema. The spores are of endogenous origin, are highly refractive to light, and resistant to heat, and chemical disinfectants. No bacillus is known to form more than two spores and this is practically confined to saprophytic organisms. The appearance of two spores in an anthrax bacillus is rarely seen. The purpose of spore formation is not multiplication but preservation; it is a resting stage. Spore formation is a result of the concentration of the nuclear substance. The spore may be formed in any part of the cell, but the location in the same species is usually constant. In some bacteria the spore does not exceed the diameter of the cell; in others it is larger. A large spore located at one end of a bacillus gives it a "drum-stick" appearance; when in the middle, it forms a "spindle-shaped" organism. Untoward conditions, such as scarcity of food, the presence of deleterious agents and an accumulation of metabolic products, favor the development of spores.

* A micron is one thousandth of a millimeter and is the equivalent of $1 / 25,400$ of an inch. 
The bacterium passes into the resting state and awaits more favorable conditions. When these arrive, whether it be days or years later, the spore passes into the vegetative form and reproduction and multiplication begin anew.

Multiplication.-When bacteria reach a certain size, which is fairly constant in the species, the cells divide. In bacilli and vibrios fission occurs at right angles to the long axis. In cocci the cleavage may occur in only one plane forming streptococci; in two planes forming staphylococci; or in three planes, forming sarcinae. The rapidity of multiplication and growth to maturity varies with conditions. It has been estimated that if fission occurs hourly without interruption, in forty-eight hours the descendants of a single individual would number more than $200,000,000$. However, such a rate of multiplication can hardly occur since growth would be checked by scarcity of food or by the accumulation of excreta from the bacteria themselves. The rate of multiplication under most favorable conditions is the best measure of the intensity of life processes, and in the case of pathogenic bacteria, of virulence. The "generation period" is the time interval between fissions in the same bacillus. This varies greatly with varying conditions. Some of these conditions seem inherent in the strain while others are more variable. Under most favorable conditions the cholera bacillus has been found to divide about every half hour. When a culture tube is inoculated there is a variable period during which there is no multiplication, then fission begins. As the culture grows older the rate of multiplication falls on account of the accumulation of metabolic products. In infection the rate of multiplication is determined by the number of bacteria introduced as well as by other conditions. However, one strain of the same species may multiply a thousand times as fast as another.

Antagonism.-As happens in all forms of life, the most destructive agents to bacteria are other bacteria. It is fortunate that this is true, and man and other animals profit greatly by the conflict continually being waged between different species of bacteria. A drinking-water supply becomes contaminated with the typhoid bacillus which flourishes for a few days and is then completely destroyed by other bacteria. So true is this that by the time the disease has developed among 
those who drink the water, there are no longer typhoid bacilli in the water. The bacteriologic examination of drinking-water after an epidemic has developed, is in the large majority of instances, a useless procedure. A city's water-supply should be examined daily in order to be of value. The weapons used in this warfare among bacteria are many and varied. Some simply eat up the food supply and the invaders die of starvation. Others produce waste products which are harmful to other species. Anthrax bacilli planted in sterile cholera cultures are greatly weakened. Sterile cultures of the pyocyaneus dissolve anthrax bacilli. Some change the reaction of the common medium by the development of acid or alkali and their enemies die. The streptococcus kills the plague bacillus, and thus the conflict of nations and races goes on among the unicellular organisms much as it does among the lords of creation.

Symbiosis.-Some species form allied armies and contend against a common enemy or overrun a foreign country. The pus bacteria are found in many combinations and most men die from diseases in which these cocci play an important part. After the tubercle bacillus has fed on one's lungs for years and prepared the soil, some pus germ finds its way in before death and contributes largely to its coming. The cancer cell opens up ports of entry through which pus organisms enter. The lesions of syphilis are plundered and looted by the hordes of cocci. Thus, as Mayo has pointed out, sepsis plays an important rôle in the last acts of the three great tragedies of life; tuberculosis, cancer and syphilis. Some pathogenic bacteria receive aid from organisms which by themselves are harmless. The tetanus bacillus is much more virulent when it enters the animal body in company with certain saprophytes. When alone, the phagocytes speedily fall on and devour it, while certain products of the growth of its friend repel the phagocytes.

Capsules.-Some bacteria are surrounded by mucilaginous capsules. When two or more individuals are attached, the capsule usually includes the group, and when many are imbedded in one large capsule the whole is known as a zooglia. The capsule is believed to be formed for protective purposes, since many bacteria develop them only when in the animal or when grown in animal fluids, secretions or excre- 
tions. The presence of deleterious agents, such as arsenic, seems to favor the development of capsules.

Flagella.-All bacteria show passive movements when suspended in fluids and watched under the microscope. Such motion is known as molecular or Brownian and is common to all finely divided particles when suspended in fluid. Apart from this, certain bacteria are capable of active motion, which is accomplished by the contractions of flagella or whips. Those without flagella have no active motion. There may be only one whip at one end, as in the cholera bacillus; a single whip at each end, as in many saprophytic vibrios; a bunch of whips at one end as in certain large saprophytic vibrios; and many whips distributed over the cell, as in the typhoid bacillus. The flagella seem to be outgrowths from the ectoplasm and they may be removed from certain bacteria by shaking and then centrifuging, or by filtration through porcelain. Their presence favors agglutination, which however, is not wholly dependent on them.

Oxygen Need.-Pasteur observed that some bacteria grow best when supplied with oxygen, while others have their optimum growth when this element is excluded. The former he designated as aerobic and the latter as anaerobic. Further study has divided bacteria according to their need of oxygen into the following classes:

1. Obligate aerobes are those which will not grow save in the presence of free oxygen. This does not mean that they must have an abundant air-supply, because some do grow when the oxygen tension is only one-hundredth that of the air. Among the pathogenic bacteria, the plague and influenza bacilli and the pneumococcus and gonococcus belong to this group. An excess of oxygen may prove harmful to even the obligate aerobes.

2. Facultative anaerobic bacteria are those that grow best in the presence of oxygen, but may grow when this element is wholly excluded. Many pathogenic organisms belong to this class, such as the cholera vibrio, anthrax and typhoid bacillus and pus cocci.

3. Obligate anaerobes are bacteria which grow only in the absence of free oxygen. In this group are the bacilli of tetanus, symptomatic anthrax and malignant edema. These bacteria obtain their oxygen if they utilize this element at all, from the combined oxygen in their 
pabulum. Pasteur found that fermentation is due to obligate anaerobes and he defined fermentation as life without oxygen. However, this does not mean that all life without oxygen results in fermentation. The growth of bacteria of this group is favored by the presence of reducing agents in the medium. Anaerobic bacteria may grow in the presence of free oxygen provided there are present aerobic organisms which absorb all the oxygen. The development of tetanus is favored by puncture wounds, also by the presence of aerobic bacteria.

Structure.-In the higher plants and animals, all cells capable of multiplication consist of protoplasm and nucleus. There has been much controversy among bacteriologists concerning the structure of the bacterial cell. Some say that this cell has no nucleus because, with the analine dyes, it stains uniformly. Others say it is all nucleus because the staining which it takes throughout is nuclear. These are the two extremes, but most agree that the greater part of the bacterial cell consists of nuclear material. Fats and waxes have been accumulated especially by those organisms, as the tubercle bacillus, which have lived so long as parasites. Food material, inorganic salts, ferments and various extractives are present in the bacterial cell, but for the most part it is of nuclear composition. Its chief function is to multiply, and this is accomplished in the simplest possible way by nuclear division. Most authorities define bacteria as low forms of plant life. The one characteristic and constant constituent of the plant cell is cellulose. This certainly does not exist in the pathogenic bacilli and bacteria are not plants. This seems certain unless we radically change our conception of the plant cell. Bacteria may be more properly defined as nuclei, probably protected by a protein ectoplasm. I and my students have devoted many years of work to this subject and we have shown that chemically the greater part of the bacterial cell is nuclear substance. It contains two carbohydrates, one of which has been located in the nucleic acid group while the position of the other has not been determined. It yields phosphorus and xanthin bases and when broken up with acids or alkalies supplies mono-amino and diamino acids. Chemically, bacteria are nucleoproteins. It has been assumed by some that, chemically, bacteria are of simple strucure. This is pure assumption and rests solely on the fact that, 
morphologically, bacteria are relatively simple. Biologically and chemically their structure is as complicated as that of the highest cells of the animal body. In common with all proteins, bacterial cellular substance contains a powerful poison. This is true alike of pathogenic and non-pathogenic bacteria and true of all proteins-bacterial, vegetable and animal.

In fact, bacteria in their essential parts are living molecules, of definite chemical composition and structure. In different species the molecular composition differs. As Benecke has shown, the pyocyaneus requires for its growth, in addition to protein substances, two elements, potassium and magnesium. The former cannot be replaced by sodium or ammonium, nor the latter by calcium. The tubercle bacillus needs glycerin in order to assimilate amino-acids, carbohydrates and organic acids. Cramer found that the cholera bacillus assimilates as much as 95 per cent. of the nitrogen in alkaline bouillon, and at most 3 per cent. of that in Uschinsky's solution. The obligate parasites feed only on the fluids and tissues of the animal body and some only on some particular species of animal. The influenza bacillus grows only on media containing hemoglobin or some chemically related body.

Metabolism.-Every living thing must feed, assimilate and eliminate. It thrives and multiplies when food is abundant and conditions of life are favorable. It hungers and dies when the food supply fails. These things are as true of unicellular as of multicellular forms of life. All bacteria, even the anaerobic, absorb oxygen and eliminate carbonic acid. In this gaseous exchange more oxygen is absorbed than is eliminated in the form of carbonic acid. This shows that some oxygen is used in nitrogen metabolism. When the food supply is suddenly withdrawn in the midst of rapid multiplication, the deathrate is great, and greater among the young than among the older individuals. Fisher has shown that when a growth of cholera bacilli twenty-four hours old is suddenly transferred to salt solution, all the organisms die within thirty-six hours. With older cultures some live bacilli are found much later and with a seven-day culture, some will be found to be alive after fifty days. When the food supply is gradually withdrawn the death-rate is not so high and the more hardy 
individuals retain their vitality for months and even years, especially at low temperature. The respiratory quotient remains constant in the same species under identical conditions and is a measure of rate of growth and multiplication.

All living cells must depend on the pabulum within their reach. This must be digested or broken up into particles which will fit into the bacterial molecule. This is accomplished by agents which we designate as ferments or enzymes. Each species of bacteria elaborates its own specific enzymes, the functions of which are to cut the pabulum into proper blocks and to place these blocks in the structure of the cell. These enzymes are specific in two senses. First, they are specific in origin; the ferments produced by typhoid bacilli are not identical with those of anthrax bacilli. Secondly, they are specific in their action. Given the same pabulum, the shape and size of the blocks into which it is split differ with the ferment acting on it. Besides, a given ferment cannot act on all pabulum. What is food to one bacterium may be of no value to another.

Pathogenicity.-Why is it that one bacterium is capable of inducing disease while another is harmless? The answer to this is quite clear. Some bacteria can feed only on dead matter. Their ferments will not prepare the fluid and tissues of the animal body for the sustenance of their cells; or it may be that the ferments of the body cells digest these bacteria and prevent their growth. These bacteria, which compose the great majority of existing species are known as saprophytes. There are other bacteria which can digest, absorb and eliminate the constituents of the fluids and tissues of the animal body and which are not digested by the body cells. These are parasites and their growth and reproduction in the body cause disease and consequently such bacteria are said to be pathogenic. Such an organism may be able to grow in one species of animal and not in others. It is pathogenic only to those animals in which it can grow. It may be able to grow in certain individuals of a species and not in others. To the man who has had smallpox or has been properly vaccinated, the smallpox virus is not pathogenic. Vaccination has developed in the body cells the function of producing a ferment which digests smallpox virus and consequently this cannot grow and multiply in the body of the vaccinated man. 



\section{CHAPTER IV}

\section{AVENUES OF INFECTION}

The Skin. - While certain paråsites, molds and fungi may be implanted on a healthy skin by contact, either direct or indirect, there is no known bacterium which will penetrate the healthy, unbroken cutaneous covering of man under natural conditions. When pus bacteria are vigorously rubbed into the skin, especially when incorporated in a salve, impetigo, furunculosis and even abscess formation may result. Experimental infection of the lower animals has been induced in a similar manner with plague, glanders, anthrax, tuberculosis and recurrent fever. The plague bacillus may penetrate the unbroken and unshaven skin of the guinea-pig and cause general infection. The protection afforded by the skin is wholly mechanical. Infection through the skin may result: $(a)$ from the bites of animals, as rabies from the bite of the dog; $(b)$ from the bites of insects, as malaria and yellow fever, transmitted by mosquitoes, and plague and other diseases transmitted by fleas and possibly by other insects; (c) from wounds, as syphilis, tuberculosis, diphtheria, tetanus, pus infections, et cetera.

The Eye.-Local infection of the conjunctiva is a common accident. Gonorrheal infection is the most common cause of ophthalmia neonatorum. Primary anthrax, tuberculosis, diphtheria and syphilis in the eye have been observed. Animals have been inoculated through normal eyes with glanders, plague and rabies.

The Nose.-Notwithstanding the marked germicidal character of the nasal secretions, this organ furnishes lodgment for many bacteria and is the seat of primary glanders and leprosy. Flexner has induced poliomyelitis in apes by inoculating the nasal mucosa with the filterable virus, and a minimal quantity of a plague-bacillus culture placed in the nose of a rat leads to general infection.

The Mouth.-The pavement epithelium of the normal mouth furnishes a fairly good mechanical protection against the local introduc- 
tion of bacteria into the lymph and blood, but this cavity does not receive the sanitary attention it should. Tartar is permitted to accumulate about the teeth and cause atrophy of the gums. Particles of food lodge between and about the teeth and furnish suitable material for the growth of bacteria. Carious teeth are neglected and ports of entry are directly opened up. Normal saliva has a distinct bactericidal action, but this is without practical effect on the pneumococcus, the bacilli of diphtheria and tuberculosis, the spirochete of syphilis and the organism of actinomycosis. The crypts of the tonsils offer places for the lodgment and growth of bacteria, and from these localities some of them find their way into the lymph and blood. Some hold that tuberculosis frequently has its primary location in the tonsils from which it passes through the lymph vessels to the apices of the lungs.

Many pathogenic bacteria pass through the nose and mouth without causing local infection. It is not pleasant to state, but it is true that much which is discharged from the bowels of one goes into the mouth of another. This may be by short or long circuit, but the result is likely to be unfortunate in either case. We drink water infected with typhoid discharges and milk drawn with unclean hands, and polluted with the excrement of man and beast. We enjoy fruits and vegetables from orchards and gardens strewn with filth. We eat bread and meat handled without gloves by baker and butcher, and for all of this we pay heavy toll, as is shown by the morbidity and mortality statistics.

The Lungs.-There has been much discussion whether tuberculosis is most frequently acquired by inhalation or by deglutition. Animals have been experimentally infected by both of these avenues by numerous investigators from Villemin down to the present day, but the opponents of the inhalation theory say that even when bacilli are drawn with the air through the nose or mouth, they are deposited in the pharynx and are swallowed. The reply to this is that colored bits of dust when inhaled may be carried directly to the apices of the lungs where they may be recognized. Furthermore, attention is called to the inhalation of coal dust by miners and the resulting condition of the lungs, known as anthracosis. The dog is quite readily infected 
with tuberculosis by inhalation, rarely or not at all by feeding. The number of bacilli necessary to infect a guinea-pig by inhalation is less than one one-thousandth of that necessary to infect by feeding. When animals are infected by inhalation, the lesions can be detected in the lungs long before they appear after feeding.

The evidence that infection does result from inhalation and that the primary seat of the infection is in the apices of the lungs in the great majority of cases of pulmonary tuberculosis seems to be indisputable. On the other hand, it is equally certain that infection may develop by way of the intestinal tract. The frequency with which primary tuberculosis due to the bovine bacillus, occurs in the abdominal organs of children leaves no room to question. The contention of Koch that infected milk might be neglected in our attempts to eradicate tuberculosis is not supported by the results of the most thorough study that has been devoted to it. There is probably no avenue of infection which has not been traveled by the bacillus tuberculosis.

The Stomach.-There is probably no specific infectious disease which develops primarily in the stomach. Indeed, the acid secretion of this organ, while by no means affording constant or full protection against intestinal infection, undoubtedly does much in this direction. The ubiquitous pus germ does develop a gastric ulcer now and then, but a more favored site for this process is in the duodenum. In the intervals between digestion all kinds of harmful bacteria may pass the portals of this viscus in safety and some of them make a successful passage even when digestion is at its height. It is not wise to depend on the gastric juice to sterilize our food.

The Intestine.-There is general agreement that the intestine of the infant is more permeable to bacteria than that of the adult. Young guinea-pigs are easily infected with anthrax by feeding, while adults are not. Even attenuated cultures will infect a larger number of the young than virulent cultures will in adults. Like results have been reached by experiments with tuberculosis. Platte fed guinea-pigs a few days old and adults with tubercle bacilli, 80 per cent. of the former and 30 per cent. of the latter became infected. Ficker found that many bacteria easily penetrate the intestinal walls of suckling animąls, while they have no effect on adults. These facts correspond with observations on the summer diarrheas of infants. Milk that proves 
highly injurious to infants is without harmful effect on adults. In the fetus digestion is wholly parenteral and it continues to be partially so during the nursing period, and the intestinal walls of infants are more permeable to both formed and unformed substances than are those of the adult. According to von Behring, the great majority of cases of tuberculosis are due to infection from milk in infancy. The bacilli are retained in the lymphatic glands and invade other organs, especially the lungs, later in life.

Calmette teaches that in every period of life tuberculosis generally enters the body through the intestinal walls where it leaves no lesion and from which it travels to other organs. It has been shown that the tubercle bacillus may pass through the intestinal walls without leaving any recognizable lesion, but it is not so certain that this is the usual port of entry. Even in the adult, the intestine seems to be the most vulnerable point in bacterial invasion. It is the exclusive port of entry for cholera, dysentery and typhoid. The most virulent cholera bacillus injected under the skin in amounts which would fatally infect by the intestine, would be without serious effect. The list of animal infections, which are essentially intestinal, embraces anthrax, chicken cholera, the hemorrhagic septicemias, hog cholera, and mouse typhoid.

It is a noteworthy fact that in experimental infection by feeding, larger numbers of bacilli must be employed than can possibly be required in natural infection. It has been inferred from this that in natural infection the intestinal conditions must be especially favorable to the multiplication of the organisms. This has led to the assumption that slight intestinal disturbances predispose to typhoid and other intestinal infections. This was carefully investigated by the board which studied typhoid fever among our soldiers in 1898, and was found to be without support. Soldiers, who were frequently on sick report with diagnoses of gastric catarrh, intestinal indigestion, etc., furnished actually a smaller percentage of typhoid fever than those who had not been on sick report for any cause. Moreover, many of the short and intermittent disturbances, under a variety of diagnoses, were found by the Widal test to be typhoid fever. Some have claimed that the normal intestine is not easily traversed by bacteria, but the difficulty in this is to know when the intestnial walls are in a healthy condition and when they may have suffered slight injuries. 


\section{CHAPTER V}

\section{TUBERCULOSIS}

History.-That the people of ancient Egypt were afflicted with tuberculosis has been demonstrated by an examination of the bones of mummies. We have no means of estimating the extent of this disease among these people. The writings of the great Greek physician, Hippocrates, show that he was quite familiar with various forms of tuberculosis. The period of the Roman and Byzantine Empires added nothing to the knowledge of the ancients on this subject. During the seventeenth and eighteenth centuries there was much discussion concerning tuberculosis, but no experimental investigation into its nature.

In the seventh decade of the nineteenth century, Villemin, who should be regarded as the founder of modern knowledge of tuberculosis, conducted a series of exact experiments which settled for all time disputes concerning the contagiousness of this disease. He inoculated many and varied animals in diverse ways with the sputum and other products from tuberculous lesions in men and cattle, and in all developed tuberculosis. He established not only the unity of the various tuberculous manifestations in man but demonstrated the existence of tuberculosis in cattle. He went further and showed that certain nodular diseases, which had been confounded with tuberculosis, were distinct from it. He found that the inoculation of animals with other than tuberculous products did not lead to the development of this disease. He overthrew the theory of heredity in this disease and established the fact that it does not result from colds or other ills. He went so far as to suggest house infection as an important factor in the dissemination of the disease. Men who tried to contradict the findings of Villemin experimentally, confirmed him in practically every detail.

In 1882, Koch, after long and patient studies succeeded in isolating the specific bacillus, growing it in pure culture, and demonstrating its pathogenicity. 
The Bacillus.-The specific causal agent of tuberculosis is a rodlike organism whose length varies from one-fourth to one-half the diameter of a red blood corpuscle (1.23 to 4.12 of a micron). It is slender and non-motile. It was formerly believed that this, like other bacteria, should be classed among microscopic plants, but the most exact chemical studies have failed to show the presence of cellulose in their structure. This organism does not take the ordinary basic aniline stains readily, but when treated with certain stains, such as carbol-fuchsin, and heated, it stains deeply and retains the color even after washing with dilute mineral acid. For this reason it is known as an acid-fast bacillus and it has been found that this group contains a number of micro-organisms whose relationship has been a matter of great interest. By special staining, tubercle bacilli are easily detected in sputum and other excretions from tubercular lesions.

There is still some discussion whether or not this bacillus forms spores. The low temperature at which it is destroyed and the fact that it is speedily killed by sunlight renders spore formation highly improbable. In old cultures, branched forms are occasionally seen. The tubercle bacillus contains large amounts of fat and wax and it is probable that these protect this organism from the destructive action of the secretions of the body cells. It has been a parasite for so long that it has developed this method of protecting itself. It grows slowly both on artificial media and in the animal body. It is not its purpose to kill its host but to feed on him as long as possible. Unaided it seldom does kill, but the necrotic tissue caused by its growth forms a suitable medium for the lodgment and growth of other bacteria and tuberculosis usually terminates as the result of a mixed infection. So long as the infection is unmixed, the progress of the disease is slow. As a rule, there is no sputum until the infection becomes a mixed one; consequently when one waits for a diagnosis of this disease until the bacilli are found in the sputum, he waits too long. The physician of thirty years ago believed tuberculosis an incurable disease, because at that time he could not make a diagnosis until there was a troublesome cough with much expectoration, marked emaciation and a long-continued hectic fever. All patients that reached this stage died. After Koch's discovery of the bacillus, diagnosis had to await the detection of this organism in the sputum. Again, it was too late. With 
improved methods the diseàse can be recognized in most instances while it is still an unmixed infection and amenable to proper treatment.

The behavior of the bacillus outside the animal body is a matter of great importance in attempting the restriction of this disease. Fortunately, under ordinary conditions, the tubercle bacillus does not multiply outside the animal body. It is rapidly overgrown and starved out by saprophytic organisms. It has been a parasite so long that the range of temperature at which it will multiply is limited. Even in pure cultures, protected from other organisms and provided with an abundance of suitable food, it grows but slowly at a temperature only a few degrees below that of the body. It needs oxygen and when the supply of this element is short, growth is slow.

However, the practical question is, How long will it retain vitality and virulence outside the body? Multiplication as a saprophyte is under ordinary conditions not at all probable, but how long will the organism thrown off from the body in the sputum remain a source of danger? This depends on many conditions. A mass of sputum deposited on a glass plate and allowed to stand at ordinary room temperature and in diffuse light may contain virulent bacilli for six months. When the sputum is spread on a plate in a very thin layer and submitted to the direct sunlight, only a few hours are necessary to destroy its virulence; when only placed near a window, days are necessary, and sputum deposited on carpets, rugs, bedding, handkerchiefs, clothing, etc., may retain its virulence for months. Sputum on walks and floors dries and is scattered by winds and drafts and may be inhaled or deposited on food. The fly may carry the organism to food. Heat immediately kills the tubercle bacillus when suspended in water or milk on boiling. Lower temperatures must be maintained for longer periods of time. According to Forster the following Centigrade temperatures must be continued for the periods mentioned in order to be effective: 55 for four hours; 60 for one hour; 65 for fifteen minutes; 70 for ten minute; 80 for five minute; 90 for two minutes; 95 for one minute.

Milk should be boiled at least three minutes to insure the destruction of this bacillus. In thoroughly baked or roasted meat the bacilli are destroyed, but in the rare portions they may retain their vitality. 
Dry heat must be carried to a higher degree or continued for a longer time. Low temperatures are without effect. On account of their fat and wax content tubercle bacilli are highly resistant to disinfectants. Mercuric chlorid 1:500 and 5 per cent. phenol (carbolic acid) are not efficient in the sterilization of sputum even when the contact continues for twenty-four hours. The ordinary gaseous disinfection of rooms with formaldehyd is unreliable in case of infection with this bacillus. Sputum from the tuberculous should be burned.

The Bovine Bacillus.- It has been shown, largely through the work of Theobald Smith, that the human and bovine tubercle bacilli are not identical. They show certain well-marked and characteristic differences in shape, size, rapidity and manner of growth, in response to stains and in pathogenicity. Some years ago Koch announced that in the crusade against tuberculosis in man we can afford to neglect milk as a causative agent. This assertion led to much investigation into the resemblances and differences between these varieties of the tubercle bacillus. With the cultural and tinctorial differences we need not concern ourselves at present.

Cattle are highly resistant to infection with the human variety. Cattle have been fed for months with large quantities of the human bacillus without developing an infection. Some of the material accumulates in the mesenteric glands and undergoes calcification but the animal does not develop tuberculosis. In ordinary infecting doses, intravenous injection is without effect. With larger amounts the animal may be poisoned as might result from similar treatment with any one of a number of foreign proteins. The human bacilli when thus injected into a cow may live for months and may be detected in the milk. Intraperitoneal injections are without effect and the same is true of those given subcutaneously, except that large quantities may cause a local inflammation and this may extend to neighboring glands. Inhalation is without effect. It is safe to say that cattle are free from the possibility of being infected with tuberculosis from man.

The guinea-pig is highly susceptible to both varieties, but the bovine kills it quicker. The human variety is uncertain in its action on rabbits. If it develops at all, it does so slowly and as a rule requires some weeks and possibly months to cause death. On the 
other hand, this animal succumbs in most instances in about three weeks to the bovine variety. Intravenous, intraperitoneal, intraocular and subcutaneous inoculations result in generalized fatal tuberculosis.

Cattle, which as we have seen are highly resistant to the human variety, succumb readily to the bovine, whatever the method of inoculation. Calves fed on pure cultures or on the milk of tuberculous cows speedily develop the disease, which usually begins in the formation of ulcers in the upper intestine and extends to the mesenteric, lymphatic and retropharyngeal glands. Infection may result from a single feeding. Calves from tuberculous cows are free from infection. but one nursing from the mother may infect. The inhalation of a very minute portion $(0.01 \mathrm{mg}$.) of a pure culture is followed by the development of pulmonary tuberculosis.

Sheep, hogs and goats are highly susceptible to the bovine variety, much less so to the human.

It seems safe to say that tuberculosis among our domestic animals results generally from infection with the bovine rather than the human variety. However, some facts need to be stated. Tuberculosis is common among chickens and it is quite natural to suppose that these animals become infected by picking up human or bovine material, but experiments show that chickens are immune to both these varieties. Feeding, intravenous and subcutaneous inoculations of these varieties do not develop tuberculosis in chickens. The bacilli retain their vitality in these fowls for a long time but fail to develop tuberculosis in the hosts, as has been demonstrated by inoculation of susceptible animals, such as the guinea-pig. Apes seem to be equally susceptible to the human and bovine varieties.

Having ascertained that our domestic animals do not run great risk in being infected with the human variety, let us see what danger there is to man from infection with the bovine variety. Is it wise to follow the advice of Koch and neglect milk as a factor in the causation of tuberculosis in man? This important question has been investigated in this country by Park and Krumwiede, by an English commission, by two German commissions, and by many individuals in various parts of the world. In 1,441 deaths from tuberculosis in man, the variety of the bacillus has been determined. In 117 of these ( 8.1 per cent.) the bovine variety alone has been found. In seven cases ( 0.5 per 
cent.) the infection has been found to be a mixed one, both varieties being present. This, however, does not tell the whole story.

In pulmonary tuberculosis in adults the bovine variety is rare (4 cases out of 732). In tuberculosis of the bones and joints, at all ages, the bovine variety occurs more frequently ( 5 cases out of 98 ). In meningeal tuberculosis at all ages the frequency is still greater ( 3 cases out of 32). In general tuberculosis at all ages there is a further increase (33 cases out of 172). In tuberculosis of the glands of the neck, the proportion is still higher (45 cases out of 157). In tuberculosis of the abdominal organs the presence of the bovine variety reaches its highest point (30 cases out of 99).

When we study the proportion of the two varieties in adults and in children, we get more practical information. In children 23.8 per cent. of generalized tuberculosis, 40 per cent. of tuberculosis of the cervical glands and 49 per cent. of tuberculosis of the abdominal organs are due to infection with the bovine variety. It is quite natural that the greater number of cases of bovine tuberculosis should be found among children. These figures demonstrate that the character of the milk cannot be neglected with safety in the crusade against tuberculosis. At the same time, they show that the chief source of infection in man is the human variety and that as a rule tuberculosis is transferred from man to man.

The Avian Type.-The barnyard fowl is frequently tuberculous. Much of the poultry that comes to market, when properly inspected, shows enlarged livers filled with yellowish tuberculous nodules. This variety of the tubercle bacillus can be distinguished morphologically and culturally from other forms. Chickens are easily infected by feeding, developing intestinal and hepatic tuberculosis and loss of weight. Intravenous injection, even of a minute quantity, leads to rapid emaciation and death may result before macroscopical changes are in evidence. In less rapid cases the liver shows the characteristic enlargement and nodules. Intraperitoneal and intramuscular inoculations are slower, but in time develop the disease. Ducks and pigeons may be infected, but in nature the disease is much less frequent in these than in chickens.

The testimony concerning the susceptibility of the guinea-pig to this variety of the tubercle bacillus is conflicting. Evidently it is less 
than that shown by this animal to either the human or bovine variety. Rabbits seem to be more susceptible, though typical tubercular nodules are not always developed in these animals, many dying from septicemia. Calves fed on the avian bacillus may develop local tuberculosis in the intestine and mesenteric glands, but this seems to have little effect on the growth and health of the animal. Subcutaneous injections in cattle cause an inflammatory reaction which may extend to neighboring glands, but fail to develop general tuberculosis. In the studies of the varieties of tubercle bacilli found in man, already referred to, three cases of infection with avian bacilli were found. However, it is not certain that these people were not also infected with one of the other varieties. In at least three other cases the avian bacillus has been found.

That the flesh of tuberculous fowls frequently comes to the table is beyond dispute. The methods of cooking probably kill all the bacilli. Besides, the appearance of the liver is so striking that this organ is removed before dressed fowl comes under the eye of the consumer. No observant cook could overlook so abnormal an organ as the liver in a well-developed case of tuberculosis gallinaceus.

The Piscidian Variety.-Fish, amphibians and reptiles are susceptible to a form of tuberculosis due to a variety of the bacillus which is not capable of growth at the temperature of the body in mammalians and, therefore, cannot be a source of infection in man. One would not knowingly eat a tuberculous fish, but if he unknowingly does so, tuberculosis will not result.

Other Acid-Fast Bacilli--There are several well-known and thoroughly studied saprophytic bacteria which have a close resemblance to tubercle bacilli in their reactions towards certain stains. They are not easily stained by ordinary dyes, but when thoroughly stained with carbol-fuchsin or similar agents the color is not removed by washing with dilute mineral acid. These organisms are classed with tubercle bacilli as "acid-fast" organisms. These have been especially studied by Moeller who has defined several species or varieties. One point of interest is that they may be mistaken for tubercle bacilli. This is likely to occur because one of them is found on timothy hay and is known as "Moeller's timothy" bacillus and another is found in cow dung. So far as they have been tested they are not pathogenic to any animal. 
Whether or not all of these acid-fast organisms have been evolved from a common ancestor is a fruitful field for theoretic discussion. No one has, as yet, converted one of these into a pathogenic organism, though this has been tried by frequent passage through animals. They may produce local reactions which closely resemble those developed by inoculation with one of the pathogenic types, but they do not cause general tuberculosis. That their cellular structure is similar, chemically at least, to that of the virulent types is shown by the following: (1) their similar behavior toward stains, (2) their local effects, (3) animals sensitized to one of these saprophytic forms are partially sensitized to the virulent types.

Many attempts have been made to convert one virulent type into another. The human and avian types have been carried through many cows and the human and bovine varieties have been carried through chickens. The results of this work have been by no means uniform. Some investigators have convinced themselves that transformation from one type to another is easily and quickly secured, while another man, equally competent, repeats the work and is sure that such a transformation never results. The conditions under which such work must be done render mistakes easily possible and to obtain satisfactory and convincing proof seems quite impossible.

For instance, one man attempts to carry the human type successively through many calves in order to transform it into the bovine variety. At last he inoculates a calf and later finds in that animal a typical bovine organism. The experimenter claims that he has demonstrated a transformation, but his critic says the tuberculosis found in the last calf is not a result of the inoculation, but is a true bovine tuberculosis from a wholly different source.

One of the most convincing experiments in favor of a transformation in type is that of Nocard. He placed a culture of the human type in a collodion sack and introduced the sack into the abdominal cavity of a chicken; after some weeks he transferred the sack to the abdominal cavity of a second chicken and after another interval to a third. After this he found that the type had been changed to avian.

This has been repeated by two other investigators, one of whom confirms and the other denies Nocard's claim. The solution of the question concerning the relation of the saprophytic acid-fast bacilli to 
the pathogenic, and of the different types of the latter to one another must await future investigations.

Avenues of Infection.-The most important of these lies in the respiratory organs. The nose serves as a filter and its secretion is germicidal. Besides, there is free exit for accumulations, and the ease with which sneezing is induced by slight irritation and air can be forced through it by blowing the nose, tends to keep this cavity clean. The nose is seldom, probably never except in wounds or abrasions of the mucous membrane, the seat of a primary tuberculous infection. It may be secondarily involved in tuberculosis of the lungs. Mouth breathing increases the chances of infection. The retronasal pharynx is less easily kept clean and is more frequently the site of infection, but this also is generally secondary. The tonsils frequently, even in non-tuberculous persons, are found to contain tubercle bacilli. Whether these glands do more than retain the bacilli is not known. The larynx is more frequently the seat of primary infection, and is involved sooner or later in about one-fourth the cases of pulmonary tuberculosis.

Infection of the trachea and large bronchi is rare. The primary seat of most cases of pulmonary tuberculosis is in one of the apices of the lungs. This is due to the fact that bacilli having reached these localities are not easily dislodged. This is true of inhaled particles of any kind and when these are hard and rough they cause slight wounds which form suitable places for the entrance and growth of the bacilli. This accounts for the greater susceptibility to tuberculosis of those engaged in dusty occupations, especially marble cutters and steel filers.

The next most favorable avenue for tuberculous inoculation is through the digestive organs. Carious teeth provide a port of entry and the infection introduced in this manner finds its way into the adjacent glands. Sore and raw gums due to deposits of tartar and the fermentation of lodged particles of food, offer additional points of entry not only for the tubercle bacillus but for other pathogenic organisms. These facts emphasize the importance of oral hygiene, which is greatly neglected in both children and adults. Tubercle bacilli have been detected in carious teeth, in tartar and in the coating 
on the tongue. Demme reports four childdren who were infected by a nurse who was accustomed to put the spoonful of food to her lips and tongue in order to test its temperature in feeding the children and I have seen a mother chew the food given her children. The esophagus and stomach are seldom or never the sites of tuberculous lesions. The food quickly passes the esophagus and the acidity of the stomach contents protects that organ. In most cases of infection by way of the alimentary tract the bacilli find lodgment in the small intestine, through the walls of which they may pass without leaving a recognizable lesion.

There are three forms of tuberculous skin affection, tuberculosis verrucosa, lupus and tuberculous ulcer. These may be due to scratching with infected finger nails, cuts with infected knives or wounds with other infected instruments. Tuberculosis of the skin is especially frequent among butchers. A general infection may result through the skin. Several cases of infection through the rite of circumcision have been reported and medical students have been infected in dissecting tuberculous bodies and surgeons in doing operations and making postmortems. In all these instances the infection extends to the nearest lymph glands and then on to the next. The point of entry may or may not show a lesion. Infection of the joints and bones is always secondary.

Sources of Infection.-The most abundant source of infection is dried tuberculous sputum. So long as the sputum is moist it is not distributed through the air. When deposited on sidewalks, the sputum adheres to the feet or may cling to the clothing and in either case is carried into the house where it becomes more dangerous. The greatest danger is in closed rooms in which sputum has been deposited on the floor. Cornet made the following experiment which illustrates how infection may be spread. A carpet which had been contaminated with infected sputum some days before was spread on a floor. Cages containing 48 guinea-pigs were placed at different levels in the room and the carpet was vigorously swept with a broom until the room was filled with a cloud of dust. Of the guinea-pigs exposed to this dust, all but one became tuberculous. The same investigator sponged the walls of a room occupied by a tuberculous patient who expectorated 
on the floor, and the material absorbed by the sponge was injected into guinea-pigs with positive results.

Flügge has called attention to the fact that in coughing, sneezing and even in speaking the consumptive may eject an infected spray. Not only is there immediate danger from the inhalation of the spray but subsequent danger from the dried droplets which may fall on the floor or furniture. The house-fly walks in sputum, eats it, and subsequently may feed on food, or drink or even drown himself in milk. As we have seen, the milk of tuberculous cows is a source of danger, especially to children. Cream and butter from such milk may contain tubercle bacilli. There is less danger in meat on account of the cooking, but meat when made into sausage is eaten raw by some people.

Tuberculosis is in no proper sense an inherited disease. When the mother suffers from general tuberculosis, the placenta may be involved and the child may be infected in utero. This is congenital, not inherited, tuberculosis, and only a few cases of this are known.

\section{PSEUDOTUBERCULOSIS}

We are indebted for our knowledge of this disease largely to French investigators who recognized it as early as 1883 . It is designated a tuberculosis because in its lesions, the histologic changes closely resemble, though they are not identical with, those seen in true tuberculosis. It is caused by wholly different bacilli, of which there are several varieties, and none of these is acid-fast. They are easily stained, the stains are easily washed out with dilute mineral acids and the bacilli are destroyed by relatively weak disinfectants. Besides, the bacilli do not contain the large amounts of fats and waxes found in true tubercle bacilli.

The most important manifestation of this disease is in sheep and it is said that 15 per cent. of these animals in Australia and 10 per cent. in Argentina, as they come to the market, are infected. The bacillus which infects sheep is a long (1-3 microns), non-motile, non-liquefying organism which grows easily and abundantly on gelatin, coagulated serum and agar, and in bouillon. Unlike the tubercle bacillus, it produces a soluble toxin. An antitoxin has been prepared which protects against the toxin but not against the bacillus, and consequently, while of great scientific interest, is of no practical importance in pro- 
tection against infection. Sheep are supposed to acquire the infection largely through feeding.

As the disease is slowly progressive and most sheep are slaughtered, the condition is usually not recognized during life.

This variety of the bacillus is pathogenic, not only to sheep but, experimentally at least, to goats, rabbits, guinea-pigs and mice, but not to chickens and pigeons. A second variety of this organism is pathogenic to mice, especially to gray mice. It is not known to be pathogenic to any other animal. Bouillon cultures of this variety become slightly cloudy and deposit abundant coffin-lid crystals (ammoniomagnesium phosphate).

A third variety seems to be pathogenic to many rodents and may cause epidemics in rabbits and guinea-pigs. This produces crystals in both gelatin and bouillon cultures and does not elaborate a soluble toxin. A fourth variety infects children and several cases have been reported by French physicians. The cat is suspected as a carrier. 


\section{CHAPTER VI}

\section{LEPROSY}

History.-This disease prevailed among the Egyptians as early as 2,400 years before Christ. The records show that it existed in India and China at least 1,000 years B. C. Whether the word leprosy as used in the Old Testament was confined to this disease or included other loathsome conditions, has been a matter of dispute among scholars and remains without definite settlement. Some say that the Israelites became infected with this disease in Egypt and the claim is made that on account of the prevalence of this disease among them they were driven out of that country. The Persian wars apparently led to its introduction into Greece, and with the Roman subjugation of Greece it was diffused over Italy, in parts of which it had existed long before this time. During the first and second centuries of our era it became quite common in Italy and gradually spread over the greater part of Europe. It had become so common and had awakened so much apprehension in France in the sixth and seventh centuries that the segregation of lepers was begun.

With the general scientific awakening of the fifteenth and sixteenth centuries, more attention was given to the restriction of this disease. It is said that the number of leprosaria in France reached 1,500 and that in the whole of Europe it was as great as 19,000. Lepers were generally known as Christ's poor, and the leprosaria were under the special care of the order of St. Lazarus, and were directed by priests, who were themselves lepers. The attempt was made, and it must have been on the whole successful, to segregate all lepers in these institutions. When a leper went abroad he wore a peculiar garb and at night he carried a bell. Recognized by these signs he was shunned. During the seventeenth century the number of lepers in Europe rapidly decreased until the disease practically disappeared, "except on the fringe of the continent." However, traces of it have continued, especially in Norway and parts of Russia. It has continued in Asia and Africa. Whether the North American Indians or the Aztecs of 
Mexico were infected with this disease in pre-Columbian days is still a matter of dispute, with the evidence clearly in favor of the negative side. Leprosy was probably introduced into what is now the territory of the United States by slaves from Africa in the last quarter of the eighteenth century, and first appeared in Florida. Since that time and even up to the present there are occasional fresh importations from Norway, China, Russia and the islands of the Pacific.

Present Distribution.-This ancient disease is still distributed over all tropical and temperate regions. There is no nation wholly free. There are colonies or nurseries here and there and every century some seed from at least one of these finds growth in some other locality. Some of these nurseries have been in continuous existence since the dark ages. Such is the colony at Bergen where, according to Hansen, there was leprosy as early as the eleventh century and probably earlier. The seeds have never been entirely destroyed and the number of lepers fluctuates with the effectiveness of restriction. From 1836 to 1856 the number of lepers in Bergen multiplied more than three times. This led to stricter regulations and by 1907 the number had fallen to about two-thirds of what it was in 1836. From this nursery at Bergen, seed has been scattered to the furthermost parts of the earth and daughter colonies have been established in Russia and in the United States.

The guess as to the number of lepers now living runs from one to two million. These are mere guesses and it is not probable that the exact number of lepers in any country is known. Certainly we do not know how many there are in the United States. According to Brinkenhoff there were, in 1909, 146 officially reported cases, but this includes only 50 in Louisiana where, according to Dwyer, there are at least 300. Pollitzer makes the number in this country 530 and Ashmead thinks it reaches 3,000 . The former is undoubtedly too low and the latter probably too high. We should have a national leprosarium. To longer neglect to provide one is not only short-sighted but well-nigh criminal. It is true that state laws provide that lepers shall be isolated, but this is only on paper and without the possibility of enforcement. Neither state nor nation has any provision for the isolation of these unfortunates, and the way in which some of them have been tossed from pillar to post is not a credit to our civilization. 
Even in Louisiana where there is a state colony, isolation is not effectively carried out.

The Bacillus.-The bacillus discovered by Hansen of Bergen is believed to be the specific cause of leprosy, although all the conditions necessary to establish this fully have not been complied with. This organism is a long (1.5-6 microns), slender (0.2-0.5 micron) rod, which is acid-fast and belongs to the same group as the tubercle bacillus: It takes fuchsin and similar stains more readily than the tubercle bacillus and loses the stain more easily when washed with dilute mineral acid. However, these differences are so slight and vary so much with different strains of both organisms, that they do not give a means of positive differentiation. The leprosy bacillus is oftener found in bundles and these are larger than those of the tubercle bacillus. This is not always distinctive, however. Much effort has been made to find some certain method by which the microscopic distinction between the two organisms may be determined. An expert in this work may distinguish these in many instances, but ordinarily it is not easy. The bacillus of leprosy may be mistaken not only for the tubercle bacillus, but it may be confounded with nonpathogenic acid-fast organisms, such as the smegma bacillus. The leprosy organism seems more truly parasitic than the tubercle bacillus and so far it has not been grown satisfactorily on artificial media, unless the method of Clegg be an exception. This American investigator uses a bouillon to which amebas'from dysenteric stools have been added. This preparation is inoculated with leprosy tissue and some observers have succeeded in obtaining a growth which at the last report had been carried to the tenth generation. Attempts to inoculate the lower animals with leprosy material have not been convincing. A number of men have submitted themselves to this experiment and still the result is left in doubt. In several cases this test has been negative. In others it has been positive, but in all of the latter the tested individuals have been associated more or less intimately with lepers. The Hawaiian convict, who had his choice between suffering the death penalty and inoculation, developed local lesions but these soon disappeared. For nearly two years he remained apparently well and then developed the disease, of which he died after four years. This 
test cannot be considered final, because the disease had affected some of his family.

The fact that the Hansen bacillus is found in all lepers, when a thorough examination is made, must for the present be accepted as a justification of the belief that it is the causal agent. However, many problems in the etiology of this disease remain unsolved. This bacillus may be aided by some other causal agent or it may be infective only in certain conditions or states of health or in certain deviations from health. It seems safe to say that the evidence available at present indicates that leprosy is a transmissible disease, but that it requires more intimate contact for its transmission than most of the other bacterial affections. Its history, even when studied most superficially, indicates its contagiousness. Such a colony as that at Bergen has brought it down continuously for at least eight hundred years. When a leper finds his way into a region where the disease has never been known, it slowly spreads. In this way, cases have developed in Minnesota, Michigan, Iowa and elsewhere in this country. From Norway the disease has been transplanted to the Baltic provinces of Russia, where the number at present is estimated at more than one thousand. In Finland there is a leprosarium which was established in 1355 and in 1908 it housed 87.

Avenues of Infection.-Supposing that the disease first manifests itself at the site of inoculation, there is reason for believing that the bacillus finds its entrance through wounds of the surface. It is a common observation in leprous countries that those who go barefooted are more frequently attacked than those who wear shoes, and that the first recognizable lesions are on the feet. Two French physicians report that among 2,437 cases under their observation in CochinChina, 526 were general from the start, 550 showed the first lesions on the feet, 420 on the hands, 321 simultaneously on feet and hands, and 337 on the face. It is an old belief that infection frequently develops in the nose. Heiser found nasal ulceration in 799 out of 1,200 cases and others have reported even larger percentages. In recognizing this disease, one of the first things to do is to stain the nasal secretion of the suspected person for the bacilli. Among the healthy associated with lepers the bacilli are frequently found in the nose. There is 
no reason for thinking that it develops from deep breathing in of the bacillus, because the lungs are never primarily involved.

The possibility of the transmission of the disease through the agency of insects has been considered, but its wide geographical distribution does not render this view probable. The relation of fish diet to leprosy, so earnestly advocated by the late Jonathan Hutchinson, has not found wide support. 



\section{CHAPTER VII}

\section{ASIATIC CHOLERA}

History.-We have no positive knowledge of Asiatic cholera before 1816. It is assumed by some that it had long existed in endemic form in the region about the delta of the Ganges and it is reported to have appeared in the Goa district (Portuguese Settlement) as early as 1543 and in the Pondicherry (French Settlement) in 1768, but there is no positive knowledge of these facts. In 1816 this infection began its first recorded travels and reached countries so remote that it could be regarded as pandemic. The time assigned by Haeser to the first great excursion of this infection extended through seven years (1816-1823). It traveled slowly at that time, before the general use of steam transportation, and did not get beyond the confines of Asia and Africa. To the east and south it visited Borneo, Java, the Philippines and China. To the west and north it spread through Arabia, Persia, Syria, Egypt and Northern Africa. It lingered in various localities for some years, after which it was known only in its home until 1826 when the second visitation began. This continued for eleven years, terminating, according to Hirsch, in 1837. This time it spread over the greater part of Europe and America. It broke up into parties which traveled different routes, some by sea and some by land. The faithful from further India brought it to Mecca where it found ready but slow transportation to all points of the compass. Nothing more was known of the infection outside its own domicile until 1846. The third pandemic reached the farthermost parts of the earth and lasted until 1862. It killed in France alone, in 1853-54 nearly one hundred and fifty thousand and it pursued the gold seeker on his way across the plains to California. The fourth pandemic was well in evidence by 1864 and continued until 1875. As the records show, it found 114,683 victims in Prussia alone on this trip. The fifth pandemic began in 1883, spread over the eastern hemisphere and reached New York harbor, but was refused admission. This time the number of victims in European Russia alone is given at 800,000 . The notable 
outburst at Hamburg belongs to this period. In 1902 cholera for the sixth time became pandemic. It was disseminated by 400,000 pilgrims gathered together at Mecca. Since that time and up to the present it has been found in various parts of Europe and has repeatedly reached our own shores, but has not been permitted to gain a foothold.

In all these excursions, among all kinds and conditions of men, in every degree of civilization, in the tropics and amid the snow and ice of northern Russia, in the thronged city and in the emigrant's wagon, with high and low, slave and master, wherever it has traveled, cholera has maintained its individuality and has shown no modification in manner of attack or variation in the symptoms induced in its victims. Its vehicle of transport has been man's body and it has followed the lines of human travel, on foot, on horse or camel, by stage or ox team, by steam, on land and sea. The sick and dying have scattered its progeny around the world. The science of preventive medicine is the only detective who can trace this criminal, the only officer who can arrest it and the only executioner who may finally remove it for all time from the earth.

The Bacillus.-In 1883 the German government sent a commission with the distinguished bacteriologist, Robert Koch, at its head, first to Egypt and then to India to ascertain the cause of this disease. Many months were spent in the study of the discharges of the sick, the postmortem examination of the dead and the investigation of the food and drinking-water of the infected. The result was the discovery of the infective agent, and this has placed in man's hands the possibility of completely eradicating this disease. The bacillus is a slightly curved rod, averaging about 1.5 micron in length and one-third this in breadth, but with many variations. Frequently, many individuals are attached, end to end, forming something like the letter S. It is known as the comma bacillus or the cholera vibrio. It is distinguished from similar vibrios by having a single flagellum or whip at one end. Its rapid motility in suspension is due to this whip. Sometimes the form is ovoid, often much longer and shows a long whip. It is easily recognized in the stools by an expert and the diagnosis in suspected cases is easy and certain. It takes the ordinary basic stains easily and deeply, but in order to stain the whip a mordant dye is desirable. It grows 
rapidly on gelatine plates at $22 \mathrm{C}$. (71.6 F.), forming, within twentyfour hours, colonies visible as small bright points.

Under a low power the colonies appear like fine bits of glass strewn over the gelatine. They are easily distinguished from colonies of Bacterium coli, found in normal stools, by their greater refraction. After forty-eight hours the gelatine under and about the colony begins to liquefy, forming a small funnel or crater in the bottom of which lies the colony. Old subcultures develop colonies on gelatine plates which are less characteristic than those freshly obtained from cholera stools. In gelatine stick cultures the bacillus grows along the line and looks like a white thread. Liquefaction begins at the top and extends downward forming a funnel-shaped depression. Colonies grown on agar plates are also quite characteristic. On other media it grows quickly, especially so in alkaline 1 per cent. peptone solution. The cholera bacillus does not grow in the absence of air and consequently is known as an obligate aerobe.

The cholera bacillus grows most abundantly at or a few degrees above body temperature and does not wholly cease to multiply until the temperature is at or below 8 C. (46.4 F.). Freezing does not destroy it and it retains its virulence after having been frozen in ice for several days. It is quickly destroyed by drying. A drop of a bouillon culture placed on glass and allowed to dry in the diffuse light of a room shows no growth when placed in proper medium after two hours. When exposed to direct sunlight life is destroyed in even less time. This indicates that the bacillus does not form spores and that the disease is not air borne.

Boiling destroys the bacillus instantly; at $80 \mathrm{C}$. (176 F.) five minutes is long enough to destroy its vitality and a temperature as low as $55 \mathrm{C}$. $(131 \mathrm{~F}$.) has the same effect after half an hour. It is also highly susceptible to chemical agents. One per cent. carbolic acid, $1: 3,000,000$ corrosive sublimate and feebly acid solutions kill it within a few minutes. According to Harding one part of chlorin to one million parts of water destroys the bacillus within fifteen minutes. In distilled water it soon dies but in ordinary drinking-water or tankwater, such as is used in India, it may retain its vitality and virulence for weeks and even months. According to Hankin the organism soon 
dies in the water of the Ganges, which is feebly acid. How quickly it dies in stools depends on many conditions such as dampness and light.

No lower animal, however intimate the contact with infected men may be, is known to develop cholera. This disease seems to be, at least under natural conditions, confined exclusively to the human species. Furthermore, no one has succeeded in inducing a true cholera in an animal by inoculation. However, some of the attempts to accomplish this purpose have been partially successful and are of sufficient interest to justify brief review. Filter paper impregnated with cholera cultures fed to mice induces diarrhea, but filter paper alone has the same effect. Large quantities of cholera cultures fed to pigs cause death, but cultures of many other bacteria produce like results.

Nikali and Rietsch opened the abdominal cavities of guinea-pigs, tied the bile duct in order to exclude the bactericidal action of this fluid, and injected cholera cultures into the duodenum. In the intestines of the recovered animals the cholera bacilli multiplied and the epithelial lining of the intestines was found altered. Other bacteria behave in a similar manner. Koch neutralized the stomach contents with soda and then introduced cholera culture into this organ through a tube. At the same time the animals were stupefied with opium from which they soon recovered, but the next day became ill and died on the second or third day in collapse. After death the intestine was found to contain a colorless fluid consisting of a pure culture of the comma bacillus. Like results may be secured with other vibrios. Indeed, Metschnikoff did better in his experiments on rabbits with the Vibrio Maszanah which is known to be quite different from Koch's comma bacillus. He polluted the teats of a mother rabbit with this culture and found that at least half of the nursing young died of a choleraic diarrhea. Moreover, when the sick young rabbits were placed in a cage with healthy fellows from another litter, many of the latter became infected. Thomas injected cholera cultures into the ear veins of rabbits. After a few days the animals died, and inflammatory changes were found in the walls of the intestines and cholera bacilli in the intestinal content.

Many bacteria when injected intravenously find their way into the intestine and may induce the same changes in the intestinal walls. Cholera cultures injected into the abdominal cavities of guinea-pigs 
cause a fatal peritonitis. Many saprophytic organisms will act in the same way and quite as promptly. It is safe to say that all attempts to induce genuine and distinctive Asiatic cholera in the lower animals, made up to the present time, have failed, and that we know no animal susceptible to this disease under either natural or experimental conditions. To man alone belongs the function of serving as host, preserver and distributor of the comma bacillus. Without man to supply warmth, shelter, food and transportation, the cholera bacillus would soon disappear from the face of the earth.

Every man who goes into battle is not killed; likewise not every man who swallows the cholera bacillus becomes infected and of the infected all do not die. The cholera bacillus is highly susceptible to acids, and the acidity of the stomach is a protective agency. But the acidity of the stomach is widely variable among people and scarcely less so in the individual from time to time. Infected drink, taken when the stomach is empty and non-acid, is likely to carry its infection on into the alkaline intestinal content. Bacilli protected by masses of food, difficult of digestion, may also pass through. In the midst of cholera epidemics, many harbor the bacillus and distribute it in their stools without being at all affected by it. Others are only slightly ill and there is every degree of gravity up to those in which the disease is fatal within a few hours.

In typical cases of cholera the bacillus does not find its way through the intestinal walls. It multiplies so abundantly in the intestinal content that it starves out all other bacteria and after death there is a pure culture in the intestine. It not only grows abundantly, but its cells speedily die and in doing so the poison contained in their structure is liberated, exerts its local effects on the intestinal walls, is absorbed and produces the symptoms of the disease, and death. In fact, cholera as an infection is limited to the alimentary canal; as an intoxication it kills.

In acute cholera the bacillus is found only in the intestine and gallbladder after death. All other organs and tissues are sterile. The intestine is converted into a great culture flask from which the chemical poison, elaborated by the bacterial growth, diffuses into the blood, while the water from the blood diffuses into the flask. This results in the condensation of the circulating blood, the drying out of the 
tissues, the suppression of urine, perspiration, saliva and even of the tears. The cholera poison, irritating the intestinal wall, increases peristalsis until it becomes most painful and leads to the ejection of large volumes of rice-water stools. The constant nausea and vomiting render even drinking quite impossible. Through mouth and anus the culture flask is discharged while it is constantly replenished by the withdrawal of water from the blood and tissue. In the acute form, a few hours suffice to dry out the tissues so thoroughly that death results.

Several cases of laboratory infection with the cholera bacillus have been reported. The first of these occurred in Koch's laboratory in 1884. A careless worker infected himself. Dr. Oergel of Hamburg died from accidental infection with the cholera bacillus. Some halfdozen additional laboratory infections have been reported. Besides these accidental infections, several have intentionally swallowed cultures. The most notable instance of this kind were the Munich professors, Pettenkoffer and Emerich. They alkalized their stomachs and then drank the dilute cultures. The former suffered only a severe diarrhea, but the other passed into the algid stage with suppression of urine and barely escaped with his life. A similar instance occurred in Paris under the observation of Metschnikoff. It has been observed in these cases that the period of incubation is short, from twenty-four to forty-eight hours.

The cholera poison, on which much work, ending in diverse and even contradictory conclusions, has been done, is probably the protein poison found in all proteins. Ordinarily this poison is without effect when given by mouth on account of the slowness with which it passes the intestinal wall, but with the lumen of the intestine filled with an abundant cholera culture, the walls are so injured that the poison is rapidly absorbed. The cholera poison is not more active than that obtainable from other bacteria, both pathogenic and non-pathogenic, also from other proteins both vegetable and animal.

Sources of Infection.-Every case of cholera means that some one has swallowed bacilli which have come from the stools of some one else. The route may have been quite short and direct or may have been long and circuitous. The bacilli bred in the intestine of one indi- 
vidual may find their way into the mouth of another, or many generations of bacilli may lie between the two subjects. In all instances, the connection is sure and certain. This disease spreads in no other way. The only infected discharges from the cholera patient are those that come from the alimentary canal. The vomited matter may contain virulent bacilli but this is rarely the case on account of the great susceptibility of the organism to acid solutions. Practically the only infectious discharge is the stool. Among filthy people the stool may go quite directly to the mouth by the hands. Mothers often infect their children in this way and sometimes it is transferred from child to parent.

This contact infection is illustrated in the voyage of the Carlo $R$. which sailed from Naples, Aug. 1, 1893, for Brazil, with 1,472 steerage passengers. The ship's water was not infected. On the outward trip cholera appeared. On reaching South America the vessel was not permitted to dock and was compelled to return. The double voyage occupied two months and during this time there were 141 deaths among the steerage passengers. Scarcely less direct is the transference from soiled clothing or bedding or when the infected stools are deposited on fruits and plants which are subsequently eaten. The less cleanly people are, the more liable to harbor this disease.

Before the discovery of the bacillus, Pettenkoffer had observed that, in its European visitations, this infection spared certain localities. These were relatively clean places, such as would not afford opportunity for contact infection. The great outbreaks, such as that at Hamburg in 1892, are due to infection of the general water-supply. At that time Hamburg used the unfiltered water from the Elbe. At first there were a few cases among those employed about the wharves. Finally the pollution extended up the river and reached the city water-supply. The first case was recognized early in August and the explosion came on the 20th of the same month and by the 31st the number of new cases per day reached one thousand. Hamburg and Altoona are one city, but separated administratively. On one side of the street the houses are in Hamburg and on the other in Altoona. The latter had a separate and uninfected water-supply and was free from the disease except among those who drank from the Hamburg water. 
Certain cities in Italy, notably Naples and Genoa, have in recent years been mildly infected and the disease has been kept alive by contact infection, but their water-supplies being free from pollution, severe outbreaks have not developed. Suspected persons and their families and neighbors should be tested by an examination of their stools and kept under observation so long as these contain the bacilli. A convalescent may carry the organism in his intestine and expel it in his feces for sixty days after recovery. Many who do not develop the disease carry the bacilli and distribute them in their stools. 


\section{CHAPTER VIII}

\section{TYPHOID FEVER}

History.-In his writings on epidemics, Hippocrates (fifth century B. C.) describes certain continued fevers with moderate disturbances of the bowels, much wasting and delirium, lasting sometimes forty days, and recovering rarely by crisis, more frequently irregularly. These can hardly be other than cases of typhoid fever. Galen observed similar cases and described them under the names "hemitritaeus" (used by Hippocrates) and "febris semitertiana." These names were used for centuries. In the seventeenth century Spigelius writing under the title "De Febre Semitertiana" reports necropsies in which spots and sloughs were observed in the intestine. Similar lesions were found and reported by other Italian physicians. Near the middle of the same century an English physician, Willis, made necropsies and observed like changes in the intestine. About the same time, the father of English medicine, Sydenham, described a fever lasting from fourteen to thirty days with a tendency to diarrhea, delirium and epistaxis.

In the eighteenth century many contributions to the knowledge of this disease were made. Morgagni described the intestinal ulcers, perforations, and enlarged mesenteric glands and spleen. Tissot of Lausanne gave a good description of the disease as did Huxham of England. The latter's picture is sketched in the following words:

The patient at first grows listless and feels slight chills and sudors with uncertain flushes of heat and a kind of weariness all over. This is always attended by a heaviness and dejection of spirit. A nausea and disrelish of everything soon follow. Though a kind of lucid interval of several hours intervenes, yet the symptoms return with aggravation, especially towards night; the head grows more heavy, the heat is greater, the pulse quicker; a great torpor or obtuse pain affects the head and is commonly succeeded by some degree of delirium. In this condition the patient often continues five or six days, seeming not very sick; about the seventh or eighth day the giddiness, pain or heaviness of the head becomes much greater, often delirium appears with universal tremors and muttering, the tongue grows often very dry, often very thin stools 
are discharged; now, nature sinks apace; the pulse may be said to tremble and flutter rather than to beat; the sick man becomes quite insensible; and the delirium ends in a profound coma; and that soon in an eternal sleep.

Up to the nineteenth century all the continued fevers with delirium were known under the general name "typhus," which means smoky or cloudy, and refers to the mental state. Early in the seventeenth century some of the more observant physicians began to suspect that two quite distinct diseases were included under the diagnosis of typhus and on this point there grew up a discussion which continued for two hundred years. In order to gain knowledge to settle this question, necropsies were frequently resorted to and most minute and exact studies of the lesions were made. In a medical way the dispute became partially at least an international one. French physicians, led especially by Bretonneau of Tours, held that in their necropsies they found, quite usually, lesions, inflammatory and ulcerative, in the ileum, while British physicians for the most part failed to find such changes.

The great clinicians of Paris in the early part of the nineteenth century were Trousseau and Louis and these were earnest in presenting their views. At that time many of the brighter young medical men of this country went to Paris to continue their studies. There they heard the lectures and saw the necropsies. Stopping in Great Britain in their visits to and from Paris, they heard lectures and saw necropsies. In France ulcers were found in the intestines; in England they were not. In this country some necropsies revealed intestinal lesions while others did not. It soon became evident that there were two distinct diseases, differing not only in the lesions found after death but in onset, progress, and in other respects. The old name, typhus, was retained for the form without intestinal lesions and the new term "typhoid" given to that with such lesions. Louis selected the new name, and in giving it he said: "I have long searched for a word to express the anatomical character of this disease which would not be disagreeable to the ear, and having failed to find such an one, I have adopted the expression 'affection typhoide,' as being at least free from inconveniences." Bretonneau had used the designation "dothinenterie" meaning pustule in the intestine. The word "typhoid" is unfortunate and not so good as the English designation "Enteric 
fever." The Germans know it as "Abdominal typhus." Gerhard of Philadelphia is generally given the credit of finally settling the dispute concerning the duality of the old typhus. Valliex wrote in 1839: "Gerhard established for the first time the very important fact that there can exist, and that there do exist, at the same time in the same country two diseases that may be clearly distinguished and in which one can predict during life the lesions which will be found after death. These diseases are typhoid fever and the true typhus."

Early in our civil war, medical officers reported fevers which in their opinion differed from typhoid fever as seen in the north. The first board, appointed (1861) to investigate this matter, reported that "the fever prevalent among the soldiers was bilious remittent fever, which, not having been controlled in its primary stage, has assumed that adynamic type which is present in enteric fever." A second board was convened (1862) for the purpose of revising the sick report. Major Woodward, the chief of this board, insisted that "the prevailing fevers of the army of the Potomac were hybrid forms, resulting from the combined influences of malarial poisoning and of the causes of typhoid fever," and he insisted that they should be reported as "typhomalarial fever." This designation became official July 1, 1862, and from that time to June $30,1866,57,400$ cases, with 5,360 deaths, were reported under this name.

While Woodward's designation of the disease was adopted, his understanding of its nature was quite generally ignored. He believed it to be a hybrid resulting from coincident malarial and typhoid infections while the greater part of the profession understood it to be a severe form of malarial infection. In Woodward's opinion typhomalaria was quite as severe and fatal as typhoid, because it was typhoid in one already infected with malaria or vice versa. He also believed that a trace of scurvy, often unrecognizable until typhoid infection developed rendered the latter more grave. The majority of physicians and the laity regarded typho-malaria as a severe malaria, but much less grave than typhoid; the new term took a part of the sting out of the diagnosis of typhoid and many a practitioner in the kindness of his heart, in his desire to spare patients and friends, found the compound word a welcome subterfuge. With the mobilization of troops in the war with Spain (1898) the same fever spread rapidly through 
the camps, small and large, north and south of the Mason and Dixon line, and was recorded on sick reports under a multitude of names, chiefly malaria, but often typho-malaria and many other designations hitherto and subsequently unused. The board of medical officers appointed to investigate, employing scientific methods of diagnosis, soon showed that malaria was very infrequent and that more than 99 per cent. of the cases were typhoid. Among nearly 20,000 cases, 12 of coincident malarial and typhoid infection were found and even in these the malarial manifestations were suppressed during the course of the typhoid. A man already malarial is not immune to typhoid or vice versa, but even in coincident infection there is no peculiar or characteristic symptom complex. It follows that "typho-malaria" in any sense is a misnomer and should not be used.

Malaria is not the only infection which may be coincident with typhoid. Cases, though few in number, have been reported in which typhoid has been coincident with the following: Malta fever, recurrent fever, anthrax, Asiatic cholera, diphtheria, miliary tuberculosis, scarlet fever, and both amebic and bacterial dysentery. These facts simply show that the above mentioned infections establish no immunity to typhoid nor does this disease protect the individual against other bacterial invasions. Of more importance are the secondary infections which may develop in typhoid. The intestinal lesions open ports of entry especially for pus-producing bacteria, which may develop abscesses in various parts of the body, and these are slow to heal and difficult to reach.

The Bacillus.-In 1880 Eberth discovered short, motile bacilli in the spleen and mesenteric glands of those dead from typhoid fever. Four years later Gaffky isolated this organism and secured pure cultures. An almost endless amount of research has been devoted to the Bacillus typhosus with the hope of finding easy means of sure recognition under all conditions. There is an extensive group of bacilli with the typical typhoid at one extreme and the typical colon bacillus at the other and with many intermediate varieties. It is easy enough to distinguish the extremes, but it still remains quite impossible to locate exactly every member of this group. The colon bacillus is a normal dweller in the intestinal tract and causes trouble only when it 
finds its way into some place where it has no business. Normal feces contain colon bacilli in great numbers.

When the typhoid bacillus finds its way into man's intestinal tract it is likely to develop typhoid fever. The stool of the typhoid victim is laden with the Bacillus typhosus. Between the extremes of the typho-colon group, there are two varieties of the B. typhosus, Paratyphus A and B, B. enteritidis, mouse typhoid, dysentery bacilli and $B$. fecalis alcaligenes. A typical typhoid bacillus is highly motile; it does not coagulate milk; it does not redden litmus milk; it forms blue colonies on plates of gelatine colored with litmus; when grown in whey colored with litmus it produces only a slight cloudiness and at most only slightly reddens the medium; when grown in fermentation tubes in a solution containing grape sugar it develops no gas; when grown in agar colored with neutral red it does not change the color or develop any gas; when grown in peptone solutions or bouillon it does not develop indol. A typical colon bacillus is non-motile; it does coagulate milk; it reddens litmus milk; it forms red colonies on plates of gelatine colored with litmus; when grown in whey colored with litmus, it produces a marked cloudiness and deeply reddens the medium; when grown in fermentation tubes in solutions of grape sugar, it develops gas abundantly; when grown in agar colored with neutral red it does develop gas and changes the color; when grown in peptone solution or bouillon it develops indol. It will be seen from these facts that it is easy to distinguish between a typical typhoid and a typical colon bacillus, but there are varieties of each which may contradict any one of these statements, while the intermediate organisms differ from one another and in their own varieties. It follows that only an expert in this line is fitted to locate exactly the members of this large group of organisms. However, with proper training one becomes quite expert and the identification of typhoid bacilli in the stools and urine of suspected cases becomes less difficult than one would suppose from the above statements.

The recognition of this organism in drinking water remains so diffcult in spite of all the work that has been done that it is seldom attempted and the fitness of a water for drinking purposes is determined by the number of colon bacilli in a given volume of the water. This is easily done by counting the number of red colonies which 
develop on litmus gelatine plates or on gelatine containing some other color affected by the colon bacillus in a similar manner. The number of red colonies developing on such plates is taken as an indication of the extent to which the water carries fecal contamination. If fecal matter from healthy people finds its way into the water that from those infected with the typhoid bacillus may, and the only safe procedure is to condemn all waters bearing fecal matter. This does not mean that the colon bacillus in any of its varieties will cause typhoid fever.

Nothing like typhoid exists so far as we know in any of the lower animals. Moreover, with the possible exceptions to follow, all attempts to induce a chronic fever with the typhoid lesions in animals by inoculation with the specific bacillus have failed. Injected in large enough doses it kills, but without infection. The dead bacillus does the same thing. This shows that the cellular substance contains a poison, but this is true of all bacteria, both pathogenic and non-pathogenic. Grünbaum claims to have developed typhoid fever in a chimpanzee and Weinberg reports positive results with apes infected with certain intestinal parasites, which inflict on the mucous membrane wounds through which the bacillus find entrance. While our domestic animals do not become infected with this bacillus, they may bear it from place to place on their bodies or distribute it in their excretions. Several cases of accidental laboratory infection and a few acquired intentionally have occurred. These demonstrate the pathogenicity of the bacillus for man.

Sources of Infection.-It is true of typhoid fever, as it is of Asiatic cholera, that every case of infection is due to the transference of the fecal matter of the infected either by a short or a long circuit, to the alimentary canal of another, There is, however, this important difference; cholera is widely disseminated only at certain times and in certain places, while typhoid is well-nigh ubiquitous. Up to the present time there is no part of the world absolutely free from this disease for any great length of time. In one sense typhoid is a filth disease inasmuch as it is scattered through the excretions of the human body, especially in the urine and feces. No wonder that it was thought that typhoid may originate de novo. Now, we know that this is not true, 
but until the discovery of the causal agent this truth was difficult of demonstration.

It follows from what has been said that the prevalence of typhoid in any community is largely determined by the personal cleanliness of the inhabitants and largely by the method of disposing of human excreta. In the past typhoid has been the most destructive disease in armies, miners' camps, exploring parties and wherever the disposal of fecal matter has been primitive and imperfect. The dissemination of this disease among our soldiers in 1898 was thoroughly investigated, and some of the conclusions may be not only of interest but of value to civilians.

During the Spanish war of 1898 every regiment constituting the first, second, third, fourth, fifth and seventh army corps developed typhoid. This includes all the soldiers assembled in that war except those who went to the Philippines and consequently were not investigated by the board. More than 90 per cent. of the volunteer regiments developed typhoid within eight weeks after going into camp. The disease developed in certain of the regular regiments within from three to five weeks after going into camp. These facts negative an old claim that sudden change from civilian to military life favors the development of this disease. The disease became epidemic in small and large camps, in those in the north as well as in those in the south. It had been held that simply bringing large numbers of men together was enough in and of itself to cause a typhoid epidemic. Some had argued that change of climate alone caused the disease.

At that time typhoid was so widely and abundantly distributed in this country, the chances were that whenever and wherever one thousand or more men should be brought together, an average of four in this number would reach the camp already infected. Those who came with the infection would scatter the seeds before the disease in them would be recognized. The number of cases in the different camps varied directly with the methods of disposing of the excretions. The disease was disseminated by contact, by flies and by water. Contact infection was the most important factor. The grounds were covered in some places with feces. The men tracked this infected matter into their tents, soiled the floors, blankets, clothing, and tents. Men were detailed to act as orderlies at the hospitals where they handled bed 
pans and otherwise polluted their clothing and person, and then returned to their mess tents and handled food for themselves and passed it to their neighbors without even washing their hands. It was estimated that in some regiments at least 60 per cent. of the cases were contracted through lack of personal cleanliness and the consequent pollution of clothing, bedding, tentage, food, etc. Flies served as carriers of the infection. They swarmed over infected matter in the latrines and then visited and fed on the food prepared for the soldiers at the mess tents. In some instances when lime had recently been spread over the fecal matter in the latrines, flies with their feet whitened with lime were seen on the food. Flies carry the bacilli on their bodies mechanically and pollute what they subsequently touch and they eat infected matter, swallowing the bacilli, which they subsequently deposit with their own excretions. In some camps the watersupply was contaminated by the natural drainage from the infected earth.

At Jacksonville, Fla., it was probable that infection through inhalation was a minor factor in the spread of the disease. Change of location did not rid the soldiers of the infection, because they carried it with them, in their intestines, on their hands, in their clothing, blankets and tentage. They even transported the infection with them to Cuba and Porto Rico. These are fair samples of the dissemination of typhoid not only in military but in civil life, for the difference is only one of degree. Every village is a small camp and every city a larger one. Typhoid in the past was more prevalent in military than in civil life because in our more permanent homes we dispose of our excreta more effectively. Had we not learned to do so, urban life would have remained impossible as it once was.

It must not be inferred from the above brief account of typhoid in 1898 that our soldiers were less cleanly or more ignorant than those of other nations. When the Franco-German war began, every corps of the German army was infected with typhoid and the second division of the eleventh corps was at that time suffering from a marked epidemic of this disease. The infection was not confined to the Prussians, but extended to every contingent of the German army. The seeds of the disease carried with them rapidly bore fruit, especially among the troops besieging Metz and later at Paris. Within less than two months 
after war was proclaimed typhoid had extended so extensively among certain divisions of the German troops, notably in the eleventh corps of the Prussian soldiers and in the Wurtemberg division, that more than 15 per cent. of these commands were sick of this disease. The total number of cases among the under officers and men in the German army during the Franco-German war amounted to 73,396, which was equivalent to 9.31 per cent. of the average strength. The invasion of France began about the middle of July, 1870. During the second half of this month the total number of cases in the German army was 345 , less than the average for preceding years of peace. In August the number perceptibly increased, amounting to 2.6 per thousand, but not enough to cause apprehension, and up to September it could not be said that there was an unusual prevalence of the disease. Early in this month there was an explosive outbreak and the cases ran up to 12,463 , which was equivalent to 15.3 per thousand. In October there were 17,253 new cases. In this month the epidemic reached its climax and fell slowly.

Typhoid may be transported by an army into regions practically uninhabited. This is illustrated by the Afghan war of 1878-80. Some of the sites occupied by English soldiers were never before peopled. It is not at all likely that the waters of the mountain streams were specifically contaminated with the typhoid bacillus; nor was it likely that the virgin soil covered by these encampments was infected, except as it became so by occupation, and yet typhoid developed at nearly every station occupied by the English troops. Only one explanation is possible. It is known that the English troops drawn from various parts of India were widely infected with typhoid when the invasion of Afghanistan was begun. A similar experience is furnished by the history of French expeditions in Northern Africa. In the Oran campaign, in 1885, French commands encamped in desert stations never before occupied, and in these typhoid not only appeared, but developed epidemic proportions. In the English expedition to Suakin in 1885 every precaution was taken to supply the troops with pure water. In fact the drinking water was distilled. Notwithstanding, typhoid developed extensively. The east Surrey regiment joined the expedition already infected and it is more than likely that these men infected the latrines and the disease was spread by contact and by flies. In 
the expedition for the relief of Chitral in 1895 typhoid infection was carried by the soldiers, and when they encamped at Kahr an epidemic developed. In the invasion of Egypt infected regiments were drawn from Mediterranean stations. On the disembarkment at Ismalia occasional cases began to appear and continued to do so until a serious epidemic manifested itself in the permanent camp at Cairo. In the South African war the English failed to profit by the lesson for which all nations had paid so dearly. The restriction of typhoid in armies was first successfully practiced in the Russo-Japanese war by both parties and this was the first great war in which the victims of typhoid did not greatly add to the death lists. Now, with our knowledge of sanitation, aided by the protection afforded by vaccination, typhoid in both military and civil life should recede rapidly and soon be known only in the records of the past.

The typhoid bacillus is eliminated from the infected person chiefly in the stools and urine. Vomited matter, the saliva and the discharges from posttyphoidal abscesses may contain the virus, but compared with the stools and the urine these are of minor importance. The stools of every person infected with this disease contain the bacilli, but in widely varying amounts, from a few, difficult of recognition on account of the great numbers and rapid growth of other bacteria, up to a pure culture. As a rule, typhoid bacilli are most numerous in the stools during the third week of the disease, at a time when the intestinal ulcers are sloughing. The stools of all suffering from this disease should be thoroughly disinfected. However, the bacilli may be present in the stools both before the disease is recognized clinically, and long after clinical recovery. In many instances the stools continue to be infected for from six to eight weeks after the subsidence of the fever. In a few instances the individual becomes a constant and chronic carrier of the infection and may remain so for years. Moreover, everyone who harbors this organism does not develop the disease. Any one of these classes, the convalescent, the carrier and the apparently well man, may infect wide areas and diverse places. The only hope of complete protection lies in provision for the disposal of the excreta of all men in such manner that they cannot find their way, directly or indirectly, by short or long circuit, into the alimentary canal of others. 
The urine in about 30 per cent. of cases of typhoid is infected with the bacillus and carriers may distribute the infection through this excretion.

Contact infection is the most common mode in the distribution of typhoid. Different students of epidemiology in widely distant lands agree in this and even go so far as to place practically the same estimate on the number of cases originating in this manner. About 60 per cent. of all cases of typhoid are believed to be due to contact infection. The board of medical officers in 1898 placed the percentage of contact cases at 62.80, while Drigalski gives it for Germany as 64.7. These conclusions seem to have been reached quite independently, inasmuch as the German makes no mention of the American studies which were conducted nine years before his. Formerly, it was supposed that typhoid is mostly water-borne and the board of officers began their investigations possessed fully of this view, but their studies convinced them that this is an error and first furnished indisputable evidence that contact is the most important factor in the distribution of typhoid. Contact is both direct and indirect. The board divided the cases between the two as follows: Direct, 35.01 ; indirect, 27.79 per cent. In more than 90 per cent. of the cases due to direct contact the hands bear the infection directly to the mouth. Klinger found this to be true in 1,315 out of 1,397 cases. This certainly should emphasize the importance of personal cleanliness.

In indirect contact infection, clothing, bedding, drinking cups, dishes, foods, etc., may serve in the transport of the infection from one person to another. Soiled clothing may retain virulent bacilli. Soiled blankets shipped from South Africa in the Boer war carried the infection to those who used them in England. In the Spanish war our camps were not rid of infection until the clothing of the soldiers, their beddings and the tents were disinfected. Infected fecal matter deposited on oyster beds render this article of food dangerous. Infected employees in dairies spread the infection through milk and its products. Not infrequently cases are so distributed as to show the route of the milk man. Greens and salads, fruits and berries may become bearers of typhoid infection.

Water epidemics are explosive in outburst and are characterized by the simultaneous infection of a large number of those who consume the water. In flowing water the typhoid bacillus dies out in from 
five to ten days. In still water it may continue to live for a much longer time. In dead ends of water pipes it may linger for many days; indeed, the statement is made that it has been found in dead ends months after the infection of the general supply has disappeared. Of course, the water is infected with the excretions of man.

Typhoid infection is widely distributed by boats and cars. At present there is no attempt to disinfect the waste from the waterclosets on either of these vehicles of transportation. Some years ago when on account of a break in the locks at Sault Ste. Marie, many downward-bound boats were detained above the intake of the city's water-supply, an explosive outbreak of typhoid developed. From railroad trains fecal matter is scattered along the roadbed and sometimes this is specifically infected. This filth may be washed into watersupplies or it may be scattered in dust to infect workers on the road and even travelers on trains. The prevalence of typhoid fever is not a credit to any community and is an indication that filth finds its way into the mouths of the inhabitants.

It is estimated that, taking into consideration the distribution of typhoid fever over a large area and for a long time, about 5 per cent. of it is due to the infection of milk. The bacilli multiply rapidly in milk until it sours. Whether or not pasteurized milk may contain the living bacillus depends on the temperature used in the process and the thoroughness with which it is carried out. A temperature of $62 \mathrm{C}$. for five minutes is not enough to insure the destruction of this organism in milk. This is the temperature at which this process was formerly generally carried out, and at which it is now sometimes done. In an improved process the temperature is carried to $85 \mathrm{C}$., which is high enough to destroy this virus in milk in one minute. In butter this bacillus can live for weeks.

Attention has already been called to the house fly as a distributor of this disease. In some sections of this country the crusade against this pest has not been pushed with sufficient energy and it is still in evidence both in the privy vault and in the dining room. Ants and other insects distribute fecal matter deposited on the earth and may carry the infection to plants and fruits. 


\section{CHAPTER IX}

\section{ANTHRAX}

History.-This disease is supposed to be referred to in the book of Exodus (9:10), the reading of which is as follows: "And it became a boil breaking forth with blains upon man and upon beast."

Homer's acquaintance with anthrax may have inspired these lines (Iliad, B. I.) :

"And first the beasts assailed he, the mule and ranging hound, But soon at man his firebolt shot, smiting to the ground."

The pestilence described in the CEdipus of Seneca is regarded by some as a dramatic description of an anthrax epidemic. The first victims are the domestic animals, one after another, until men and all beasts are being hopelessly devoured by the insatiable anger of the gods :

The sluggish ewes first felt the blight,

.For the woolly flock the rich grass cropped

To its own doom. At the victim's neck

The priest stood still, in act to strike;

But while his hand still poised the blow,

Behold the bull with gilded horns,

Fell heavily; whereat his neck,

Beneath the shock of his huge weight,

Was broken and asunder yawned.

No blood the sacred weapon stained,

But from the wound dark gore oozed forth.

The steed a certain languor feels,

And stumbles in his circling course,

While from his downward sinking side

His rider falls. . . .

The abandoned flocks lie in the fields;

The bull amid his dying herd

Is pining; and the shepherd fails

His scanty flock, for he himself

Mid his wasting kine is perishing.

The stag no more fears the ravenous wolf; 
No longer the lion's roar is heard;

The shaggy bear has lost her rage,

And the lurking serpent his deadly sting;

For parched and dying now he lies

With venom dried.

Another classical description is given by Ovid (Metam. vii). Pliny (Hist. Nat. Lib. xxvi) says:

We find it stated in the annals, that it was in the censorship of L. Paulus and $Q$. Marcius (164 A. D.) that carbuncle was first introduced into Italy, a malady which till then had confined itself to the province of Gallia Narbonensis (now Provence). In the year in which I am now writing these lines two persons of consular rank have died of this disease; Julius Rufus and Q. Lecanius Bassus; the former in consequence of an incision unskillfully made by his medical attendant, the latter through a wound upon the thumb of the left hand by pricking a carbuncle with a needle, a wound so small originally as to be hardly perceptible.

Arabian physicians described anthrax as Persian fever. In the ninth and tenth centuries the disease was widely disseminated over Europe. In the years $1375-76$ it is reported that even wild animals died of anthrax. According to Kircher in 1617 most of the domestic animals and 60,000 people died of this disease. It continued to be widely prevalent in Europe down to the time of scientific medicine and isolated epidemics still occur. In the sixties of the last century an outbreak in Russia was investigated by a German commission and reported as anthrax. From 1864 to 1870 in the province of Novgorod more than 65,000 domestic animals (horses, cattle and sheep) and 528 people succumbed to this infection. It has been extensively disseminated in South America, especially in Brazil, where it is known as "Garotilha." It is well established in Australia where it has interfered greatly with sheep raising. It has found its way into most parts of Asia and Africa. In our own country it has appeared only as local epidemics among cattle and isolated cases among men, known as woolsorter's disease and malignant pustule. Sobernheim gave the total number of deaths from this disease among cattle, horses, sheep and goats in Germany from 1900 to 1909 inclusive as 55,410.

Since anthrax is the most typically infectious of all diseases, and since so many theories have been evolved concerning it, we may be pardoned for briefly reviewing the literature. As early as 1805 
Kausch wrote a monograph on this disease in which he held that it is due to paralysis of the nerves of respiration; but he offered no explanation of the paralysis. Delafond held that anthrax has its origin in the influence of the chemical composition of the soil on the food, thus inducing pathologic changes from malnutrition. The contagious nature of the disease was clearly established in 1845 by Gerlach. This was confirmed by the studies of Heuzinger and was endorsed by Virchow in 1855, since which time it has never been questioned. However, as early as 1849 the bacilli had been seen by Pollender. Pollender did not publish his observations until 1855, but he states that they were made in the fall of 1849 . First, he examined the blood of five cows dead from anthrax, and compared this with material taken from the spleen of a healthy animal. The examinations were not made until from eighteen to twenty-four hours after death, and he states that the blood was stinking, thus indicating that it had become contaminated with putrefactive organisms, but the description which he gives shows that he actually saw anthrax bacilli. He used a crude compound microscope made by Plössl, and he gave his attention to the blood corpuscles, chyle globules, and the bacilli.

His description of the micro-organisms may be condensed as follows: The third and most interesting microscopic bodies seen in anthrax blood are innumerable masses of rod-like, solid, opaque bodies, the length of which varies from $1 / 400$ to $1 / 200$ of a line, and the breadth averages $1 / 3,000$ of a line. They resemble the "vibrio bacillus" or "Vibrio ambiguosus." They are non-motile and neither water nor dilute acids, nor strong alkalies have any effect on them, and for this reason he concluded that they must be regarded as vegetable organisms. He questioned whether they existed in the blood of the living animal or resulted from putrefaction, but was inclined to believe the former, and thought they might represent the infecting organism, or at least the bearer of the infection. It will be seen that Pollender presented no positive proof that these rod-like bodies had any causal relation to the disease. In $1856 \mathrm{Brauel}$ inoculated sheep, horses and dogs with blood taken from animals sick with anthrax, and in this way demonstrated that the disease could be transmitted to sheep and horses, but not to dogs. He found sheep highly susceptible, horses less so, and dogs quite immune. $\mathrm{He}$ also demonstrated the 
presence of the bacilli in the blood of sick animals before death. It is interesting to note that he fell into an error concerning the motility of the bacilli. He states that when seen in fresh blood they are nonmotile, but later they become highly motile. This was, of course, due to contamination. It should be noted that Brauel also made examination of the blood of various domestic animals suffering from other diseases, and demonstrated the absence of the bacillus in these.

In 1863 Davaine published three valuable papers on anthrax. In the first he states that in 1850 Rayer inoculated sheep with the blood of others dead from anthrax, and in this way transmitted the disease. It appears that Rayer published a short note of this work in the Bulletin de la Société de Biologie in 1850, but I have not had access to this publication. Davaine's own work was of the greatest value and shows great skill for that time. Probably the most important experiments that he made were those in which he demonstrated that the blood of an animal sick with anthrax is not capable of transmitting the disease to others unless it contains the bacillus. It may be of interest to describe briefly the experiments which led to the establishment of this fact. Rabbit A was inoculated with anthrax blood. Forty-six hours later, examination showed no bacilli in the blood of Rabbit A. At that time twelve or fifteen drops of blood were taken from the ear of this animal and injected into Rabbit B. Nine hours later the blood of Rabbit A was reexamined and found to contain a large number of bacilli. This blood was injected subcutaneously into Rabbit C. One hour later Rabbit A died, and twenty hours later Rabbit C died, while Rabbit B remained free from infection. Space will not permit us to follow the literature of anthrax further. Pasteur, DeBarry, Koch and others studied the morphology, life history, and cultural characteristics of the bacillus, and in this way founded the science of bacteriology.

The Bacillus.-This is a long (4-10 microns), slender (1-1.3 microns) rod with rounded ends. A drop of blood from the spleen of an animal dead of this disease discloses, even without stain, great numbers of these bacteria. They are non-motile and take the basic aniline dyes easily. Often many bacilli are attached end to end, forming what is known as bamboo rods. These are quite characteristic but 
are not seen in all preparations. Many bacilli show capsules which are less deeply stained and the contrast is quite striking. It is supposed that this capsule protects the bacillus against the destructive action of the secretions of the body cells. At least, bacilli taken from infected animals generally show the capsules, while subcultures seldom do. It has been found that cultures grown in fluid blood serum do show the capsule. These facts indicate that the capsule results from some reaction between the organism and blood. It will continue to live, but will not multiply in the absence of air and consequently must be classed as an aerobe. It grows under a wide range of temperature ( 15 to 43 C.), but its optimum growth is at or near the temperature of the animal body ( 37 to $38 \mathrm{C}$.).

It grows easily on all the ordinary culture media. In undisturbed bouillon it does not produce a uniform cloudiness, but appears in floccules. On gelatine plates after from two to three days at from 18 to $20 \mathrm{C}$. it develops characteristic colonies. Under a low power these are seen to be not compact as is the case with most bacterial colonies, but loosely aggregated. The edges are not smooth and sharply defined, but more or less fringed. These are known as medusa forms and the fringe is due, as is shown under a higher power, to the growth of the rods from the central mass into the surrounding medium. It forms a proteolytic ferment which gradually digests or liquefies the gelatine and the colonies subside into the craters thus formed. In stick gelatine cultures the bacillus grows along the line and branches off on the sides forming a picture which has been variously designated as a brush or as an inverted pine tree; very slowly liquefaction proceeds from the surface downward. On agar plates the colonies are much like those on gelatine, with the exception that on the former spore formation may be observed. Stick cultures on agar are much like those on gelatine, with no liquefaction and a spreading of the growth over the surface of the medium. It coagulates milk and then digests the coagulum. With an abundant supply of oxygen digestion may proceed so quickly that coagula are not seen.

The anthrax bacillus multiplies by transverse fission, but when it finds the conditions of life unfavorable, it does not have to strive against untoward circumstances; it simply develops seeds or spores and passes into a resting stage. In this state it does not need air or 
food. It is inactive and is only potentially alive. When conditions become favorable, the spores develop into the vegetative form. The capability of passing from one form to another is a great factor in protecting the bacillus against destructive agencies. Each bacillus produces only one spore. There is, therefore, no multiplication in the exercise of this function. The purpose seems to be solely to protect the life of the individual. When times are good with plenty of air and an abundance of suitable food, life seems to proceed merrily and the organism multiplies abundantly. When times are hard, with inadequate air or food, the bacillus drops into the resting stage in which it has no needs and awaits a change for the better. When anthrax spores are brought under favorable conditions each spore develops into a rod which for a while carries on one end the waste remnant of the spore. Vegetative life with multiplication by fission begins anew.

There are some strains of the bacillus which apparently are not able to pass into the resting stage under any conditions. These are known as asporogenous strains. According to Eisenberg, anthrax bacilli are of two varieties or races, of different "biological dignity," one sporogenous and the other asporogenous, and each breeds true through all generations. Roux converts the sporogenous into the asporogenous variety by the following method:

Bacilli grow with the formation of spores in bouillon to which from two to six parts per ten thousand of phenol has been added. When the phenol has been increased to twenty parts per ten thousand there is no growth. Between these limits the bacilli grow without spore formation. Bacilli kept in these intermediate solutions for from eight to ten days permanently lose even in following generations the ability to produce spores.

The resistance of the anthrax bacillus depends on the presence or absence of spores. The latter are among the most stabile and resistant forms of pathogenic bacteria. They are more easily killed than the spores of certain nonpathogenic organisms, such as the potato bacillus. Anthrax spores on silk threads supply standards for testing the relative efficiency of disinfectants. Spores in cultures eighteen years old have been found not only viable but capable of developing into virulent vegetative organisms. Bouillon cultures of the vegetative form are sterilized by heat at $80 \mathrm{C}$. $(176 \mathrm{~F}$.) for one minute, while 
boiling for at least three minutes is necessary to insure the destruction of the spores. Dry heat at 100 C. (212 F.) must be continued for two hours in order to destroy the vegetative form, while three hours at $140 \mathrm{C} .(284 \mathrm{~F}$.) are necessary to exterminate the spores. The effect of direct sunlight on the two forms has been studied with varying and even contradictory results. This is easily understood when we think of the many variable factors, such as thickness of layer, intensity of light and temperature, entering into such experiments and influencing the findings. According to Momont, drops of dried bouillon cultures, with the air temperature at from 25 to $35 \mathrm{C}$. ( 77 to 95 F.), are destroyed when exposed to direct sunlight within from six to fifteen hours in the vegetative form and after one hundred hours when spores are present. The ordinary disinfectants, as generally used, destroy the vegetative forms but are not certain in their action on spores. Geppert found that after from two to three hours in corrosive sublimate $(1: 1,000)$ all spores are not killed.

We may be thankful that this bacillus, armed as it is with so many advantages and possessed of weapons effective against so many species of animals, has some powerful antagonists. Were this not true the world might have been depopulated by the unopposed activity of this microscopic organism. As it is, it is possible that the extinction of certain species of animals may have resulted from this infection. Many other bacteria are markedly antagonistic and destructive to the anthrax bacillus. Chief among those in which this function has been observed and studied is the Bacillus pyocyaneus. In mixed cultures of these organisms the pyocyaneus only survives. It not only survives but it seems to feed on the anthrax bacilli. If across a gelatine plate parallel lines be drawn alternatingly with needles moist with cultures of the two bacilli, the pyocyaneus only will develop. If crosses be made with the needles the pyocyaneus only will develop at the cross. The pyocyaneus develops a bacteriolytic body known as pyocyanase, which readily digests and destroys the anthrax bacillus. This seems to be a proteolytic ferment, but unlike similar bodies it is not destroyed by prolonged boiling. This fact has led to the suggestion that it destroys the anthrax bacillus by osmotic changes. A few drops of a solution of pyocyanase added to a bouillon culture of anthrax leads to a speedy dissolution of the bacilli. Moreover, laboratory animals, 
sheep, rabbits, and guinea-pigs, infected with anthrax, have been cured by injections of pyocyanase. Among other less thoroughly studied antagonistic bacteria are the staphylococcus, the streptococcus and the pneumonia bacillus.

Certain fluids of the animal body have a destructive action on the anthrax bacillus. Strange to say, this does not seem to have any marked effect on the susceptibility of the animal to this infection. The blood serum of the rabbit in vitro is markedly bactericidal. According to Pane 1 c.c. of such serum will destroy 8,000 anthrax bacilli and still the rabbit is easily susceptible to inoculation with this bacillus. The destructive agent in rabbit's serum seems to be a ferment, inasmuch as it is destroyed by a temperature of $56 \mathrm{C}$. (132.8 F.). The blood of the rat, an animal which has some marked resistance to anthrax inoculation, is highly bactericidal to this organism. This is believed to be due to the relatively high alkalinity of the rat's blood. Fodor showed many years ago that arterial blood is destructive to the anthrax bacillus.

While mammals are susceptible to anthrax they differ in this particular widely in degree. Epidemics are most common in cattle ind sheep and the latter are easily inoculable with pure cultures, while the former are unexpectedly more resistant and require larger doses. Algerian sheep are highly resistant. Hogs are less susceptible than cattle and sheep, and here again there is marked variation in varieties, American and English breeds being more susceptible than those of Hungary. Among our more valuable domestic animals horses are somewhat more resistant than cattle and sheep but in some epidemics they die in great numbers. Dogs are least susceptible but succumb to intravenous inoculations. Goats resemble sheep in susceptibility. Of the smaller laboratory animals, the rat is the least susceptible, while rabbits, guinea-pigs, and mice succumb to every form of inoculation. It is said that a single bacillus will kill a guinea-pig. All menagerie animals are susceptible. Birds are highly resistant and epidemics among them are not known, but all may be infected artificially. Frogs are highly refractory but the disease may be induced in them. Snails are said to be wholly refractory. Turtles and fish are susceptible to artificial inoculation, the former readily so. 
Avenues of Infection.-The virus may find admission to the animal body subcutaneously, intravenously, by feeding or by inhalation. A break in the continuity of the skin or mucous membrane may afford a port of entry. Even in feeding the point of entry may be in the mouth, pharynx or esophagus, caused by a slight wound. Especially is this true in animals in which slight wounds may be caused by hard bits of food, dust or other accidental constituents. The dried spores may infect through any of these avenues quite as effectively as the vegetative forms. The spores are especially suitable for infection by inhalation. Moreover, in feeding, the spores are more resistant than the vegetative forms to the acid of the gastric juice. While the blood may be free from bacilli in the first stage of the disease and while ir. rare non-fatal cases the infection may remain localized, in most instances the blood becomes a vehicle for the transport of the virus and it reaches every part of the body. The bacilli are eliminated from infected animals with the urine and feces. They have been found in milk drawn from sick cows a short time before death. The fetus in utero may become infected. This has been observed in both lower animals and man. In epidemics, fields, barnyards and stalls become infected and the most common port of entry is the mouth. The feces and urine of infected animals pollute all about them and the virus is easily and quickly transferred to the well. Naturally, anthrax develops, in epidemics, among men who are brought into close contact with the sick animals. In Russia from 1904 to 1909 the average annual deaths from anthrax among men numbered sixteen thousand; in Italy from 1890 to 1900, about two thousand one hundred. In 1910 the number of persons infected with anthrax in Germany is given as 287, with 40 deaths. Certain occupations, such as butchers, tanners, sheep shearers, furriers and glove makers, shoemakers, saddlers and haruess makers, dealers in hay and grain, and wool-sorters, are especially exposed to this infection. The primary infection in man is most frequently through slight wounds on the skin where malignant pustules form. The lungs may be infected through inhalation. Intestinal infection in man, though infrequent, has been reported. Fruit and vegetables may be polluted by the urine or feces of animals and may carry the virus into the alimentary canal. 



\section{CHAPTER X}

\section{DYSENTERY}

History.-Epidemics characterized by frequent, painful and bloody discharges from the bowels are mentioned in the oldest medical records. They have been observed in both civil and military life and have at times contributed largely to the high mortality of cities and camps. However, no differentiation of the diseases marked by these general symptoms was possible before the development of the science of bacteriology began. As early as 1875 Lösch of St. Petersburg reported the presence of amebas in the stools of a patient with bloody dysentery. Some years later (1886) Kartulis made like reports concerning the dysentery of Egypt. These widely separated observers were the first scientific contributors to our knowledge of what is known as amebic dysentery. When work along this line was taken up in dfferent parts of the world, it became evident that there are two forms of this disease, amebic and bacillary. Further discussion of the former will be reserved for another section.

When it was shown that amebas are not found in many severe epidemics of dysentery, so many investigators in different parts of the world began the search for other causal agents and so many findings were reported, that it is now quite impossible to say with absolute certainty to whom the greatest credit is due. There have been many claims to priority and it is possible that the names now generally attached to the several bacilli known to produce this disease are not those of the men who first saw them. However, I will not add to the controversy over these matters but will use the names generally employed by writers on this subject.

In 1898 Shiga showed that amebas were not found in the severe epidemics of dysentery prevalent in Japan at that time, but he did find in the stools during life and in the body after death a welldefined and easily recognized bacillus. Since this organism was found in all cases, and since its cultures were agglutinated by high dilutions of blood serum of those ill with this disease, Shiga felt justified in 
claiming that he had found the specific cause, and subsequent studies by others have confirmed this claim. This organism is now generally known as the Shiga bacillus.

Two years later (1900) Flexner, in a report of an expedition to investigate the diseases prevalent in the Philippines, described a bacillus found in epidemics on these islands. It also was present in all cases and agglutinated with dilutions of the blood serum of the sick. There was for a time much discussion about the identity of these two organisms. It would be profitless to follow these discussions since it is now generally admitted that the differences are sufficient to justify the conclusion that they are different species, and this is now known as the "Flexner" bacillus. There are two other bacilli capable of causing dysentery. These are varieties of the Flexner organism. One is known as the "His-Russell," and the other as the "Strong" bacillus.

The Shiga Bacillus.-This is a small plump rod with rounded ends. It was at first believed to be motile, but closer study shows that it has no flagellae and no active motion, although it demonstrates the Brownian movements in a marked degree. It is sporeless and ordinarily it needs frequent transplantation in order to keep it alive. However, according to Martini, if an agar-culture tube be hermetically sealed the rods disintegrate into a granular debris which is not easily stained and shows no rods. If this granular mass, even after a year, be placed in fresh medium, normal rods develop. This observation has been confirmed by similar findings with the plague bacillus and it should be more closely and thoroughly studied. Fresh cultures have a sperm-like odor, while older ones develop trimethyl and ammonia. Very old growths have a strong and penetrating fecal smell. It takes the ordinary stains easily, but the staining is not always uniform; sometimes it is polar. It develops on ordinary media without any characteristic exhibitions. Culturally it is distinguished from the Flexner and related dysentery bacilli by the fact that it develops no acid when grown on media containing mannite, maltose or saccharose. The Shiga bacillus is furthermore distinguished from the other organisms by the development of a soluble toxin. This will be discussed in more detail later.

The Shiga bacillus is not highly resistant to unfavorable conditions. It is easily destroyed by the usually employed disinfectants, 
both the soluble and the gaseous forms. However, it retains both viability and virulence for days when deposited on clothing or food. It soon dies out in running water and epidemics of bacillary dysentery due to infected water are probably rare. In sterilized water it lives for many weeks, but in the presence of the usual saprophytic bacteria of water it soon dies out.

The Flexner Bacillus.-Morphologically, culturally and tinctorially this organism is but little different from the Shiga bacillus. It, however, produces indol in peptone cultures more abundantly; produces acid in mannite cultures; rapidly reduces nitrates to nitrites; and elaborates a soluble toxin, either not at all or only in small amount. These differences in function rather than in form, lead to the conclusion that the two organisms are of different species. The HisRussell organism is a variety or strain of the Flexner bacillus. It produces indol more slowly, reduces nitrates less energetically, and decomposes mannite, but is without action on maltose and saccharose. The Strong organism is even more closely related to the Flexner bacillus and in fact there seems to be no constant differences when many strains of both are studied. The Shiga bacillus with its subvarieties is known as the dysentery bacillus rich in toxin production, and the others as poor in this product. The latter are found to be the more stabile. They are not so easily overgrown by saprophytic bacteria; they retain their vitality for a longer time under adverse conditions and they are not so easily destroyed by disinfectants. They may persist for many days in drinking water, for many weeks on clothing, and cultures need to be transplanted only every second or third month.

Rabbits, mice, dogs, goats and horses are highly susceptible to subcutaneous, intra-abdominal and intravenous inoculations with these bacteria, especially the Shiga bacillus. Very minute doses introduced by these avenues cause acute fever with paralytic symptoms in the extremities, diarrheic stools with mucus and blood, then a rapidly falling temperature ending in death: Post-mortem examination shows an inflammatory condition of the kidneys, lungs and the mucous membrane of the intestinal tract. The bacilli are found in these cases in the stools, in the blood, and in the various organs. With still smaller doses the disease is more chronic and the lesions are more advanced 
with necrosis of the intestinal epithelium and ulceration in the large intestine. These effects are produced by both living and dead bacilli of the Shiga type, also with filtered cultures. This shows that the nature of the process is an intoxication rather than a pure infection. Even one one-hundredth of a loop of a culture may induce these symptoms and lesions in mice. Strange to say, the guinea-pig is relatively resistant to this organism. From the researches of Gay we learn that the horse shows marked elevation of temperature, with prostration and labored breathing when treated with one-fourth the minimum fatal dose for guinea-pigs.

There has been much controversy concerning the nature of the soluble toxin found in cultures of the Shiga bacillus. Some claim that it is a true toxin, a secretion of the bacillary cells, while others contend that it is an autolytic product, resulting from the cleavage of the bacilli. Antitoxic sera in variety have been made and have been used for both prevention and cure. Living and dead cultures have been used in the preparation of the toxins, and, as happens when bacterial cell substance is repeatedly injected, many animals die in the process of immunization. There is no standard method of preparing the antitoxin as there is for diphtheria. It follows that the antitoxic sera are not of uniform value and there is still some doubt as to whether their effects should be ascribed to bactericidal or antitoxic properties. Gay has obtained a serum by treating horses with Flexner's bacillus, and has treated cases of dysentery with good results, but Escherich in Vienna did not find it so valuable. Numerous observers have reported great reduction in the mortality in cases of Shiga infection by treatment with the specific antitoxin.

All attempts to induce typical dysentery in ordinary laboratory animals by feeding with dysentery bacilli have failed. It is true that massive doses may cause some intestinal inflammation with loose stools, but many bacteria will bring about this result. In apes the disease may be induced by feeding, and it is stated that dysentery is sometimes epidemic among these animals. This is certainly true of confined animals, one such epidemic having been observed in Paris, and another in Manila. Subcutaneous injections of dead bacilli in man have been used for vaccination purposes, but quite naturally the value of such a procedure must remain undetermined until it is done on a large 
number of persons living in the midst of epidemic dysentery. Lüdke vaccinated himself in this way, but later became infected while working with living cultures. He, therefore, concludes that if subcutaneous injections of dead cultures have any protective value, it is of short duration. In a local epidemic in an insane asylum Fuksch vaccinated the men and left the women without treatment, and states that the disease did not spread further among the former while it continued among the latter. Shiga in 1898-1900 vaccinated ten thousand Japanese in localities in which dysentery was prevalent and found that this procedure did not reduce the morbidity but had a most marked and gratifying effect on the mortality. In some localities, while the death-rate among the unvaccinated reached from 30 to 40 per cent., there were no deaths among the vaccinated. The same investigator vaccinated large numbers of the Japanese troops in the war with Russia. At this time he suspended dead bacilli in antitoxic serum and made three injections at intervals of three or four days, increasing the size of the dose at each injection.

There can be no doubt concerning the causal relation of these bacilli to dysentery in man. As has been stated, high dilutions of the blood of those sick agglutinate cultures of these bacilli. This is positive evidence, but there is confirmatory proof. Strong fed pure cultures of the Shiga bacillus to two criminals sentenced to death, and both developed typical dysentery. Jehle drank mixed Shiga and Flexner cultures and developed the disease on the third day. He found both bacilli in his stools. Several accidental laboratory infections have occurred.

Each of these bacilli produce typical dysentery with characteristic symptoms and lesions. The Shiga bacillus is the most virulent, but otherwise the results are the same. Close study shows that the varieties of these bacilli might be multiplied, but while this is of scientific interest it is not of great practical importance. These bacilli are distributed all over the world, having been found in all climes and among all conditions of men.

Sources of Infection.-Like typhoid fever, dysentery is always due to the transfer of the excreta of one person to the ingesta of another. In the great majority of instances the infection is transferred through contact, which may be direct or indirect. The 
prevalence of dysentery is determined by the extent to which fecal contamination exists. The disease is most abundant when fecal disposition is most primitive. With improvement in the latter, the disease grows less. Thirty years and more ago, dysentery under various names, such as "mucous and bloody diarrhea" and "bloody flux," reaped a rich harvest, especially among children, in various sections. of this country. As methods of the disposal of fecal matter grew more efficient, the death-rate from this disease decreased. It decreased at first in cities, with the introduction of water closets, then it grew less in villages in which the same improvement was inaugurated and lastly its highest prevalence was in the less progressive and more ignorant communities. Its dependence on ignorance and filth for its dissemination is shown in the frequency of outbreaks in insane asylums. and especially in wards occupied by those who pollute themselves, their clothing and bedding, and even the walls of their rooms with fecal matter. In primitive places there are not even privy vaults, and stools are deposited at random on the ground. Everything about the individual home and throughout the village becomes soiled with fecal matter. These are the localities in which dysentery most abundantly flourishes. With typhoid fever, it has spread through camps and decimated armies. It has accompanied military and civil explorations even into uninhabited regions and has flourished wherever man has found even a temporary abiding place and has surrounded and befouled himself with his own excretions. This does not mean that it may originate de novo, for it does not, but the sick and the well may long harbor the bacilli in their intestines and plant it over wide regions in their stools. Hands, the person, clothing, bedding, food and water may bear the infection. From the dirty hands of the milker, the cook or the waiter these organisms may find their way into the food. Those recovering from the disease may continue for weeks as veritable culture flasks for the growth and distribution of this virus. Others may carry the bacilli without developing the disease themselves.' Flies and possibly other insects aid in its distribution. While the bacilli are not spontaneously generated in filth, they are widely disseminated and they flourish in polluted places. 


\section{CHAPTER XI}

\section{TYPHUS FEVER}

\section{HISTORY}

There are medical historians who find evidence of the existence of typhus fever among the ancient Hebrews and their contemporaries, but this is a matter of conjecture. While this disease has long been known as morbus pauperum, associated with want and famine, we must not infer that it is the only fever which develops and thrives among the needy and in times of scarcity of food and other privations. Poverty and overcrowding favor the development and distribution of many infections. Some of the cases reported by Hippocrates in his book on epidemics are certainly suggestive of typhus.

The following is the report of a case, now believed to have been typhus, made by Hippocrates, as translated by Adams:

In Thasus the wife of Dealces, who was lodged on the plain, from sorrow was seized with an acute fever, attended with chills. From first to last she wrapped herself up in her bedclothes; still silent, she fumbled, picked, bored and gathered hairs (from the covers); tears and again laughter; no sleep; bowels irritable, but passed nothing; when directed, drank a little; urine thin and scanty; to the touch of the hand the fever was slight; coldness of extremities. On the ninth (day) talked much incoherently, and again became composed and silent. On the fourteenth, breathing rare, large, at intervals; and again hurried respiration. On the sixteenth, looseness of the bowels from a stimulating clyster; afterwards she passed her drink, nor could retain anything, for she was completely insensible; skin parched and tense. On the twentieth much talk and again became composed; loss of speech; respiration hurried. On the twenty-first she died. Her respiration throughout was rare and large; she was totally insensible; always wrapped up in her bedclothes; either much talk or complete silence throughout. Phrenitis.

The great Athenian pestilence so well described by Thucydides was either typhus or the pneumonic form of the plague. Livy and Tacitus tell of many epidemics in the classical period of Rome. Some of these undoubtedly were epidemics of the plague, while the descriptions of others suggest typhus. The dark ages were so overshadowed by dis- 
ease and superstition that medical records of value are almost wholly wanting. In the siege of Granada in 1489 no less than 17,000 of Ferdinand's soldiers died of a fever which was designated as "Tabardillo," on account of the spots appearing on the skin. This term is still one of the Spanish names for typhus. In the sixteenth century two Italian physicians, Fracastorius of Verona and Cardanus of Pavia, described typhus fever so plainly that there can be no doubt about the disease which then prevailed. In four years (1550-1554) more than one million people in Tuscany were destroyed by typhus. Fracastorius describes the disease as "Febris pestilens," and states that it was vulgarly known as "Lenticulae" or "Puncticula." He says from the fourth to the seventh day red eruptions appear on the arms, chest, and back. They resemble flea bites, only are somewhat larger. They also resemble lentils and from this comes the popular name. The most marked symptoms mentioned are great prostration, feeble pulse, injected conjunctivae, and low muttering delirium. Some are somnolent while others are excited and wakeful, while in still others these states alternate. The disease lasted from seven to fourteen days, rarely longer. The majority of those who were bled died and a supporting treatment proved best. Cardanus and other Italian physicians stated that many of the practitioners of the time mistook this disease for measles, and Massa of Venice wrote on the distinctions between the eruptions of this disease and those of measles and smallpox. About the middle of the sixteenth century this disease was widely prevalent in France and Coyttarus of Poitiers wrote a monograph on it, under the title "De Febribus Purparatis" and somewhat later Ambrose Paré, the distinguished surgeon, wrote of "febris pestilens" which was marked by eruptions resembling the bites of fleas or bed bugs.

Morbus Hungaricus appeared in the army of Maximilian II in Hungary in 1566, and soon spread over the greater part of Europe. Sennertus and others have left descriptions of this epidemic. The skin was marked by flea-bite eruptions. Headache was intense and followed by delirium. In some, the tongue became black, parotid abscesses developed and gangrene of the limbs occurred.

Under the title, "Febris maligna puncticularis seu peticularis," Castro of Verona (1580) pictured the symptoms. The pulse is small and weak; the tongue dry and black; the face and eyes greatly con- 
gested; delirium, followed by stupor deepening into coma; parotid abscesses in some, the eruption appearing about the seventh day and the disease continuing from fourteen to twenty days. Castro says that this disease was known to the French as "La Pourpre;" to the Italians as "Petecchie;" to the Spaniards as "Tabardillo," and to the Germans as "Fleckfieber."

During the sixteenth century typhus fever was so prevalent in the jails of England that the disease spread among the court officers when prisoners were brought before them for trial. This happened repeatedly and gave to court sessions the designation of "black assizes." The first of these of which record is left occurred at Cambridge in the thirteenth year of the reign of Henry VIII (1522). The justices, bailiffs, gentlemen and other persons in court were seized with a fever which proved fatal to many. The most notable report of a "black assize" is that at Oxford in the twentieth year of the reign of Elizabeth (1577). The prisoner was Rowland Jenks, a bookbinder and a Roman Catholic, who was charged with treason and profanity of the protestant religion. He was sentenced to lose his ears. The trial was held at Oxford Castle, July 4. Several prisoners were brought into court in the couurse of the trial. The chronicle states that "an infectious damp of breath" spread through the room. "Above six hundred sickened in one night; and the day after, the infectious air being carried into the next village sickened there more than an hundred more." By the twelfth of August 510 persons perished. "The infection arose from the nasty and pestilential smell of the prisoners when they came out of the jail, two or three of whom had died a few days before the assize began." The disease was marked by loss of appetite, headache, sleeplessness, loss of memory, deafness and delirium, so that the victims behaved like madmen. The Catholics saw in this the scourge of God for the unjust punishment, and the Protestants attributed it to the "diabolical machinations of the Papists."

During the thirty years war (1619-1648) the whole of central Europe was desolated by war, famine and pestilence. The nature of the epidemic is plainly shown by both medical and lay writers and its ravages were portrayed in both prose and poetry. One verse of a song runs as follows: 


\section{Per omnes}

Burgundos et quas stagnans Arar irrigat urbes

Insolita exarsit febris, quae corpora rubris Inficiens maculis (triste et mirabile dictu)

Quarta luce frequens fato pendebat acerbo. Pulsus erat minimus, tremulusque soporque Mens vaga, visque labens; totium crassemque rubensque Interdum tenuae instar aquae.

In 1658, Morton states that England was one vast hospital filled with the victims of a fever with "maculae latae et rubicundae morbillis similes in toto corpore." The great plague of London (1665) was preceded, accompanied, and followed by typhus and some of the most eminent medical men of the time, notably Sydenham, frequently confounded plague and typhus in the reports of their cases. Under the title, "Febris Petechialis vera" Hoffmann of Halle (1700) gave an excellent account of typhus and pointed out its distinction from the plague, which he designated "Febris Pestilens." The eighteenth century saw no abatement of epidemics of typhus. This disease had long afflicted Ireland under the name of "Irish ague," but it was not until 1708 that permanent records of its ravages were made. From that time on for more than a century and a half Ireland was afflicted by one epidemic after another, just as fast as new generations supplied a crop of susceptible material. The historian has no difficulty in showing that each exacerbation was coincident with a period of great want and poverty, but this was a chronic condition of the Emerald Isle during this period. The people were oppressed by their rulers, divided among themselves, held in the grossest ignorance and fed on supersition. Most of those who had enough energy emigrated to foreign lands, thus impoverishing their native land of its best blood to such an extent that it has not yet wholly recovered. An account of one epidemic of typhus in Ireland is much like all others. Nothing to eat but potatoes; and an adult would devour ten or more pounds of these tubers each day in the vain attempt to supply his body cells with the minimum amount of protein demanded. Driven by hunger to sell the cow, furniture, and even his clothing, the Irishman and his family huddled together in rags and filth, while vermin fed on their bodies and simultaneously inoculated them with typhus. Murchison says: "In Dublin, 
the servants of the upper classes were not allowed potatoes, and bread was portioned out to them sparingly, few persons had more than a quartern loaf in the week. The poor pawned their clothes, and even their bedding for money to purchase food, and, as a natural consequence, it was common for several members of one family to sleep in the same bed." According to 'O'Connell, eighty thousand Irish died in 1740-1741 of famine and spotted fever and one-fifth the population of Munster perished. Writing of a nineteenth century epidemic of typhus in Ireland, Murchison says:

Extreme distress ensued. The four pound loaf was sold in Dublin in 1817 for $1 \mathrm{~s}, 9 \mathrm{~d}$; and the poor throughout Ireland are described as wandering about the country gathering nettles, wild mustard, and other weeds, to satisfy the cravings of hunger. . . The probable population of Ireland at this time was, in round numbers, six million, and the number of sick was estimated at 737,000 , or at about one-eighth. In Dublin alone there were about 70,000 cases, making about one-third of the inhabitants.

\section{Of the same epidemic Carleton wrote:}

People collected at the larger dairy farms waiting for the cattle to be blooded, so that they might take home some of the blood to eat mixed with a little oatmeal. The want of fuel caused the pot to be set aside, windows and crevices to be stopped, washing of clothes and person to cease, and the inmates of a cabin to huddle together for warmth. This was far from the normal state of the cottages or even of the cabins, but cold and hunger made their inmates apathetic. Admitted later to the hospitals for fever, they were found bronzed with dirt, their hair full of vermin, their ragged clothes so foul and rotten that it was more economical to destroy them and replace them than to clean them.

The roads were filled with infected vagrants and many a poor cottier not only divided what he had in alms, but by giving shelter to the wanderer introduced the infection into his humble home, while "the dogs of the gentry kept all beggars from their gates."

The last great Irish famine (1845-1848) was the occasion for the prevalence of relapsing fever and scurvy as well as typhus fever. This scourge was foreseen in the development of the potato blight and was mitigated somewhat by the repeal of the corn laws and by a change in the navigation laws permitting the carrying of food supplies in other than British bottoms. At that time Ireland lived almost exclusively on milk and potatoes. Although it produced more than enough grain 
to feed itself, even in these years of the potato blight, most of this had to be sent to England to pay the rents. Years before both Malthus and Cobbett had protested against a people trying to live so largely on potatoes. The former wrote as follows:

When the common people of a country live principally on the dearest grain, as they do in England, on wheat, they leave great resources in scarcity; and barley, oats, rye and cheap soup and potatoes all present themselves as less expensive, yet at the same time wholesome means of nourishment, but when their habitual food is the lowest in the scale, they appear to be wholly without resource except in the bark of trees like the poor Swedes; and a great portion of them must necessarily be starved.

After this famine the Irish ceased to rely so largely on the potato, emigration to this country and Canada greatly increased, and "the population has steadily declined and the well being of the people steadily improved."

Before dismissing the subject of Irish typhus epidemics, I wish to add a quotation from Creighton, showing that the case mortality in this disease is higher among the robust and well fed than among the weak and hungry. "There appeared to be a scale of malignity in the fevers in an inverted order of the degree of misery. The most wretched had the mildest fever, the artisan class or cottagers had typhus fatal in the usual proportion, the classes living in comfort had typhus of a very fatal kind. This experience, however strange it may seem, was reported by medical observers everywhere with remarkable unanimity. One says that six or seven of the rich died in every ten, others say one in three. Forty-eight medical men died in 1847 in Munster, most of them from fever; in Cavan County seven medical men died from fever in twelve months and three more had a narrow escape of death; two of the three physicians sent by the Board of Health to the coast of Connemara died of fever. Many Catholic priests died as well as some of the established Church Clergy; and there were numerous fatalities of the resident gentry and among others who administered the relief. Yet a case of fever in a good home did not become a focus of contagion; the contagion came from direct contact with the crowds of starving poor, their clothes ragged and filthy, their bodies unwashed, and many of them suffering from dysentery. 
The greater fatality of fever among the richer classes (of course, with a much smaller number of cases) has been a commonplace in Ireland and is remarked by the best writers.

Creighton in his valuable "History of Epidemics in Britain" has shown some interesting facts concerning typhus in England during the eighteenth century. I will follow his facts but will draw my own conclusions. During the half century from 1715 to 1765 England was most prosperous financially. Monied men built up great fortunes and the necessities of life were abundant and cheap. With two or three exceptions the harvests were rich and grain was exported in great quantity. Historians state that under the first two Georges there was general prosperity. Even Adam Smith speaks of "the peculiarly happy circumstances of the country during the reign of George II (1726-1760)." Hallam speaks of this period "as the most prosperous that England had ever experienced." Lecky says:

All the evidence we possess concurs in showing that during the first threequarters of the century the position of the poor agricultural classes in England was singularly favorable. The price of wheat was both low and steady. Wages, if they advanced slowly, appear to have commanded an increased proportion of the necessaries of life, and there were all the signs of growing material well-being. It was noticed that wheat bread, and that made of the finest flour, which at the beginning of the period had been confined to the upper and middle classes, had become before the close of it over the greater part of England the universal food, and that the consumption of cheese and butter in proportion to the population in many districts almost trebled. Beef and mutton were eaten almost daily in the villages.

Johnson wrote:

There every bush with nature's music rings,

There every breeze bears health upon its wings.

However, there were even at this time some who saw beneath the surface of abundance and prodigality. An economist, Rogers, pointed out that the prosperity was all on the side of the ruling classes and the capitalists, while the laborers were in "irremediable poverty and without hope." Their wages were artificially fixed by the quarter sessions and they were kept "in a condition wherein existence could just be maintained." 
Creighton writes:

But the Eighteenth Century, even the most prosperous part of it, from the accession of George I to the beginning of the Industrial Revolution in the last quarter or third of it, was none the less a most unwholesome period in the history of England. The health of London was never worse than in those years, and the vital stastistics of some other towns, such as Norwich, are little more satisfactory.

\section{In 1782, White wrote of the fever in London:}

The annual deaths under the old regime exceeded by a good deal the annual births; in the seven years, 1728-35, according to the figures in the parish registers, the burials from all causes were 3,488 and the baptisms 2,803 , an annual excess of 98 deaths over the births in an estimated population of 10,800 (birth rate 37 per 1,000 , death rate 46 per 1,000 ).

\section{Creighton says :}

The mean annual deaths were never higher in London, not even in plague times over a series of years, the fever deaths keeping pace with the mortality from all causes, and, in the great epidemic of typhus in 1741, making about a fourth part of the whole. The populace lived in a bad atmosphere, physical and moral.

It is stated that the consumption of alcohol in London amounted to six gallons per head per annum. A duty of 20 shillings per gallon did not prevent the poor from getting it, and large quantities of gin were smuggled in from Holland. In 1726 the College of Physicians presented this matter to the House of Commons with the following statement:

We have with concern observed for some years past the fatal effects of the frequent use of several sorts of distilled spirituous liquor upon great numbers of both sexes, rendering them diseased, not fit for business, poor, a burthen to themselves and neighbors, and too often the cause of weak, feeble and distempered children, who must be, instead of an advantage and strength, a charge to their country.

The poor in London were crowded into small quarters. In 1737 one house was found to contain eleven married couples and fifteen single persons. A tax was levied on each window in a house and each window in cellar, stairway and outhouse was counted and skylight included. "No window or light shall be deemed to be stopped up unless such window or light shall be stopped up effectually with stone or brick or plaister on lath." 
Debtors were thrown into prison where some remained for years and if they had any comforts in the prison they had to pay for them. Jailors grew rich out of the necessities of their wards. Those unable to pay were crowded into unbelievably small quarters. The first commission to inquire into these abuses reported:

George's ward, sixteen feet by fourteen and about eight feet high, had never less than thirty-two in it all last year and sometimes forty; there was no room for all to lie down, one-half the number sleeping over the others in hammocks; they were locked in from 9 p. m. to 5 a. m. in summer, longer in winter, and as they were forced to ease nature within the room, the stench was noisome beyond expression.

It is a matter of common knowledge that the work of prison reform in England at the time of which we write was due largely to the efforts of John Howard and his work was begun in 1773 .

While the great land owners accumulated wealth, the poacher who snared a rabbit was sent to jail or deported. The condition of the poor was hopeless and the best blood of England flowed willingly or unwillingly into the United States, Canada and Australia. However, typhus often pursued the poor emigrant in his flight by sea and it is said that one-third the immigrants to America in the eighteenth century died during or soon after the voyage. It is well known that the fatality from ship fever continued through the early part of the nineteenth century. During the American War (1774-1780) the number of British seamen raised was 175,990 , the number of those who died of disease was 18,545 , and the number killed was 1,243.

It is interesting to note that during the eighteenth century English physicians for the most part were not much concerned with the poor and many of them saw but little typhus, while a colleague busy among the poor saw much of it. A Dr. Moss, writing of diseases in Liverpool, said that typhus was rare at a time when Dr. Currie was seeing more than 3,000 cases a year. In 1790 Liverpool was the second city in England with a population of 56,000 , while that of London was estimated at 800,000 . According to Currie 7,000 of the people of Liverpool lived in cellars and 9,000 more in back houses with small courts and with narrow passages to the streets. In ten years (17871796) 31,243 cases of fever were registered, an average of 3,124 per year. In the last quarter of the eighteenth century Chester was 
regarded as the most desirable residence city in the kingdom. Within the walls, it had a population of about 3,500 and from 1764-1773 the death rate was only 17.2 per 1,000 , but the poor lived outside the walls and Haygarth describes the condition as follows:

The houses were small, close, crowded and dirty, ill supplied with water, undrained, and built on ground that received the sewage from within the walls. The people were ill-fed and they seldom changed or washed their clothes; when they went abroad they were noisome and offensive to the smell. . . In these poor habitations when one person was seized with the fever, others of the same family are generally affected with the same fever in a greater or lesser degree.

The second half of the eighteenth century saw the great manufacturing development of England by the employment of machinery. Now the poor were exploited by the manufacturer. The houses occupied by the operatives are said by Ferrier to have been dirty, without ventilation, and with the beds almost touching. "As soon as one poor creature dies or is driven out of his cell, he is replaced by another, generally from the country, who soon feels in his turn the consequences of breathing infected air." The only voices heard in behalf of the poor were those of medical men, and in Manchester Ferrier pleaded for them in strong language:

I have seen patients in agonies of despair on finding themselves overwhelmed with filth and abandoned by everyone who could do them any service. - . The situation of the poor at present is extremely dangerous, and often destructive to the middle and higher ranks of society. . . . The poor are indeed the first sufferers, but the mischief does not always rest with them. By secret avenues it reaches the most opulent and severely revenges their neglect or insensibility to the wretchedness surrounding them.

It was the fact that typhus occasionally found its way into the midst of the rich, and, when it did, killed so many and so quickly, that they were compelled to recognize that the misfortunes of the poor were of concern to themselves. Finally in a half-hearted way, urged by physicians, growling about the wastefulness and improvidence of the laboring classes, driven by the occasional deadly outbreaks in their own ranks, the ruling classes began to provide special hospitals for the isolation and care of cases of typhus. The London fever hospital was established in 1802. 
The epidemiologic history of Britain during the Napoleonic wars presents many points of interest. Food prices were high. For a time American markets were closed to British manufacturers. Still, the period (1803-1816) was comparatively free from typhus, so far as Britain was concerned. In peace the poor man's business is to serve the rich, clothe himself in rags, rear his family in a stye and eat nothing. In war he becomes a hero, the defender of his king and country. He is well clothed, well fed and all that is asked of him is that he die for his country if need be. The wife and children at home must be cared for because more soldiers will be needed.

Immediately after the declaration of peace (1816) typhus began to increase and within another year it took on epidemic proportions. The condition of the London slums of the time is shown by a Parliament report as quoted by Creighton:

Calmel's Buildings, a small court near Portman Square, consisting of twentyfour houses, in which lived seven hundred Irish in distress and profligacy, neglected by the parish and shunned by everyone from fear of contagion. George Yard, Whitechapel, consisting of forty houses in which lived two thousand persons in a similar state of wretchedness.

In 1831 typhus became epidemic in England and continued its ravages for more than ten years. The destitution and sickness among the poor of Manchester in the latter part of this epidemic (1839-1841) formed the basis of the story of Mary Barton written by Mrs. Gaskell. The author dwells on the bitterness on the part of the poor.

The most deplorable and enduring evil that arose out of the period of commercial depression to which I refer, was this feeling of alienation between the different classes of society. It is so impossible to describe, or even faintly to picture, the state of distress which prevailed in the town at that time, that I will not attempt it; yet I think again that surely in a Christian land, it was not known so feebly as words could tell it, or the more fortunate and happy would have thronged with their sympathy and aid. In many instances the sufferers wept first and then cursed. Their vindictive feelings exhibited themselves in rabid politics. And when I hear, as I have heard, of the sufferings and privations of the poor, of provision shops where ha'porths of tea, sugar, butter and even flour were sold to accommodate the indigent - of parents sitting in their clothes by the fireside during the whole night for seven weeks together, in order that their only bed and bedding might be reserved for the use of their large family - of others sleeping upon the cold hearth stone for 
weeks in succession without adequate means of providing themselves with food or fuel - and this in the depth of winter - of others being compelled to fast for days together, uncheered by any hope of better fortune, living, moreover, or rather starving in a crowded garret or damp cellar, and gradually sinking under the pressure of want and despair into a premature grave; and when this has been confirmed by the evidence of their careworn looks, their excited feelings, and their desolated homes - can I wonder that many of them, in such times of misery, and destitution, spoke and acted with ferocious precipitation?

In 1847-1848 there was a revival of typhus, under the name of "Irish Fever," in England. The last epidemic in England occurred in 1863-1864, and was in part due to the "cotton famine" resulting from the Civil war in our own country. Since that time typhus has gradually decreased in Britain, but has not entirely disappeared.

From the fact that $I$ have dwelt on typhus in Britain, it must not be inferred that it was unknown or was less prevalent on the continent of Europe during the seventeeth, eighteenth and nineteenth centuries. It was constantly present and assumed epidemic proportions of varying intensity in diverse places at different times. No European nation has been wholly free from it and it has continued to develop epidemics especially in Austria and Russia. The present war has developed the conditions most favorable to its dissemination and I shall not attempt to predict the part it may play in the savage struggle now going on.

Taking Europe as a whole the period from about 1670 to about 1850 may be considered as the typhus age. This does not mean that this disease did not exist before this period or that it ceased with the close of it. Neither assumption would be true, but before that time typhus was overshadowed for many centuries by the more deadly plague. Still it is a question if even at that time typhus did not kill more than the plague. The former was constantly present while the latter lapsed from time to time apparently on account of lack of susceptible material. Even during the typhus age other deadly infections, as smallpox, tuberculosis, diphtheria, etc., aided in rolling up heavy mortality lists. A complete history of typhus would be a valuable contribution to human knowledge and should be studied by statesmen and all interested in the welfare of the race, as well as physicians. 
There is certainly one great lesson which it teaches and that is that the health conditions of the poor are of interest to all. No nation can be great so long as its laboring classes live under unhygienic conditions. Typhus impoverished Europe not only by its high mortality but by the great emigration from its shores, leaving the degenerate to beget its generations.

Before leaving the history of typhus in Europe, I wish to quote the definition of the disease given by the greatest English authority of the nineteenth century, Murchison:

A disease attacking persons of all ages generated by contagion, or by overcrowding of human beings, with deficient ventilation, and prevailing in epidemic form, in periods or under circumstances of famine and destitution. Its symptoms are: more or less sudden invasion marked by rigors or chilliness; frequent, compressible pulse; tongue furred and ultimately dry and brown; bowels, in most cases, constipated; skin warm and dry; a rubeoloid rash appearing between the fourth and seventh days, the spots never appearing in successive crops, at first slightly elevated, and disappearing on pressure, but, after the second day, persistent, and often becoming converted into true petechiae; great and early prostration; heavy flushed countenance; injected conjunctivae; watchfulness and obtuseness of the mental faculties, followed at the end of the first week by delirium, which is sometimes acute and noisy, but oftener low and wandering; tendency to stupor and coma, tremors, subsultus, and involuntary evacuations, with contracted pupils. Duration of the fever from ten to twenty-one days, usually fourteen. In the dead body no specific lesion; but hyperemia of all the internal organs, softening of the heart, hypostatic congestion of the lungs, atrophy of the brain, and edema of the pia mater are common.

Typhus fever became epidemic in Mexico soon after the conquest (1530) and has continued in endemic form with occasional severe exacerbations to the present time. According to Liceaga the second recorded epidemic occurred in 1545 and the third in 1575 . In 17361737 the disease is said to have killed 192,000. During the nineteenth century there were many exacerbations, the most extensive of which was in 1861. At the present time typhus is common in Mexico.

Importations of typhus by immigrants into this country have been constant and it is probable that at no time have our large cities been wholly free from it, but in most instances it has been limited to recently arrived immigrants and those directly in contact with them. 
Doty says: "Out of 439 cases of typhus fever which occurred in New York during 1892-1893, 434 were removed from the poorer tenement and lodging houses, principally the latter."

In the records of the civil war 1,723 cases with 572 deaths are reported under this name, but the diagnosis of many of these were questioned by the best medical officers, such as Woodward and Clymer. No cases were reported by Confederate officers. It is certain that typhus did not play any marked part in the mortality of that war.

\section{THE TRANSMISSION OF TYPHUS}

In 1909 Nicolle, stationed in Algiers, made two notable discoveries concerning the transmission of typhus fever. In the first place, he induced the disease in the chimpanzee by injecting the blood of patients and in like manner he transferred the disease from the chimpanzee to the macacus monkey. He was not able to transfer the disease in this way directly from man to monkey, but could do so indirectly through the chimpanzee. This suggests that the virus is increased in intensity by passage through the chimpanzee. In the second place, Nicolle succeeded in transmitting typhus from monkey to monkey by the bite of the body louse. Typical eruptions were secured in the chimpanzee constantly, but not uniformly in the monkey.

The fact that typhus is transferable by the bite of the body louse has been confirmed by Anderson and Goldberger, Ricketts and others. This renders it desirable for us to know as much as possible concerning the life history of this parasite. Shipley of Cambridge, England, has recently made studies along this line and I follow him principally in the following statements: The body louse (Pediculis vestimenti) is somewhat larger than the head louse and carries longer antennae. The male is about $3 \mathrm{~mm}$. long and $1 \mathrm{~mm}$. broad. The female is about one-tenth larger. Its color is said to vary with that of the people on whom it feeds, black, brown, and with different shades of grayish white. It does not move about over the surface but is always attached to the inner side of the underclothing. Even in feeding, it remains attached by at least one of its six legs to the clothing. When a lousy person is stripped, no lice can be found on him, but the inner side of the underclothing may be alive with them. When grown for the purpose of study, they must be permitted to attach themselves to 
bits of flannel and these must be brought into contact with the skin and the lice allowed to eat twice a day. They take hold promptly and feed greedily but never detach themselves from the flannel. The female after pairing begins to deposit eggs or nits at the rate of about 5 per day. These hatr,h after periods which vary markedly with the temperature. Cold delays the hatching, but even freezing does not destroy the nits. Under favorable conditions the larvae emerge about the sixth day, and immediately begin to feed. Body lice seem not to be hardy and soon die unless they have frequent opportunity of feeding, but the clothing may carry the nits quite indefinitely and these may hatch when the conditions become favorable. The newly hatched do not survive more than thirty-six hours without food. The lice are easily killed by gasoline or benzine or by turning the underclothing inside out and carefully applying a hot iron. Special attention should be given to the seams. Boiling quickly destroys both the insects and their eggs. It will be seen that as simple as these requirements are in ordinary life they are quite impracticable to the soldier in the trenches, especially when he has no change of underclothing. It is said that this parasite feeds only on dirty people and that it will not infest those who wear silk, but the soldier must be dirty, sometimes at least, and he is not supplied with silk underwear. Gasoline and benzine cannot be used by the soldier on account of their ready inflammability. A dilute solution of lysol or cresol soap made into a lather is applied to the inside of the clothing and left there to dry. Physicians and nurses in caring for typhus patients are exposed to great danger and the death-rate among them has always been high. In recent years more than one medical man has contracted typhus in trying to solve its etiology and of the six American physicians who have recently studied typhus fever in Mexico three have contracted the disease and two have died-Conneff of the State University of Ohio and Ricketts of the University of Chicago. These are names now added to the martyr roll of science. Of Ricketts, his teacher and friend, Hektoen, has deservingly said:

Those near him know that he fully understood the dangers to which he would be exposed and the risks he would run. He decided he would take those risks, meet the dangers with all possible means of prevention, and do the work that would come to his hands. And so he made the great sacrifice and gave all that a man can give to his fellow men. 
Other American medical men and nurses have given their lives in the combat with this disease in desolated Serbia and others still are there and elsewhere in war-scourged Europe, seeking not to destroy but to save lives, fighting under the great battle flag of humanity and science.

Quite independently of the work of Nicolle, Anderson and Goldberger, Ricketts and Wilder, Conneff and others studied the etiology of typhus in Mexico. They found that the disease could be transmitted from man to the lower monkeys, without passage through a chimpanzee, that the virus in the blood is removed by filtration through porcelain, that one attack in the monkey gives immunity and that Nicolle was right in his claim that the disease is transmitted by the body louse. All attempts to transfer the disease by fleas and bed bugs have failed, while those with the head louse (Pediculis capitis) have not given uniform results.

For some years Brill has observed a peculiar disease in the wards of Mount Sinai Hospital, New York, and up to the present time he has records of about three hundred cases. Brill has described this disease as follows:

An acute infectious disease of unknown origin and unknown pathology, characterized by an incubation period of from four to five days, a period of continuous fever, accompanied by intense headache, apathy, and prostration, a profuse and extensive erythematous maculo-papular eruption, all of about two weeks duration, whereupon the fever abruptly ceases either by crisis within a few hours or by rapid lysis within three days.

Anderson and Goldberger have shown that Brill's disease is typhus fever by injecting the blood of patients into monkeys and thereby establishing immunity to typhus.

Nicolle has reduced typhus in Tunis from 838 cases in 1909 to 22 cases in 1912. The only measure employed consists in freeing the people of lice.

\section{THE ORGANISM}

Plotz has isolated the organism and with Olitsky and Baeher has shown by complement fixation and agglutination tests that he has, most probably, found the infecting agent. In the agglutination tests only positive reactions in dilutions $1: 50$ were considered. 
Of twenty-four cases tested before the crisis all were negative except two which were tested one day before the crisis, both of which had a titre of 1:100. Of ten cases tested on the day of the crisis, three were positive and seven negative. After the crisis, thirty-eight cases were studied, 92.6 per cent. of which were positive. Agglutinins have been demonstrated as late as five months after the crisis. Of a very large series of control cases, no case gave a reaction in a dilution above $1: 50$, except three cases in which the occurrence of a previous attack of typhus fever could not be excluded. In these cases the reactions varied from $1: 100$ to $1: 200$. Control studies made by testing the serum of typhus cases against various other organisms were negative.

The opsonic index increases at the crisis and remains high in the convalescent stage.

The organism is a small gram-positive bacillus, from 0.9 to 1.93 microns in length, the breadth being from one-fifth to three-fifths of the length. It is not acid-fast, has no capsule, and polar bodies can be demonstrated by appropriate methods. When first isolated, it grows only anaerobically, but after a time it can be grown aerobically.

Intraperitoneal inoculation of a pure culture of the organism into guineapigs produces a rise of temperature in from twenty-four to forty-eight hours, the temperature remaining high for four or five days, and then dropping by crisis. This corresponds to the reaction seen in guinea-pigs after inoculation with defibrinated blood from typhus fever patients, except that the incubation period is shorter. Serum from a convalescing typhus patient has bactericidal properties against the organism obtained from Brill's disease and typhus fever. 



\section{CHAPTER XII}

\section{THE PLAGUE}

History.-According to Sticker the history of this disease can be traced back to the time of the exodus of the Children of Israel from Egypt. The Egyptians of the Pharaohs drained the land, built aqueducts, disposed of their dead hygienically, reared temples, maintained law and order, developed the elements of literature and science and cevised and employed simple machinery. In speaking of the ancient Egyptians, Diodorus says, "The whole manner of life was so evenly ordered that it would appear as though it had been arranged by a learned physician rather than by a lawgiver." Herodotus declared ancient Egypt the healthiest of countries, but filled with physicians, of whom "one treats only the diseases of the eye, another those of the head, the teeth, the abdomen, or the internal organs." Writing of a later time, Gibbon said "Ethiopia and Egypt have been stigmatized in all ages as the source and seminary of the plague." It is evident that in the time of its great civilization Egypt was salubrious; coincident with the decline in the learning and wisdom of its people, it was visited and desolated by pestilence. That Egypt had lost its salubrity as early as the exodus of the Children of Israel is shown by many passages in the Bible in which the chosen people are threatened with the diseases of Egypt if they neglect or violate the laws. Moses, "learned in all the wisdom of the Egyptians" codified his sanitary rules and regulations in the form of religious rites and ceremonies and thus secured their observance among the faithful, even down to the present time.

Sticker is quite confident that the pest among the Philistines spoken of in the first book of Samuel, when the captured ark was returned with five golden emerods and five golden mice, was the bubonic plague.

Of the true nature of the Athenian plague described by Thucydides there is some doubt. It is generally believed to have been the plague, but the description is not sufficiently clear to justify a positive con- 
clusion. It has been suggested that it might have been typhus fever, but I think that the greatest probability is in favor of its having been the pneumonic form of the plague.

The time of the earliest appearance of the plague in Italy is not known. It was certainly quite well established there in the first century of the Christian era and in all probability this was not the first visitation. The historian, as a rule, confines his descriptions to martial and political events and consequently gives a wholly erroneous idea of true conditions. Gibbon says: "If a man were called upon to fix the period in the history of the world, during which the condition of the human race was most happy and prosperous, he would without hesitation, name that which elapsed from the death of Domitian to the accession of Commodus" (from 96 to 180 A. D.). Noah Webster, in his work on epidemics and pestilence, quotes the preceding with the following just comment:

It is certain that, at this time, the Roman Empire was in its glory, and governed by a series of able and virtuous princes, who made the happiness of their subjects their principal object. But the coloring given to the happiness of this period is far too brilliant. The success of armies and the extent of empire do not constitute exclusively the happiness of nations; and no historian has a title to the character of fidelity, who does not comprehend, in his general description of the state of mankind, moral and physical, as well as political evils.

Let us make brief inquiry into the diseases of this "most happy and prosperous" period. It was preceded by, it begun in, continued in, and closed in pestilence. That the plague was endemic in Italy at that time and that it developed in epidemic form with each increase in susceptible material there can be no doubt. Of the epidemic of $68 \mathrm{~A}$. D. Tacitus says :

Houses were filled with dead bodies and the streets with funerals; neither age nor sex were exempt; slaves and plebians were suddenly taken off, amidst the lamentations of their wives and children, who, while they assisted the sick, or mourned the dead, were seized with the disease, and perishing, were burned on the same funeral pyre. To the knights and senators the disease was less mortal, though these also suffered in the common calamity.

About this time the plague appears to have spread over the whole of Asia, northern Africa and Europe. According to Short, the deaths 
from this disease in Scotland between 88 and 92 A. D. amounted to not less than 150,000 . This was probably not less than one-fourth, possibly one-half, the population of Scotland at that time.

In the year $80 \mathrm{~A}$. D. the deaths from the plague in Rome at the height of the epidemic numbered 10,000 a day. It is estimated that the population of Rome at that time was somewhat more than one million. Rufus of Ephesus, who lived in the reign of Trajan (98-117 A. D.) has left a description of the epidemic of his time which leaves no doubt about its being the plague. "Pestilentes bubones, maxime letales et acuti, qui maxime circa Lybiam, et Aegyptum et Syriam observantur."

Exacerbations of the disease in Rome are recorded for the years 102, 107 and 117 A. D. According to Short, 45,000 died of the plague in Wales in 114 A. D. The year 167 A. D. is noted for an unusually severe outbreak of the plague at Rome, where it continued for many years. In the year $173 \mathrm{~A}$. D., the Roman army was threatened with extinction by disease, and special epidemics, or rather exacerbations of the epidemic, prevailed in Rome in 175 and $178 \mathrm{~A}$. D. That the "happy and prosperous" period was followed by a continuation of the plague is shown by the following quotation from Herodian:

A great pestilence raged throughout Italy at that time (about 187 A. D.) but with most violence in the city, by reason of the great concourse of people assembled from all parts of the earth. The mortality among men and cattle was great. The emperor, by advice of physicians, retired to Laurentium, on account of the coolness of the place, which was shaded with laurels. It was supposed that the fragrance of the laurels acted as an antidote against the contagion. The people in the city also, by the advice of physicians, filled their noses and ears with sweet ointments and used perfumes, etc.

Under the spell of the historian we have been inclined to regard the period when the great philosopher, Marcus Aurelius Antoninus, sat on the throne of the world, as the golden age. Let us therefore listen to a few words from his personal attendant, courtier and historian, who writes:

Unless he, M. Antoninus, had been born at this juncture, the affairs of the empire would have fallen into speedy ruin, for there was no respite from military operations. War raged in the east, in Illyricum, in Italy and in Gaul. Earthquakes with the destruction of cities, inundations of rivers, frequent 
plagues, a species of locusts ravaging the fields; in short, every calamity that can be conceived to afflict and torment man scourged the human race during his administration.

The physician and historian, Procopius, in his account of the great pestilence in the reign of Justinian "emulated the skill and diligence of Thucydides in the description of the plague at Athens." Of this epidemic Gibbon says:

In time its first malignancy was abated and dispersed; the disease alternately languished and revived; but it was not till the end of a calamitous period of fifty-two years, that mankind recovered their health, and the air resumed its pure and salubrious quality. No facts have been preserved to sustain an account, or even a conjecture, of the numbers that perished in this extraordinary mortality. I only find that during three months, four and at length ten thousand persons died each day at Constantinople, that many cities of the east were left vacant, and that in several districts of Italy, the harvest and the vintage withered on the ground. The triple scourge of war, pestilence and famine afflicted the subjects of Justinian, and his reign is disgraced by a visible decrease of the human species, which has never been replaced in some of the fairest countries of the globe.

This epidemic spread over the whole of Europe and it took more than a century to reach England, where "it fabled long after in prose and verse as the great plague of Cadwalader's time." Then for quite a thousand years it reaped its periodic harvests as often as immunity was lost in new generations.

In the fourth century the seat of government was removed to Byzantium. It is probable that this change was, in part at least, determined by the insalubrity of Italy. Early in the fifth century Rome was pillaged, but the real conquerors of Rome were not the Goths and Vandals, but malaria and the plague. Disease continued to devastate Italy. Creighton says:

About the year 668 the English archbishop-elect, Vighard, having come to Rome to get his election confirmed by the pope, Vitalanius, was soon after his arrival cut off by the pestilence with almost all who had gone with him. Twelve years after, in 680, there was another severe pestilence in the months of July, August and September, causing a great mortality at Rome and such a panic at Pavia that the inhabitants fled to the mountains. In 746 a pestilence is said to have advanced from Sicily and Calabria and to have made such devastation in Rome that there were houses without a single inhabitant left. 
From that time on the plague periodically spread over Italy until the seventeenth century, while malaria has been in continuous possession down to our own time. We are told that the epidemic of 1348 reduced the inhabitants of the Eternal City to 20,000.

We are familiar with the graphic description of the plague in Florence by Bocaccio, who wrote:

Such was the cruelty of Heaven and perhaps of men, that between March and July following, it is supposed, and made pretty certain, that upwards of a hundred thousand souls perished in the city only, whereas, before that calamity, it was not supposed to have contained so many inhabitants. What magnificent dwellings, what noble palaces were then depopulated to the last person, what families extinct, what riches and vast possessions left, and no known heir to inherit, what numbers of both sexes in the prime and vigor of youth - whom in the morning neither Galen, Hippocrates nor Esculapius himself, but would have declared in perfect health - after dining heartily with their friends here, have supped with their departed friends in the other world.

It is worthy of note that Guy de Chauliac, body physician to Clement VI (pope from 1342 to 1352) recognized the two forms of the plague. He wrote:

Pestis habuit duos modos. Primus fuit per duos menses cum febre continua et sputo sanguinis. Et isti moriebantur infra tres dies. Secundus fuit per residuum temporis cum febre etiam continua et apostematibus et anthracibus in exterioribus, potissime in subaxellis et inguinibus. Et moriebantur infra quinque dies. Et fuit tantae contagiositatis, specialiter quae fuit cum sputo sanguinis, quod non solum morando, sed etiam inspiciendo unus recipiebat ab alio.

There are but few passages in literature so tragic as the short record of the plague of the fourteenth century begun by the friar of Kilkenny, but soon interrupted by his death:

I friar, John Clyn, of the order of Friars Minor and of the convent of Kilkenny, wrote in this book those notable things which happened in my times, which I saw with my eyes, or which I learned from persons worthy of credit. And lest these things worthy of remembrance should perish with time and fall away from the memory of those who are to come after us, I, seeing these many evils, and the whole world lying, as it were in the wicked one, among the dead, awaiting death - as I have truly heard and examined, so have I reduced these things to writing; and lest the writing should perish with the writer, and the work fail altogether with the workman, I leave parchment for continuing the 
work, if haply any man survive, and any of the race of Adam escape this pestilence and continue the work I have commenced.

It is estimated that during the dark ages the average of human life was less than twenty years. A high birth-rate was necessary to keep the race alive, but notwithstanding this, Europe was sparsely inhabited. At the time of the Norman conquest the inhabitants of England numbered between two and two and one-half million, probably nearer the former, for they had not reached the greater number a hundred years later. Creighton says: "It would be within the mark to say that less than one-tenth of the population was urban in any distinctive sense of the term. After London, Norwich, York and Lincoln, there were probably no towns with five thousand inhabitants." Indeed, urban life, as we now know it, was quite impossible in this age of pestilence and would soon become so again were the functions of preventive medicine relaxed.

Most of the great epidemics of the middle ages were designated as pestilentia or magna mortalitas. In the most deadly visitations the bubonic plague is so accurately described that there can be no doubt about its identity, but it must not be supposed that the people enjoyed any high degree of health even in those periods when this contagion languished on account of exhaustion of susceptible victims. Ergotism, under the name of Saint Anthony's fire, was endemic in France and adjacent territories; Normandy was filled with lepers, but Christ's poor were not confined to that country. England was regarded as the special home of hunger, but abundance was a stranger to the masses in every land. The mysterious sweating sickness, apparently brought to England with Henry Tudor in 1485, developed in five distinct epidemics which were characterized by the fact that the mortality was greater among the rich than the poor. Typhus, known as morbus pauperum, prevailed largely in the jails, on ships and among the squalid inhabitants of the cities. Even the discovery of America carried to Europe the scourge of syphilis, which was spread over Italy by the soldiers of Charles VIII, and within a few years reached the most distant parts of Europe. Smallpox appeared in England in the sixteenth century, having journeyed, according to the most reliable authority, all the way from the Orient. That tuberculosis, diphtheria, dysentery and other diseases, still with us, prevailed during the middle 
ages is shown by the records, but they were overshadowed by the higher mortality of those mentioned above. Improved agriculture has extinguished the fire of St. Anthony, except in the most benighted provinces of Russia. The great fire in London in 1666 destroyed the infected rats and relieved England of the bubonic plague, which had been endemic in that country since 1349 . Something more than one hundred years later the discovery of Jenner robbed smallpox of its horrors, wherever vaccination is properly enforced. The investigations of Howard improved the sanitation of jails and workhouses, and did much to eradicate typhus.

Bacillus.-This was discovered and isolated by Yersin and Kitasato independently in the epidemic in Cochin China, and at Hongkong (1893-94). Since the descriptions given by these investigators did not agree in every detail, it was suggested that the organisms obtained by them are not identical, but subsequent studies have shown that they are only slightly different strains of the same bacterium. The bacillus is a short, plump rod with rounded ends and stains more deeply at the ends than in the middle-bipolar staining. In length it varies from 1.5 to 1.7 of a micron and its breadth is about one-third its length. However, it manifests marked morphologic variability, coccus-like forms and long rods being found in the same body, also in the discharge from buboes and in the sputum. The polymorphic growth of this bacillus must be held in mind in making a microscopic diagnosis, which is easily done by an expert. It takes the basic stains, such as methylene blue, quickly and deeply. Gaffky recommends that the dried smear be washed with 0.5 per cent. of acetic acid before the stain is applied. It is non-motile, non-liquefying and may show a mucous capsule. However, this is often not recognizable, unless it be brought out by special methods. In the first description of his find, Kitasato made it a motile organism, but subsequently it was shown that such motility as it may manifest is wholly passive. It is sporeless, but may remain viable in culture for four years. Most pathogenic bacteria have their optimum growth temperature at, or slightly above, that of the animal body. This is not true of the plague bacillus. It grows at the temperature of man's body; otherwise it could not be pathogenic to man; but in artificial cultures it grows much more rap- 
idly and abundantly some degrees lower. It grows, but'less rapidly still, at febrile temperatures. It develops on neutral and feebly alkaline media and is an aerobe. On gelatin plates at $22 \mathrm{C}$. (71.6 F.) it develops within three days fairly characteristic colonies. The superficial ones project above the surface, are coarsely granular and partially transparent. They do not liquefy the gelatin and the deep colonies are in no way characteristic. In gelatin stick cultures, this bacillus grows slowly, but uniformly along the line. In undisturbed bouillon, a deposit forms; later the surface is covered, and stalactites and stalagmites may develop. However, these formations, although striking, are not confined to cultures of the plague bacillus. Hankin uses for diagnostic purposes an agar containing from 2.5 to 3.5 per cent. of salt. On this medium well-marked involution forms develop. Swollen, spindle-shaped, and ovoid forms appear instead of the normal rods. Other investigators claim that other bacteria grown on this medium develop similar forms and that this test should not be relied on for diagnostic purposes. However, this is largely a matter of expert training. Hankin in the midst of the plague in India has in all probability acquired an expertness which a European laboratory worker with only old cultures at hand is not likely to secure after a short series of tests. The plague bacillus grows abundantly on coagulated serum, but offers nothing distinctive in such growths. It multiplies slowly in sterilized milk without coagulation, although there is a slight development of acid. In peptone solution and on potato its growth is slow and non-distinctive.

The bacillus may retain both vitality and virulence for a long time in men and rats recovered from the disease. The organism carried by these hosts, however, is not always virulent. Moreover, as a rule, men and animals, recovered from the disease, are free from the bacillus. Strong found that avirulent bacilli injected subcutaneously in apes are wholly destroyed within twenty-four hours. As has been said, cultures protected from drying and from the light may remain viable after four years and, indeed, they have been reported as still virulent. Old subcultures after many years become quite inert. While complete desiccation soon destroys the bacillus, so long as moisture persists, its destruction within a reasonable time is improbable. From this we may deduce two practical lessons. The first is that plague pus or 
sputum deposited on clothing may retain its vitality for months. The second is that air-borne infection does not play an important rôle in the distribution of this disease. The last statement must not be taken as denying the possibility or even the probability of droplet infection, especially in pneumonic cases. Direct sunlight kills speedily, the time varying with the thickness of the layer. Speaking generally, hours are necessary. An agar culture exposed to direct sunlight contains virulent bacilli after two hours and bubonic pus placed on glass and exposed directly to sunlight is non-virulent after about six hours. Bouillon cultures used for immunizing purposes are sterilized by heating for one hour at $58 \mathrm{C}$. (136.4 F.). Boiling kills in one minute. Dry heat at $100 \mathrm{C}$. continued for one hour kills the bacillus. Ordinary methods of disinfection suffice to destroy this organism.

The virulence of this bacillus is quite variable. It is probably true that the bacterium from any animal dead of this disease is pathogenic to the rat and guinea-pig, but some strains retain their virulence through many generations when grown artificially, while others soon lose it. The virulence is more quickly lost at incubator than at lower temperature. In order to preserve the virulence of cultures, passage through susceptible animals should be resorted to from time to time. Repeated animal passage may revive a failing virulence.

All rodents are susceptible to the plague bacillus, but between the different species of these there are wide variations. The most susceptible is the rat, which suffers extensively from epidemics of this disease and responds to every form of artificial inoculation. When the plague virus is rubbed into the shaved or clipped abdomen of this animal the bacillus finds its way through the skin, apparently when there is no injury, and causes a general infection. When the skin is pricked with the finest infected needle, the nearest glands become swollen and the neighboring tissue edematous, while the infection extends to other glands and soon a general infection is established. The spleen is enlarged, the lungs and liver become hyperemic and after death the bacillus is found in every part of the body. When the injection is made into the peritoneal cavity, the bacillus passes through the peritoneal walls, which seem only somewhat more moist than normal, and reaches the various organs. Given by mouth, the first visible 
effect may be an enlargement of the cervical glands, or the mucous membrane of the stomach and small intestine may become inflamed and hemorrhagic and the mesenteric and other glands may be enlarged. Either form of the disease may develop and in any case the disease terminates fatally. When a dilute culture is painted on the mucous membrane of the nose carefully to avoid abrasion or dropped into the conjunctival sac, general infection, the pneumonic or the bubonic form, develops.

McCoy found that the ground squirrel and the rock squirrel of California are quite as susceptible as the rat. Strong and others in the study of the Manchurian outbreak place the Siberian marmot in the same list. All these animals develop epidemics of the plague.

The guinea-pig is slightly less susceptible than the above named animals to the plague bacillus on inoculation. No outbreak of the plague in the guinea-pig in its native state is recorded, but there was an epidemic among these animals in the Zoological Garden at Sydney in 1902. Both gray and white mice are susceptible and may acquire the disease by feeding on infected material. Rabbits are somewhat less susceptible than guinea-pigs and mice. They are killed by subcutaneous inoculations, but are not affected by feeding. Cats may acquire the disease through eating infected mice or rats. Hunter reports such cases from Hongkong. Ferrets, also used in destroying rats, may succumb when the feeding is long continued. Hyenas, jackals and dogs are only slightly susceptible, especially by way of the mouth. According to Toyama, the Japanese bat is quite susceptible. Wilson reports an epidemic among hogs in Hongkong. Cattle, sheep, goats and horses are not susceptible. Subcutaneous inoculations in these animals are followed by local reactions, but general infection does not result. The testimony concerning the susceptibility of birds, reptiles, amphibians and fish is conflicting, but it seems to be safe to say that these animals play no part in the distribution of the disease.

In his early work, Yersin observed that an unusual number of the flies in his workroom died and later Nuttall showed that the fly may be infected, fatally to itself and may distribute the disease. The plague bacillus has been found in ticks, ants and lice. The rôle played by the flea in this disease will be discussed later. 
Apes resemble man in their susceptibility to plague, developing both the pneumonic and bubonic forms. Epidemics among these animals have been reported.

Modes of Infection.-According to Dieudonne and Otto there are five geographical foci where the plague is endemic and from which it is spread to diverse parts of the earth. Four of these are in Asia and one in Africa. The first lies in the Kwen-Fun mountains in the Eastern Himalayas. From this place the plague extended in 1893 to Cochin China and Hongkong. The second is in the southwestern foothills of the Himalayas. From this place the disease spread over India, reaching Bombay in 1896 and at the same time it traversed Persia and reached the Black sea, invading Russia by way of Samarkand. This focus has a population of about one million, and English physicians have reported thirty smaller or larger epidemics in this region between 1823 and 1897. Many of these resembled the black death of the middle ages and were certainly the pneumonic form of the plague. These epidemics affected both men and rats. Among the latter there exists a chronic plague which serves to keep the bacillus alive and virulent.

The third region is the most extensive, covering northern Mongolia and the Kirghiz Steppes. From this locality the plague in highly virulent form spread over Manchuria in the winter of 1910-11. The infection of this region was first investigated in 1895 by two Russian physicians who discovered what has since been known as the "tarabagan" plague. The tarabagan or Siberian marmot is a small animal, widely distributed in the mountains about Lake Baikal and over the high table-land of Western Siberia. It lives in large families in excavations which they make and which are several feet deep. They leave their homes in great numbers in the fall in search of food. They are valuable on account of their fur and many of them, being ill with the plague, are easily captured. It has long been known that men become infected with a highly fatal disease in skinning the animals. The bacillus, having found a human host, is spread from man to man. The crowded life in small huts during the winter favors the spread of the infection. Whole communities are wiped out and in fear many flee to adjacent territory, carrying the disease with them. The mar- 
mots die in great numbers and are eaten by dogs and wolves. It is not known whether these animals are infected from such food or not. It is not supposed that they play an important rôle in the transmission to man. In man the pneumonic form of the plague is most in evidence, and the bacillus is disseminated by droplets in talking, sneezing and coughing. The cervical glands are often involved, the inguinal less frequently. The fourth Asiatic focus lies in the mountains on the southwest coast of Arabia in the region of Assir on the Red Sea. This region has not been closely studied. The African nursery is found in Uganda near the source of the White Nile. It is supposed that this region is the breeding place of the pestilence which has given Egypt an evil reputation for so many centuries.

The distribution from these centers and from secondary foci follows lines of traffic, penetrating distant lands and traversing the widest seas.

The infection in man may be transferred directly from one to the other. This is the chief method of spread in the pneumonic form. The sputum is full of the bacilli and in crowded families droplet infection is most common. Among the more civilized and the better housed peoples, this method of transmission is rapidly becoming less potent. In 1900 out of 276 cases in Sydney there were only ten houses in which more than one case developed. While "carriers" play an unimportant rôle in the transmission of the plague, it is known that those recovering from the pneumonic form may suffer from a more or less chronic bronchitis in which the sputum remains infective. The bubonic form does not favor direct transmission, but in this form the transfer may be indirect, by soiled clothing and infected houses. It has long been known that poverty and hunger favor the spread of this disease. Undoubtedly ignorance and filthy habits are also important factors. The figures from Bombay show the following distribution per million among the several classes: Low caste Hindoos, 53.7; Brahmins, 20.7; Mohammedans, 13.7; Eurasians, 6.1; Jews, 5.2; Parsees, 4.6; Europeans 0.8.

The rat has long been suspected as playing a part in the distribution of this disease. In the great epidemics of the middle ages it was observed that rats come from their holes, lose all fear of man, become uncertain in movement and die in great numbers. The most ignorant 
came to regard deaths among rats as foretelling the coming of the plague and fled from their homes, when confronted with this evidence. The discovery of the bacillus and the study of its effects on the lower animals, as well as on man, has at least partially cleared up the mystery, although there are still unsolved problems. Rodents are the most active distributors of this disease. They carry the infection from house to house, from village to village, and from home ports to distant lands. The first appearance of the disease in a country previously free from the infection occurs in those occupied about the docks, receiving grain and other commodities from infected lands. Generally before a case has occurred in man the wharf rats are observed to behave peculiarly and then to die in large numbers. An infected rat has landed from the ship and has infected others. How does one rat infect others? The most probable answer to this question is that the sick new arrivals, one or more, have died and the natives have fed on the corpse and acquired the infection in this way. While a hungry rat may feed on the dead of its own species, it seems to prefer other food. Moreover, in a dead rat the bacilli of plague do not retain their virulence for many days, the exact time varying with the temperature. While a rat may be infected by feeding on a dead fellow, it is much more susceptible to inoculation through the skin. The conclusion is that while this method of transfer may and probably does occur, it is not the sole or even the most important method, and we shall look farther.

The urine and feces of the infected rat may be deposited on grain or other kinds of food and eaten by the native animal. This is a possibility easily submitted to experiment. It has been tried and has failed in all cases. Corn and other grains have been mixed with the urine and feces of infected rats and fed to sound ones with wholly negative results.

Rats serve as hosts to several parasites, among which is the rat flea (Pulex cheopis) and possibly this may serve in the transfer of the bacillus from one rat to another. In the first place this flea is taken from an infected rat, examined and found to contain the bacillus of plague. This seems to be a step in the right direction. Such a flea is crushed, a needle touched with the material is used to prick a healthy rat and this animal becomes infected and dies of the plague. 
Infected rats are kept in one side of a cage, uninfected ones in the other side. So long as the two are separated by a flea-proof partition the infection is not transmitted. Even when the partition is made of tangle-foot which catches the flea when it tries to pass to the other side, the sound rat remains sound. When such a partition is removed, the sound rat becomes infected. Rat fleas are captured and fed on cultures of the plague bacillus and then freed in a cage occupied by healthy rats which soon become infected. Infected rats are stripped of all their fleas and then placed in cages with healthy ones, which remain uninfected. Infected rats carrying their fleas are caged with guinea-pigs, and the latter become infected.

These with many other variations on the experiment have been made, and show conclusively that the plague is transferred from rat to rat or from rat to guinea-pig by the bite of the rat flea. This question is satisfactorily answered.

How is the plague transferred from rat to man? Evidently experiment along this line might be open to serious criticism and we must depend on observation, which is never so thoroughly convincing as experiment. Will the rat flea bite man and if it does will such a flea bearing the plague bacillus infect man? While we cannot use man in this experiment, we may employ his nearest relative, the ape. The rat flea does bite the ape, and if the flea is infected with the plague bacillus its bite induces this disease in the ape. It is the testimony of several observers that uninfected rat fleas, while preferring their own host, will in its absence feed on man.

Liston reports that in a certain house in India on April 6, 1904, many rats were found dead; on April 11 the house was so infested with fleas that the occupants sought sleep on the veranda. On April 17, two of these people were stricken with the plague. On April 20, thirty fleas were captured in this house and of these fourteen were rat fleas, while of 246 fleas captured in uninfected houses, not one was a rat flea. Tidswell of Sydney states that on a wharf where many rats were dead he was violently attacked by fleas.

It has happened that in some localities rats die of the plague, while there is no infection among men. This is explained by the absence of the flea, which, while widely distributed, is not found on all rats at all times. However, there is another factor which needs considera- 
tion. In the transmission of the plague from rats to man by the flea there is a time of variable length during which the flea is on neither rat nor man. The duration and conditions of this interval are widely variable and not equally favorable to the transmission of the disease. In a hot, dry climate rat fleas soon die when detached from their hosts. Local conditions may play an important rôle in the transfer of the infected flea from rat to man.

I think that it must be admitted that the evidence in favor of the possibility of the transfer of the plague from rat to man through the flea is strongly positive. Whether this is accomplished through other agencies or not is an open question. 



\section{CHAPTER XIII}

\section{SYMPTOMATIC ANTHRAX}

History.-Under various names, such as "blackleg," "quarter evil" in English; "Charbon Symptomatique" in French; and "rauschbrand" in German, this disease has been a cattle scourge for centuries. We owe our first and most valuable knowledge concerning it to French investigators. As early as the eighteenth century it was shown by the studies of Chabert and Boutrolle to be a specific disease. The most thorough studies of the nineteenth century were made by Arloing, Cornevin and Thomas of Lyons. As early as 1879 these men recognized the infectious nature of the disease and began their work on the bacillus, the pathology and the immunology of this pest. It is confined to cattle and no case of infection in man has been observed.

The Bacillus. - This organism is generally known as Bacillus chauvei, from the distinguished French veterinarian Chaveau. It is a large, spore-forming anaerobic bacillus, sometimes growing in chains, but usually in separate rods. The diameter of the spores being much greater than the breadth of the rod and the location being at or near the middle, the spore-bearing rod has a peculiar appearance well designated as "snowshoe" or "whetstone." In old cultures free spores may be seen and sometimes are numerous. The spores are highly resistant to heat and chemical disinfectants, and when a locality becomes infected eradication of the disease is not easy. This organism is is not nearly so virulent as the anthrax bacillus, one rod of which suffices to infect a guinea-pig fatally, while many hundred rods of the symptomatic anthrax bacillus may fail to induce a like result. Infection follows subcutaneous and intramuscular injections. In guinea-pigs the period of incubation after artificial inoculation runs from twelve to twenty-four hours, depending on the amount and virulence of the culture employed. The animal ceases to feed and soon begins to develop an edematous area about the point of inoculation. However, if this be directly on the back, the edema is more marked on the sides than 
directly about the site of injection. At first the edematous areas are soft and pasty; later gas accumulates and they become crepitant. This continues for from twenty-four to forty-eight hours, when the animal shows agonal breathing and dies either in convulsions or coma. In certain instances the development of the infection is atypical. It proceeds less rapidly, leads to the formation of an abscess and ultimately ends in recovery. On necropsy the subcutaneous tissue is found impregnated with bloody fluid and distended with gas. In the serous cavities, pleura, peritoneum and pericardium, there are exudates, more or less stained with blood and often coagulated. The heart is soft and distended; the liver and kidneys hyperemic; the lungs anemic; and the spleen normal in size. This is practically the symptomatology of the disease in cattle. Young animals are most susceptible and die within a few hours after the first indication of being ill. The disease is widely distributed and has been the cause of great commercial loss. It is most prevalent during the summer and early fall and in low-lying meadows and along water courses. Just how animals become infected is not known, but it is generally supposed that the virus finds entrance through some accidental wound. To one who has seen herds of calves die within a few days from this disease, this explanation is not wholly satisfying. It is not probable that all the animals in the herd, or even a large percentage of them, carried accidental wounds at the same time. No insect has been convicted of this crime up to the present time. The infection is not transmitted by feeding and, strange to say, animals bear without infection large intravenous injections of pure cultures, provided that none of the fluid finds its way into the subcutaneous tissues.

While epidemics have been observed only in cattle, possibly a few in hogs, many animals are susceptible to direct inoculation into the subcutaneous or muscular tissue. Rabbits, white rats, and mice are refractory, but may succumb to large inoculations.

The bacillus grows best on a medium containing an emulsion of brain tissue. As has been stated, it does not grow in the presence of oxygen and deep intramuscular injections are more certainly fatal than subcutaneous ones. Injections into serous cavities are generally without effect. Bacilli introduced into these cavities are speedily devoured by the phagocytes. When injected' with lactic acid, which 
repels the phagocytes, the bacilli develop. Inoculations on the ears or the tail induce only local reactions and cause a degree of immunity. The farther from the root of the tail the less marked is the effect. When an inoculation into the tail has been made and the site kept covered with an ice bag, the area of involvement is restricted and may escape detection. On the other hand, if the site of inoculation on the tail be kept covered with warm poultices the area involved is more extensive and a general infection may result.

Much has been done in the immunization of animals to this disease, although an ideal process has not been developed. The fundamental facts have been supplied by French investigators. At first they employed intravenous injections of fully virulent, even spore-bearing cultures. Cattle bear up to 6 c.c. of such cultures administered in this way. A slight febrile reaction follows and after this the animal is immune. As a laboratory method and in skilled hands this method works, but it fails in unskilled hands in the field, because some of the fluid is injected, not directly into the blood current but into the tissues, and fatal infection follows. The second method consisted in the subcutaneous inoculation of virulent cultures in the tail. In this locality the organism develops slowly and the phagocytes finally destroy them. A small pledget of cotton which has been moistened in a culture is introduced under the skin on the tail. This method has been used widely and successfully in Alsace-Lorraine and in Holland. A third method consists in the employment of two vaccines. The first is a culture heated for six hours at 100 to $104 \mathrm{C}$; ; the second is heated for the same time at 90 to $95 \mathrm{C}$. These are dried, ground and distributed in packages bearing directions. The first vaccine is introduced under the skin of the tail three hand's breadths from the root and the second, ten to fourteen days later one hand's breadth from the root of the tail. On account of the time required to make two inoculations this method has been cut down to the use of one vaccine heated to from 95 to $100 \mathrm{C}$. and the inoculation is made on the shoulder.

The method of Norgaard is followed by the Bureau of Animal Industry in this country. The tissue of a fresh tumor is pulverized, extracted with water and strained through cloth. The filtrate is dried to a brown scale, which is sent out in packages with directions for 
using. The powder is dissolved in water, heated for six hours at from 95 to $100 \mathrm{C}$., and injected into the animal. The number of doses of this vaccine used annually in this country amounts to more than a million and a quarter. This has greatly decreased the loss from this disease.

In 1911 Foth announced the preparation of a superior vaccine for symptomatic anthrax. Massive cultures are filtered through a hard paper and the filtrate precipitated with alcohol. This precipitate protects both cattle and guinea-pigs, and its strength can be more accurately determined than the older vaccines. However, its practical use on a large scale has not yet been demonstrated. 


\section{CHAPTER XIV}

\section{MALIGNANT EDEMA}

History.-This is a rare disease and it is impossible to secure any exact information concerning its prevalence in past ages. In 1877 Pasteur introduced bits of putrid flesh under the skin of guinea-pigs and rabbits, and thus induced a rapidly progressive disease characterized by the accumulation of fluid in the subcutaneous tissue. He was able to transfer the disease from one animal to another and found that it was due to a rod-shaped, spore-bearing organism which he designated as Vibrion septique. In 1881 Koch continued this work and since that time the disease has been known as malignant edema.

The Bacillus.-It is still a question whether there is only one or several closely related organisms capable of inducing this pathologic condition. Even when the same strain is employed in experimental inoculation, the effects are not always exactly the same. The fluid which collects in the subcutaneous tissue may be only slightly, or markedly, bloody and the infiltration may be accompanied by the evolution of more or less gas. The typical bacillus is a rod with rounded ends, slightly motile, growing in the absence of air, and developing spores. It liquefies gelatin and blood serum, coagulates milk and then digests the coagulum. It produces abundant gas in media containing glucose and traces of gas in media practically free from carbohydrates. Horses, cattle, hogs, and sheep are susceptible, but infection probably never occurs except through a wound either on the skin or the mucous membrane. It is one of the sequelae of castration in males and of birth in females among our domestic animals, although even in these conditions it is quite rare. When infected matter is taken into the alimentary canal it passes through without doing harm unless there be some break in the mucous membrane. When it infects man and the larger animals, the bacillus is found abundantly in the edematous fluid, but seldom widely distributed through the body. This indicates that it kills by the elabora- 
tion of a soluble toxin. In smaller animals, such as mice and guineapigs, a general, systemic infection may develop. In some instances the diseased condition becomes evident within a few hours after inoculation. The tissue around the point of introduction becomes edematous and the involved area rapidly extends and death may follow within twenty-four hours. Outside of putrid flesh, the bacillus has been found in polluted soil, in which the spores may retain both vitality and virulence for a long time. The spores generally develop in the middle of the rod, making it spindle-shaped.

\section{GAS PHLEGMON}

There are many related bacteria which when introduced through wounds cause death of tissue with the evolution of gas. The best known of these organisms are the following:

1. The Welch bacillus, discovered in 1891 and known as Bacillus aerogenes capsulatus.

2. The Ghon-Sachs bacillus, isolated in 1903 from a patient in a case of gaseous gangrene.

3. The Novy bacillus, found in milk in 1894 and described under the name of Bacillus edematis maligni $I I$.

4. Hibler's bacillus, found in 1894 in a case of gaseous gangrene, developing after a complicated fracture in which the wound was polluted with earth.

5. The Klein bacillus, found in the stool of a person suffering from acute enteritis.

6. The Stolz bacillus, found in a case of gas phlegmon following a fracture.

Besides the above and other related organisms, the colon and proteus may develop gas phlegmon with rapidly progressive and destructive changes under certain conditions, as for instance, in those debilitated by diabetes. All of these, with the exception of the two last mentioned, are spore-bearing, anaerobic organisms, which are found in polluted soil and become infective only through wounds. The mortality among the infected is high. 


\section{CHAPTER XV}

\section{GLANDERS}

History.-As early as the fourth century the infective nature of this disease was held by a few observing men. In the seventeenth century Solleysel taught that glanders is highly infectious, may extend from stall to stall, and that the air becomes impregnated with the infection. In the next century certain French veterinarians recommended that diseased horses should be isolated, observed, and if found to have glanders should be killed. In the last decennium of the eighteenth century a Danish veterinarian, Viborg, inoculated sound horses with pus, blood, nasal secretions, saliva, urine and perspiration from glandered animals, and succeeded in transmitting the disease. $\mathrm{He}$ showed that heat destroys the infective agent. Later it was shown that donkeys, goats, sheep, dogs, cats, rabbits and guinea-pigs are susceptible. This work led to experiments with the view of disinfecting the discharges and stalls which had been occupied by diseased animals. Chaveau showed that the infection is carried, for the most part at least, in the corpuscular elements of the discharges. In 1881 Babes and Havas of Roumania found bacilli in the pus from an abscess on a man who had the disease. Bouchard and others saw the organism, but its isolation and identification resulted from the work of Löffler and Schütz (1882). Certain cases of glanders remained difficult of diagnosis because of the organs involved, there being no available discharge. The discovery of mallein by two Russian physicians in 1890 and the demonstration that this is a valuable diagnostic agent, as tuberculin is in tuberculosis, made the recognition of these occult cases possible and aided greatly in the restriction of the disease. Acute glanders, which is seen both in men and horses, is a rapidly fatal disease. After a short (from two to five days) incubation period the temperature often becomes very high (106-107 F.), there is marked prostration and great pain in the joints and limbs. Local ulceration deepens rapidly and boils and abscesses appear on various parts of 
the body and rapidly destroy skin, subcutaneous tissue and muscle, exposing blood vessels, tendons and bones. Death usually occurs in from one to three weeks. The most frequent primary lesion is in the nose, though it may occur in the larynx, lungs or from a wound on any part of the body. In about 90 per cent. of the cases, the course is chronic and may continue for years. The chronic form in man is by no means always fatal, the percentage of recovery given by Bollinger being as high as 50 ; but no one else agrees with this estimate.

The Bacillus.-Bacillus mallei is a slightly bent rod with rounded ends, whose length varies from one to two-thirds the diameter of red blood corpuscles. It is sporeless, non-motile and non-liquefying. It takes the ordinary basic stains, as methylene blue and gentian violet, fairly well, but when intensive coloring is desired it is better to select a stain containing a mordant, such as carbol-furchsin. The stain is easily removed with dilute mineral acid. This bacillus grows on all ordinary culture media without characteristic appearances except on potato. On the second day a typical potato culture shows a hard, yellowish, transparent growth. This general appearance, which has been likened to that of a layer of liquid honey, continues until from the sixth to eighth day, when the transparence gradually disappears and the color takes on a red tint resembling that of cuprous oxid. The boundaries of the growth show a slightly greenish tint, while the uncovered surface of the potato is grayish white. While the growth on potato is quite unusual, it is not sufficiently characteristic to form the sole basis in identification. For a sporeless organism, it may, when protected from the light, retain its vitality for an unusually long time. Wladmiroff states that the organisms from glycerin-bouillon tubes, with the ordinary cotton plug, were found viable after four years. Direct sunlight destroys this organism within from a few hours to a few days depending on the thickness of the layer and the intensity of the light. Bacillus malle $i$ is rather resistant to mercuric chlorid, but is easily destroyed by phenol ( 2 per cent.), zinc chlorid ( 2 per cent.), and lime water (saturated solution). The disinfection of stables with gasecus agents is, as a rule, not feasible on account of the openness of barns. Saturated lime water is the best thing to use.

Avenues of Infection.-Many experiments have tested the possibility of glanders infection through the unbroken skin, and while the 
results are negative so long as the skin remains without a break, a minute lesion, enough to offer an atrium to a bacillus, is easily made. Babes and Cornil rubbed an ointment containing the bacilli on the shorn abdomen of guinea-pigs and succeeded in infecting them, probably through the hair follicles or some lesion not recognizable. It seems also probable that the unbroken mucous membranes of the nasal cavities exclude the bacilli, but in neither man nor horse is this structure likely to remain without microscopic lesions for any great length of time. This is especially true of the horse, on account of the character of its food. Beards and husks and dust are constantly being inhaled while the animal eats, and injury of the mucous membrane of the upper air passages is a frequent occurrence. The mucous membrane of the mouth is scarcely less exposed to slight but frequent insult. That the glanders bacillus may find its way through the intestinal walls, leaving no recognizable lesion, and first manifest itself in the lungs has been demonstrated by the researches of Nocard. Although Löffler reports a case of human infection through milk, the instance is questioned because other sources of infection were not excluded. Under Viborg's efforts one hundred army horses, found to be infected, were slaughtered in Copenhagen and their flesh used as food without ill effects. Similar instances on a smaller scale have been reported elsewhere. The possibility of intrs-uterine infection in case of a diseased mother is recognized and, indeed, such cases have been reported in both France and Italy. Of all domestic and menagerie animals, cows and the house rat are the only ones that are known to be immune to glanders, although others differ much in degree of susceptibility. 



\section{CHAPTER XVI}

\section{BOTULISM-SAUSAGE POISONING}

History.-In certain parts of Germany, especially in Wurtemburg and neighboring sections of Baden and Bavaria, where sausage, a favorite article of diet, is imperfectly cured and eaten raw, poisoning from this article of diet has long been known. Other foods, as meats, especially pork and fish, and vegetable preparations sometimes produce alarming and even fatal illness. As a rule, the foods which prove harmful are those which have been prepared for a relatively long time before they are eaten. The term "botulism," as here used, does not cover every form of food poisoning, but only those in which the poisonous substance is the product of a certain organism. In 1895 some thirty cases of food poisoning occurred in a small Belgian village and were investigated by Van Ermengem of Ghent. The food in this case was a ham which had been kept in a dilute brine. It was from a sound animal, a part of which had been eaten in the fresh state without harm. In fact, the companion ham from the same brine had been eaten without disturbing those who partook of it. The sound piece lay near the surface and was not fully covered by the brine. The faulty ham was on the bottom of the vat and completely excluded from the air: It was not noticeably decomposed, but was marked by soft, colored spots and the odor of butyric acid. In it the Bacillus botulinus was found. A watery extract from the meat was injected into various animals and found to be intensely poisonous. In cats, it caused dilatation of the pupils, an abundant mucus secretion in the mouth and pharynx, prolapse of the tongue, roughness of the voice followed by complete aphonia, difficulty in swallowing and paralytic symptoms, followed by death in from four to eight days. Mice, guinea-pigs, rabbits and apes were affected in much the same way. The last-mentioned animals were found to be equally susceptible when fed with the meat or its extract, while cats, rats, dogs and chickens were not susceptible by the mouth. Some five years later, another ham kept under similar conditions had a like effect and contained the 
same organism. Later still, other small outbreaks have been studied and the bacillus botulinus found in all.

The Bacillus.-This is a rod (from 4 to 6 microns long by 0.9 to 1.2 of a micron broad) with imperfectly rounded ends. It often appears in chains formed of two or more rods, attached end to end. It is slightly motile, carrying from four to eight flagellae. It forms spores, which for the most part are terminal, rarely central. It takes ordinary stains easily and is strictly anaerobic. In pure cultures it will not grow in the presence of air, but in mixed cultures it may do so, the other organisms consuming the oxygen. It develops gas, especially in media containing grape-sugar or other carbohydrate. It grows only feebly at the temperature of the animal body. Special interest attaches to this bacillus because it is not a pathogenic, but is a toxicogenic organism. When grown outside the body as in the ham, it elaborates a poison or toxin and it is to this that its harmful effects are due. It causes not an infection, but an intoxication. When all the bacilli have been removed by filtration through porcelain, the clear filtrate is just as poisonous as the original culture. Indeed, the bacillus does not multiply in the animal body, or does so only to a slight extent. Another very striking fact is that the soluble poison affects many animals when taken by the mouth. Most toxins and venoms are harmless when introduced into the alimentary canal, but this is not. One one-thousandth of a cubic centimeter, and even a smaller dose, of germ-free filtrate kills a rabbit. An effective antitoxin has been prepared and used.

It is to be remembered that it is not this organism which causes most instances of food poisoning, in which nausea, vomiting, and purging are prominent symptoms. Bacillus botulinus apparently is not widely distributed. So far it has been found only once except in food, and that was in the feces of hogs. As has been stated, it grows only in the absence of air and it has been found in canned foods. In such, it produces gas which bulges the ends of the can. In brine of more than 10 per cent. strength it will not grow. It is of especial interest because it is essentially a saprophytic organism, producing in food, in the absence of air, a most potent poison which affects man when taken into the stomach. 


\section{CHAPTER XVII}

\section{MALTA FEVER}

History.-It has long been known that a fever prevalent on the shores and islands of the Mediterranean differs from those of other regions. It is not malarial, nor typhoid, nor typhus. It is a low, longcontinued fever with a low mortality and characterized by a chronic course accompanied by slow but progressive emaciation. It has been given many names, such as Malta, Mediterranean, Cyprus, Gibraltar and Neapolitan fever. It has prevailed extensively on the island of Malta and has afforded a field of research for English physicians stationed there. There have been some differences of opinion as to whether or not it is included among the diseases described by Hippocrates. Since the means for its positive identification have been placed in the hands of the profession, its distribution has been found to be much wider than was formerly supposed. Besides the Mediterranean shores, it has been found in India, China, the West Indies, South America, the Philippines, and in Texas. Cases are reported in most of the great ports of the world among those who have visited infected regions. The specific cause was discovered by Bruce in 1887 in the spleen of a man who died of the disease at Malta.

The Organism.-This is known as Micrococcus melitensis and is one of the smallest of the bacteria, having a diameter of about 0.4 of a micron. It may be seen as isolated bodies, in twos, and in chains. On certain media it is more ovoid than spherical and in this form it is regarded as a bacillus. It is non-motile, save the molecular oscillations seen in all small suspended bodies, and takes the ordinary basic aniline stains readily and deeply. On artificial culture media it grows slowly with the temperature of the animal body as its optimum. Under 6 and above 45 C. it does not multiply. It does not liquefy gelatin and develops very slowly in this medium, requiring about five days at 22 to show recognizable colonies. On agar plates the colonies are not always visible to the unaided eye and when seen through a 
low power appear much like minute drops of water. It is destroyed by moist heat in about five minutes at $60 \mathrm{C}$. (140 F.), with dry heat at 95 C. (203 F.) and by direct sunlight within from a few minutes to an hour depending on the thickness of the layer and the intensity of the light. It is quite highly susceptible to the usually employed chemical disinfectants. However, in old cultures kept in the dark it may retain its vitality for more than a year, especially when complete desiccation is prevented by a rubber cap. In laboratory animals both acute and chronic infections can be induced. For the production of the former a relatively large inoculation is necessary. The weight begins to fall in a few hours, then the temperature falls and rises. The animal becomes weaker, develops general tonic convulsions and at last falls into coma with low temperature, and dies. Necropsy shows a general septicemia with frequent acute inflammation of the mucous membrane of the urinary organs.

The chronic form, after an incubation of from two to three days develops a remittent or intermittent low fever with slow progressive emaciation. For months the animal may seem quite well, save for the slow, continued wasting, when it dies suddenly. After death most of the organs are found to be sterile, but usually the coccus in small numbers will be found in the bone marrow or the kidneys, or in both. Usually it is abundant in the urine during the whole course of the disease. The spleen is generally found to be markedly enlarged, likewise some of the lymphatic glands.

Horses, donkeys, cattle, sheep and goats are susceptible to inoculation. The study of this infection in goats is of special interest. In these animals the disease is exceedingly chronic and seems to disturb the animal but little. The temperature is not altered and there is not always a decrease in weight. Frequently there is a dry cough. From the end of the first to that of the third week the blood serum of the animal promptly agglutinates the micrococcus. Indeed, this is the only way in which Malta fever can be positively diagnosed in either man or animals. In 1906 an English commission found one-third of the goats on the island of Malta infected with this disease and the microorganism in the milk of one-tenth. The question of how the goats become infected naturally is an interesting one. Experimentally this is easily done through an abrasion and it is supposed that naturally 
it occurs in the same way. The hands of the milker, moist with the infected milk of one animal may easily transfer it to another. The udders of Malta goats are unusually large and in some drag on the ground. They generally show slight wounds, and through these the virus may easily find its way from the hands of the milker. Biting flies have been suspected and have been examined with negative results.

Man and apes are easily infected by feeding. Of twenty-eight apes fed with infected milk, twenty-six developed the disease. The course is shorter and the fever higher in apes than in man. The milk of infected goats is often a pure culture of the coccus and it may be that man occasionally receives the virus through minute wounds; the great source of infection is the drinking of milk. There are several illustrations of infection from drinking milk. In 1905 the Nicholson sailed from Malta with sixty-five milk goats. The first destination was Antwerp. Of the ten men who drank the raw milk from the goats on this voyage, eight developed Malta fever within from eighteen to thirty-four days after leaving Malta. From Antwerp the Nicholson proceeded to New York. The captain and crew used the goats' milk on this trip and subsequently many of them developed the disease. Five of the goats died between Malta and New York, and of the sixty placed in quarantine, thirty-two were shown to have Malta fever by the agglutination test and the coccus was found in the milk of several. In 1910 an epidemic of Malta fever appeared in the valley of Cavenne following the importation of goats from the island and the use of their milk. Malta fever, formerly frequent among English soldiers and sailors stationed at Malta, has disappeared on the discontinuance of the use of uncooked milk from goats, while it has continued among the natives who still use the raw milk. 



\section{CHAPTER XVIII}

\section{PNEUMONIA}

History.-As early as $1878 \mathrm{Klebs}$ observed and briefly described an organism found in the bronchial content after death from pneumonia. In 1880 Pasteur experimented with a micrococcus found in the saliva of a boy under treatment for hydrophobia, found it to be highly pathogenic to rabbits and designated it microbe septicemique $d u$ salive. About the same time Sternberg gave an accurate description of the morphology and pathogenicity of an organism found in the saliva of healthy persons. In 1882-83 Friedländer studied the sputum during life and the bronchial and alveolar contents after death from pneumonia and found the same organism that had been seen by others, and for a time it was known as the capsule bacillus or Bacillus Friedländer. Simultaneously with Friedländer, Talamon not only observed the lanceolate bacillus, but grew it in artificial media. In 1884 A. Fränkel reported the finding of this organism in the sputum of normal persons and in that of those suffering from pneumonia. He observed the great differences in virulence of the strains obtained from these sources, demonstrated their effects on rabbits and mice, and, in fact, gave the most complete report made up to that time on the organism now known as "Fränkel's bacillus" or the pneumococcus. Fränkel in his early papers held that the pneumococcus is the sole cause of pneumonia. Possibly it was this positive, but erroneous, statement which succeeded in fastening the name of Fränkel to the bacillus. Certainly he was not the first to see it, or grow it, or to demonstrate its effects on animals; and he was in error in his claim that it is the sole cause of pneumonia. Indeed the work done by Weichselbaum about the same time was more thorough and, as subsequent studies have shown, more accurate. The last mentioned observer held that while pneumonia is usually caused by the pneumococcus, it may result from infection with streptococci and other bacteria. This is now generally recognized. 
The Bacillus. - The pneumococcus, known also as Diplococcus lanceolatus, and Diplococcus pneumoniae, is a small lanceolate organism, often with spherical and ovoid individuals. It presents marked variations in shape and size, but as a rule the number of typical individuals renders indentification easy. It is non-motile and takes the ordinary stains easily. It is a capsulated bacillus and when in diplococcus forms, both individuals are enclosed by the same capsule. In chain forms, not commonly seen, several links in the chain may be covered by the same capsule. The formation of the capsule is dependent on conditions. Highly virulent organisms taken from the animal are capsulated. On the other hand, subcultures grown on artificial media through many generations have no capsules or show imperfect ones. Growth in blood serum seems to favor capsular development. It seems most probable that the formation of the capsules is a protective function. The pneumococcus grows on ordinary culture media, but not abundantly, and is highly susceptible to slight modifications in composition and reaction. Fresh cultures do not develop on gelatin below $24 \mathrm{C}$., but old subcultures grow at temperatures as low as $20 \mathrm{C}$. There is no liquefaction. After twenty-four hours in the incubator, bouillon tubes are slightly cloudy and may show a flocculent deposit. As a result of the autolysis of the cells the bouillon may partially clear up after some days. On account of the low specific gravity of the cells a high speed is necessary to completely deposit the organism in a centrifuge. On potatoes there is often no growth, sometimes a slight, scarcely visible coat. In milk this bacterium develops with a scanty production of acid which may suffice to coagulate. Media containing from 4 to 6 per cent. of glycerin and those containing blood or serum furnish richer growths. Old subcultures develop on artificial media more rapidly and abundantly than fresh, virulent cultures. Air supply has no marked effect, one way or the other, on the growth of this organism. It needs frequent transplantation in order to preserve both viability and virulence. It is easily destroyed by the ordinary disinfectants, both liquid and gaseous.

There is probably no other pathogenic bacterium of such divergent virulence as this. I have worked with two strains, one of which is fatal to guinea-pigs after intraperitoneal injection only in doses of 
1 c.c. or more of a twenty-four-hour bouillon culture, while 0.0000001 of this amount of the other kills in the same time. The virulence may be intensified by repeated passage through animals, but there is great difference in the degree with which different strains hold their virulence. Some of high power rapidly lose from generation to generation, while others remain fairly steadfast through many successive generations. The difference between strains of low and high virulence seems to be in rate of multiplication. Two guineapigs are treated at the same time with the two strains mentioned above. The size of one dose is 0.0000001 that of the other, and still the animals die at the same time and the growth in one is found after death to be as great as that in the other. It seems from this that the more virulent strain has multiplied much more rapidly than the other. Moreover, when large amounts of the cellular substance of both are obtained and split up chemically, the yield of poison by the two, per gram, is the same. This certainly is strong evidence that difference in virulence is determined by rate of growth.

While the pneumococcus is quite labile in structure, under certain conditions, it easily undergoes autolysis and is destroyed quickly by disinfectants. Samples of sputum have been found to retain virulent cocci for months. All sputum should be burned or otherwise destroyed. Floors and sidewalks are not proper receptacles for expectoration from either the well or the sick.

It is a matter of scientific interest that bile not only destroys but dissolves living, virulent pneumococci. On dead and non-virulent cultures bile has no such action. This solvent effect has been found to be due to the bile acids. Since most other pathogenic bacteria easily multiply in undiluted bile, this effect on pneumococci is striking and interesting, although it is not known to be of any practical importance.

The laboratory animals most susceptible to the pneumococcus are the rabbit and the mouse. Fresh cultures in bouillon containing 10 per cent. of ox serum kill these animals on subcutaneous or intraperitoneal inoculation in doses as small as 0.0000001 c.c. However, animals thus treated do not develop pneumonia, but die of general septicemia. It has been found by examination of the sputum and by lung puncture that the virulence of the coccus abates day by day as the disease 
develops. Pulmonary hepatization has been induced in rabbits by tracheal, intrapleural and intrapulmonary inoculations with less virulent cultures. Rats are but little less susceptible than rabbits and mice, then follow guinea-pigs, dogs, cats and sheep. In the less susceptible animals local lesions are more common than in the more highly susceptible. This raises the question of the relative susceptibility of man. It is reasonable to suppose that man is quite ref ractory, compared with rabbits and mice, to the pneumococcus. He generally carries the organism in his mouth, but becomes infected with it only under certain conditions. It does not induce a general septicemia in man. Klemperer has shown that a culture highly virulent to rabbits is followed by only a local reaction when injected subcutaneously in man. Spontaneous and epidemic pneumonia has been observed in guineapigs and the disease has been induced in these animals by inhalation and by intratracheal and intrapulmonary inoculations. The pneumonia thus induced may be either acute or chronic. It often involves several lobes and presents the anatomic characteristics of a catarrhal rather than a croupous process. It is generally fatal.

The question of the production of a toxin by the pneumococcus has been the basis of much experimental work. The evidence supplied by these experiments seems to show quite conclusively that this organism elaborates or secretes no true toxin like that of the diphtheria bacillus, but like all bacterial proteins it does yield a poison when properly disrupted. When suspended in salt solution the cells easily and quickly undergo autolytic changes whereby a poison is liberated. This has been conclusively demonstrated by the work of Rosenow and others.

That a certain degree of active immunity to this organism can be established in rabbits and other animals seems to have been demonstrated. For this purpose, heated sputum, heated cultures, cultures attenuated by phenol, cocci dissolved in bile, and the residue left after autolysis have been employed. One attack of the disease in man confers at least no lasting immunity, and often appears to render the individual more susceptible. That the sera of immunized animals have some protection and even some curative value in the disease in both man and animals seems to be demonstrated, but that such sera have true antitoxic values is certainly not demonstrated. Some claim that the sera of immunized animals have a bactericidal action, 
while others think that they only render phagocytic action more effective. The best pneumococci sera either in the fresh state or after the addition of complement do not destroy the organism. They may possibly stimulate the phagocytes or they may render the cocci more susceptible to the phagocytes. In order to be of service either in prevention or treatment, a relatively large amount of the immune serum must be used. In other words, a certain degree of concentration must be reached. The law of multiple proportions which holds good between diphtheria toxin and antitoxin fails here. Some have found that the immune sera which they have studied are effective only against those strains used in immunizing the animals and this view has induced attempts to secure polyvalent sera, but up to the present time these cannot be pronounced successful.

Neufeld and Händel, in a discussion of the value of pneumococci sera, conclude that experiments on animals have shown that such have not only a protective but a curative effect on both septicemic processes and pneumonia, but not until the dose is large enough to reach a certain concentration in the body.

Some of the strongest opponents of the phagocytic theory admit that natural immunity to this disease is due to phagocytic action and that extracellular destruction of the pneumococcus has not been demonstrated. Furthermore, they state that even normal serum in large doses protects animals against this infection.

Inasmuch as a large proportion of healthy people carry the pneumococcus in their mouths and throats, the question of what happens when one develops the disease, becomes one of both practical and scientific interest. Several possibilities suggest themselves. In the first place, while this organism is found in most cases of lobar pneumonia, it is not found in all instances. Moreover, while frequently present in other forms of pneumonia, it is not so constantly present in these. The best of evidence exists for the statement that true croupous pneumonia may be due to other bacteria, such as the pneumobacillus, Streptococcus pyogenes and Streptococcus mucosius. These facts have led some to believe that pneumonia may be due to the conjoint activity of two or more organisms, but no two of these are constantly found and there seems to be no substantial basis for this idea. A second possibility is that the pneumococcus normally present in the saliva 
does not cause pneumonia and that the disease results only when one harbors a more virulent strain. Those who hold to this theory insist that disinfection of all pneumonia sputum and the isolation of those suffering from this disease should be rigidly enforced. Opponents of this theory point out that such measures do not lead to a decrease in the prevalence of this disease. They say that while isolation and disinfection are followed by a decrease in other infectious diseases, they have had no such effect on pneumonia. A third possibility is that the pneumococcus so constantly the guest of man, becomes virulent when for any reason the vitality of the individual is lowered. To-day this is the prevalent belief and it must be added that it has much support. The frequency with which pneumonia develops after exposure to cold is generally admitted. That form of pneumonia which follows injury to the lung tissue, known as traumatic pneumonia, and the frequency and the great fatality of this disease among chronic alcoholics and in the general enfeeblement of old age are illustrations. The safest plan is to isolate the pneumonia patient, to disinfect his expectoration, and to avoid all conditions which render the body more susceptible to this and other bacteria, which may cause this disease. However, it must be added that the epidemic character frequently exhibited by pneumonia leaves no doubt in my mind that exposure to an unusually virulent strain of the pneumococcus is an important factor in the distribution of this disease. 


\section{CHAPTER XIX}

\section{TETANUS}

History.-A disease with such striking, distressing and fatal symptoms, as those characteristic of lockjaw, could scarcely escape observation and comment whenever seen. It is not, therefore, surprising that the medical records of Greece and Rome supply details of the symptoms and notes of the great fatality of this disease. However, in all ages it has been relatively rare except in certain restricted localities. It was a matter of early record that tetanus was in some way connected with wounds. It was seen to be more common in military than in civil life and in the latter it most frequently follows injury. Before the development of experimental medicine, theories concerning the causation of this disease were many and diversified. It was soon seen that while it generally followed injuries, it did not follow all, and that there was no relation between the severity and extent of the injury and the development of tetanus. The infectious nature of the disease was first emphasized by French physicians, especially Verneuil. However, the first positive demonstration of its infective character was made in 1884 by two Italian physicians, Carle and Rattone, who inoculated twelve rabbits with matter taken from an acne pustule on a man with tetanus. Within two or three days, eleven of the animals thus treated developed the disease. Furthermore, they succeeded in transferring the infection to other animals. Soon thereafter, Nicolaier induced tetanus in rabbits, guinea-pigs and mice by inserting bits of earth under the skin. He also found the specific bacillus and grew it in mixed cultures, but failed to separate it from associated bacteria. This was done by Kitasato.

The Bacillus.-Kitasato found that the tetanus bacillus grows only when the air is excluded and that it forms spores which are markedly resistant to high temperature. He smeared the infected material on agar, kept the tubes at incubator temperature for two days, the time required for the bacilli to develop spores abundantly, and then heated 
at $80 \mathrm{C}$. for one hour and allowed the spores which had withstood this temperature to develop in an atmosphere of hydrogen. The high temperature killed all the bacilli, both those of tetanus and other kinds present, but did not destroy the tetanus spores. The bacillus is a rod, from 2 to 4 microns long and from 0.3 to 0.5 of a micron broad. It is feebly motile, carrying numerous flagellae and is often found in chains. The bacilli develop terminal spores, spherical or oval bodies, with a diameter larger than the breadth of the bacillus. This gives to the spore-bearing orgainsm a drum-stick appearance. It is a liquefying organism and takes the ordinary stains easily and distinctly. It is strictly anaerobic, which accounts for the fact that the disease develops most frequently in deep wounds with closed openings and rarely in those in which the infecting material is freely exposed to the air. Tetanus spores are among the most resistant forms of bacterial life. A splinter of wood bearing infected material may remain a source of danger for many years. Direct sunlight kills the spores within from two hours to many days, depending on the thickness of the layer and the intensity of the light. They are destroyed by live steam within five minutes; by 5 per cent. phenol after fifteen hours; by mercury chlorid $(1: 1000)$ after three hours.

Tetanus spores are widely and unevenly distributed over the earth. In some localities 100 per cent. of animals inoculated with earth develop the disease, while in other places such inoculations wholly fail. As a rule the spores are most abundant in filthy soil, especially that impregnated with manure. Before the days of aseptic surgery, tetanus was especially prone to follow operative procedures as was noted by Larrey, Napoleon's great surgeon, and many other operators both in the field and in the hospital. Among certain primitive and dirty people tetanus of the newly born is frequent on account of the methods of cutting and dressing the cord. On certain islands, as Reunion and Cayenne, the infantile death-rate from this cause has in some years been as high as 50 per cent. In other localities tetanus works havoc among women in the puerperal state. Some savage tribes smear their arrowheads with mud rich in tetanus spores. The marked mortality from Fourth of July celebrations in this country a few years ago was due to tetanus infection. Fortunately, the barbaric rites with which we were accustomed to celebrate the birthday of our nation 
have been beneficially modified, largely through the knowledge spread by The Journal of the American Medical Association. The parts of our country most abundantly infected with this virus seem to be the Atlantic States, Long Island and the valley of the Hudson. Commercial gelatin and catgut used by surgeons, have been the bearers of this infection and most thorough sterilization is necessary in order to destroy the spores. Formerly, we spoke of idiopathic and traumatic tetanus. Now, we are quite sure that the former does not exist. The wound may be so trivial that it has healed before symptoms of tetanus develop. In other cases the wound may be not on the skin but on a mucous membrane as in the mouth, nose or throat. I saw a case in which the virus had entered through the gum from which a tooth had been extracted. Some have claimed that tetanus is more prevalent in black and mixed races than among whites and have endeavored to show the existence of racial susceptibility. The truth is that filthiness is the predisposing agent rather than a racial difference. The simple custom of drying the wash by spreading the clothes on the ground has been found to play a part in the prevalence of this disease.

The distribution of the tetanus virus seems to be world wide. It has been found in every land and in many waters, such as those of Lake Geneva and the Dead Sea. It may be present in bilge water and ships may be generally infected. On one English ship, after a naval battle, sixteen of the wounded died of tetanus. It may be carried into wounds with bits of infected clothing, and it has been found on nearly every article worn by soldiers from the shoes to collars. Virgin forest soil has generally been found free from this virus, but the sweepings from the streets, stables, houses, boats and cars frequently produce tetanus when introduced under the skin of animals.

Of our domestic animals, the horse is the most susceptible and is a frequent victim. The ox comes next on the list, followed closely by sheep and goats. Dogs and cats are not easily infected, but do succumb to inoculations.

When swallowed the tetanus bacillus has no effect, unless there be some break in the mucous membrane, and it is eliminated with the feces unchanged. In this way the fecal matter of man and animals pollutes the soil. The tetanus bacillus produces a soluble toxin which is one of the most potent poisons known. Injected into an animal, 
even in a dose of a fraction of a milligram, it develops tetanus after a period of incubation of a few days. Great care should be used in the employment of vaccines and sera for fear of inoculation with tetanus. The vaccine may carry the infection or it may be introduced later through the vaccine lesion. Such an accident occurred at Camden, New Jersey, in 1901, when several children vaccinated against smallpox developed tetanus and died. A similar misfortune was reported from India in 1902. Out of a group of 107 persons vaccinated against plague, nineteen died of tetanus. In St. Louis, diphtheria antitoxin was drawn from a horse which was apparently well, but which developed tetanus a fe wdays later. Some of the children treated for diphtheria with this serum died of tetanus. 


\section{CHAPTER XX}

\section{STREPTOCOCCIC INFECTION}

History.-The streptococcus probably has a much longer ancestry than man and began its assaults on the animal kingdom long before there was any indication of the development of homo sapiens. The unicellular has been the companion of the multicellular through all the evolutionary forms of the latter. Man came into existence as a host to the streptococcus and the victims of the microscopic parasite are as innumerable as the sands of the seashore. Borne on the surface and in the cavities of the greater, the smaller has always been ready to find its way into the vitals of its host and to feed on blood and tissue until the whole became its prey. In peace and in war, among the good and the bad, the wise and the foolish, the streptococcus has always been a factor in determining the mortality rates. As a primary infection there is no part of man's anatomy immune to the invasion of this organism. As a secondary infection, it profits by the lesions induced by other pathogenic bacteria. As a terminal infection, it swarms over every part of dying man, and secures the greater part of the booty of every war, whether waged by itself as principal, as ally or as guerilla. In the earliest medical records wound infection is described. It became the scourge of armies and the military hospital was often more dreaded and more deadly than the field of battle. Indeed, there was a time when all hospitals, both military and civil, became great incubators for the growth and dissemination of pus germs. In the old Hotel Dieu at Paris, the simplest amputations were followed by infection and in a large number this terminated only in death. Even after the discovery of surgical anesthesia, when operations were no longer forms of torture, wound infection remained the horrid nightmare of the surgeon. Happily the science of Pasteur and its application to surgery by Lister, opened a new era in the history of surgery. In the first half of the nineteenth century, Gaspard, Leurent and others taught that wounds become infected with invisible organisms, but this was only 
theory and at that time impossible to demonstrate. Pasteur undoubtedly in some of his early work saw pus organisms, but the credit of identifying and describing them belongs to Ogston, who found that some are spherical bodies arranged in chains while others are clustered like grapes in a bunch. The former he designated streptococci and the latter staphylococci.

The Organism.-Streptococci are spherical or oval bodies, from 0.5 to 1.5 of a micron in diameter, arranged in chains of variable length. Some strains show only short, and others only long, chains. Some investigators regard these as different species, while others consider them as only varieties. It seems most reasonable to look on the streptococci as a great family with many subfamilies, and these may show marked differences in form, in cultural characteristics, and in virulence. All are non-motile and sporeless. Inasmuch as these organisms induce suppuration, they are often designated as Streptococci pyogenes, to which we may add longus or brevis, as the case may be. Some authors divide them according to the tenacity with which they cling together or the amount of mucus formed, thus providing a type known as $S$. mucosus. In the animal body the chains are generally short, often being reduced to diplococci. In artificial cultures the chains are often long and coiled in groups forming felt-like masses. Cultures rich in peptone (as high as 5 per cent.) give the most abundant growths. The presence of grape-sugar (from 0.2 to 2 per cent.) favors growth, but the development of too much acid may prove detrimental. Blood serum, either alone or in bouillon, is an excellent medium, and strains obtained from man grow best on human serum, and the same holds good for other species. The streptococcus does not grow abundantly on ordinary solid media. The optimum temperature is that of the animal body, but growth proceeds slowly at as low as 15 and as high as $42 \mathrm{C}$. The streptococcus is a facultative anaerobe, but different strains show wide variations under diverse air supply. In general, however, in the presence of air this organism loses in both viability and virulence. Different strains act differently on carbohydrates and attempts at classification have been made on this basis, but have led to no practical results. These are varieties which decompose lactose and coagulate milk. A striking action is the hemolytic effect 
of streptococci cultures. The capability of dissolving red corpuscles was first noted by Marmorek in 1895, and has been the subject of much study since that time. If a tube of bouillon to which 0.5 c.c. of blood has been added be inoculated with the streptococcus and incubated, in a few hours the corpuscles are completely dissolved, coloring the whole fluid. On prolonged standing, the color becomes brown, owing to the conversion of oxyhemoglobin into methemoglobin. It was at first thought that the hemolytic action is due directly to the living organism, but Besredka showed that germ-free filtrates of highly active cultures are hemolytic. The hemolytic substance is highly labile and is destroyed by a temperature of $60 \mathrm{C}$. It must be classed as a ferment. Indeed, it seems that there are two ferments, one of which dissolves the corpuscles, while the other converts the soluble oxyhemoglobin into methemoglobin. Although this organism is sporeless, it may not only live but retain its virulence for many months in cool, dark places. Before the days of aseptic surgery, certain wards in hospitals became infected with erysipelas and retained the infection through long periods. Puerperal fever followed, or rather, accompanied, certain midwives and obstetricians from house to house until they came to believe that some dreadful fate hung over them and in despair fled from those who sought their services. Holmes collected cases of this kind and concluded that puerperal fever and other forms of sepsis are due to a contagium. The experiences of Semmelweis in the old lying-in wards at Prague led him to the same conclusion, and he pointed out that the obstetrician could not, with safety to those under his charge, go from the dead room to the woman in labor without first making himself clean. Moreover, he demonstrated in his own work that cleanliness on the part of the accoucheur resulted in the reduction of the number of cases of puerperal fever.

The streptococcus freshly taken from an infected man is not highly pathogenic to laboratory animals. Large doses are necessary to fatal infection and subcutaneous inoculations usually induce, at most, local abscesses. When mice are inoculated at the root of the tail, the organism multiplies at the pqint, spreads through the connective tissue and finally is carried by lymph and blood to various organs, and death may result in three or four days, earlier with the most virulent strains. With less virulent cultures a local abscess may develop and continue 
active for weeks, during which time there is a slowly progressive emaciation. Intraperitoneal injections induce fatal peritonitis. Animals have been infected by feeding experiments. In such cases the primary infection develops in the small intestine, causing an acute enteritis and followed by systemic infection and death. Repeated passage through animals rapidly increases the virulence and in this way cultures have been obtained which kill rabbits in doses of 0.0000001 c.c. However, not all strains can be developed to this extent. Association with certain other bacteria, such as the proteus and colon bacillus, is favorable to an increase in virulence. The presence of bile seems to have a like effect. The condition of the animal influences the rate of increase in virulence. Starvation, overexertion, and other depressing influences render the animal more susceptible. The same is true of the condition of the infected tissue. Extensive bruises, lacerations, and other injuries favor the growth of the streptococcus. When implanted on a mucous membrane already irritated by chronic catarrh, scarlet fever, or diphtheria, this micro-organism multiplies with unusual rapidity and develops marked virulence. Each species of animal seems to have its own strain of streptococcus. The bacterium accommodates itself to its peculiar host and thrives best on that species. Those strains found on man are more pathogenic to man than those found on other animals, and when the virulence of any strain is increased by repeated passage through a certain animal, it is more pathogenic to that than to other species.

There is no tissue or organ of the human body immune to invasion by this organism. When a virulent strain of the streptococcus finds its way into the lymph vessels of the skin, erysipelas results. There is marked migration of leukocytes to the infected area, which becomes red and swollen and extends more or less rapidly. When experimentally induced, the period of incubation varies from ten to sixty hours. The injury done depends on the virulence of the infecting strain and may be slight and superficial or it may be widely destructive and fatal. The infection may extend to mucous surfaces, to internal organs and to the brain and its membranes. A case of erysipelas does not necessarily come from a preceding case of the same disease, for the infection may be transferred from any pyemic or septic source to the skin. Erysipelas may be acquired from puerperal fever or 
the reverse may be true. This was suspected long before we had any definite knowledge of bacteria. The village doctor of that time knew that it was not a wise thing to attend a childbirth while he had patients with erysipelas or scarlet fever, or while he was dressing infected wounds. This indefinite knowledge of that time has been defined by experiments. Erysipelas has been induced experimentally with matter taken from wounds, from throats in angina, and from the uterus in puerperal fever. All these and many other diseases are due to the same organism and are mutually convertible one into another.

When the infection lies deeper and in the subcutaneous tissue, diffuse phlegmon and widely extended abscesses with extensive destructive changes result. With the infection in the larger lymph vessels, lymphangitis and lymphadenitis occur. In these either the streptococcus or the staphylococcus, or both, may be found. Other skin affections due to the pus bacteria are acne, impetigo, erythema and infectious purpura. From infected wounds a scarlatinous rash may extend over the greater part of the body, and may lead to arthritis and nephritis.

The streptococcus is frequently found in every part of the respiratory passages and it seems to play an important rôle in various inflammatory diseases of these parts. Whether the normal residents of these surfaces become suddenly virulent or more virulent strains are introduced, is not always easily determined. The streptococcic sore throat, which has in recent years occurred in epidemic form and proved so highly fatal, is believed to be due to the use of milk containing highly virulent strains. There are reasons for believing that the essential, if not the sole, causal factor in scarlet fever is a streptococcus. This organism is found constantly in otitis media. Malignant endocarditis and polyarthritis are due to virulent strains of the streptococcus. Streptococcic pneumonia is recognized and may run either an acute or a chronic course. The latter may resemble typhoid fever and the intensity of the general symptoms may be out of proportion to the physical, local findings. Purulent pleurisy is not rare. The part taken by the streptococcus in the etiology of the summer diarrheas of infancy seems to be important and market milk often contains virulent strains of this organism. In inflammatory diseases of the udders of cows, highly active strains of the streptococcus find their way into the milk. 
In other cases the organism in the tonsils of the child may pass into the intestine and induce a serious enteritis. From the intestine the organism may pass into the blood and a systemic infection may result. In such cases the streptococcus has been found not only in the stools, but in the blood and urine also.

The secretions of the vagina, in both pregnant and non-pregnant women, often contain streptococci, but for the most part, at least, these are not numerous and are non-virulent. This is due to the fact that under normal conditions the vaginal tract is self-cleaning and its secretions are bactericidal. In the puerperal state, when bits of placenta or membrane are left in the uterus, the streptococci normally present may become virulent and may lead to a septic condition. It is possible, therefore, for puerperal fever to develop without extraneous infection. That this is not the usual way in which puerperal fever originates is quite certain. A virulent strain is introduced shortly before, during or after labor. It may happen before labor by vaginal examination, by improper douches or by coitus. It may happen during labor by some fault of the accoucheur. It may happen after labor by improper douches or handling the parts. The obstetrician must guard against both autogenous and exogenous infection. He must avoid those conditions which tend to increase the virulence of organisms normally present and he must prevent the introduction of virulent cocci. Puerperal fever is not confined to the human species, but occurs in cows and other domestic animals. Contagious coryza, the pleuropneumonia of horses, and certain inflammatory diseases of the udders of cows, are results of streptococcic infection. Moreover, wound infection and sepsis are frequent causes of death among all the higher animals.

The streptococcus does not produce a soluble toxin in the sense of that elaborated by the diphtheria bacillus. Its hemolytic product is a soluble toxin, but the poisonous agent in the cellular substance of streptococci is the protein poison. Filtrates from old cultures in large doses kill animals, but there is nothing specific in this. Marmorek grew cultures in blood serum for three months and found that the filtrate killed animals, but the same result may be accomplished with many non-pathogenic organisms. Baginsky and Sommerfeld grew the organism in strongly alkaline bouillon cultures for many weeks and found 
that the filtrate, in doses of 5 c.c. intravenously, killed rabbits, but the poison was not destroyed by boiling and, therefore, could not have been a toxin. Moreover, the poison from egg white is quite as potent as this. The poison in the streptococcus is that common to all proteins and it is probable that when it is isolated the yield from the protein substance of this organism will be less than the average from proteins in general. In other words, the streptococcus is probably not rich in poison. If it were otherwise, recoveries from streptococcic infection would be less rare than they are. It is true that immune sera have been prepared, their protective value demonstrated on animals and their beneficial effects in man shown, but they do not act like antitoxins. They do not fulfil the law of multiple proportions. Their beneficial effects, so far as they have any, are due to favoring phagocytosis and not to neutralizing a toxin. The immune sera are obtained by treating animals with strains the virulence of which has been greatly increased by passage through animals, and while certain amounts of the serum are protective against certain doses of the culture, when the latter remains small, multiple amounts of the serum fail to protect against like amounts of the culture. Much credit is due Marmorek, Tavel, Aronson, Menzer and others for the most careful and scientific work in attempts to prepare curative sera against streptococcic infection. Success in this would bring to medicine a great triumph and to humanity a greater blessing, but it must be admitted that, up to the present time, the problem remains without practical solution, and prevention rather than cure must demand our best efforts. 



\section{CHAPTER XXI}

\section{STAPHYLOCOCCIC INFECTION}

The Organism.-In his study of wound infection, Ogston recognized two groups of bacteria with different morphologic characteristics. In one the cocci are arranged in chains, in the other they are in bunches. The former he designated as streptococci and the latter as staphylococci. Of the staphylococci one group is chromogenic and the other is not. The former is known as Staphylococcus pyogenes aureus, and the latter as albus. The staphylococci constitute a large group with many varieties, differing more or less widely in cultural, tinctorial and pathogenic properties.

The individual cocci are quite variable in size, which seems to be influenced by food, age and temperature. They take the basic anilin stains easily, also certain acid stains, and are slightly colored by hemotoxylin. The readiness with which such a variety of stains may be employed has favored attempts to ascertain the finer structures of these organisms. Some are convinced that the cocci consist of a distinct membrane with protoplasmic content, while others find evidence of well-defined nuclei. However, all of this work needs more extended study before the conclusions reached by different observers can be correlated and accepted.

The optimum growth temperature is that of the animal body, though multiplication continues at temperatures as high as $43 \mathrm{C}$. and as low as $10 \mathrm{C}$. Free oxygen is not essential and growth will proceed in proper media in an atmosphere of hydrogen, but not in carbonic acid, nitrogen or illuminating gas. It does not grow abundantly in media containing no protein, but it may obtain its nitrogen from ammonia salts, kreatin or asparagin. It develops abundantly in peptone solutions, but this is not an essential constituent of nutritive media. A feebly alkaline reaction is most favorable, but feeble acid does not prevent growth. In bouillon at incubator temperature multiplication proceeds with great rapidity; one loop of such a culture 
twenty-four hours old may contain millions of living cocci. In milk there is a slow evolution of acid and coagulation results after about one week. It slowly liquefies gelatin by the formation of a peptonizing ferment. This ferment converts proteins into albumoses, peptones, amins and ammonia.

A temperature of $70 \mathrm{C}$. (158 F.) continued for five minutes suffices to destroy the organism, and immediate sterilization is secured by boiling. The staphylococcus is highly resistant to drying. Dried pus may contain viable organisms after many months and dust may harbor them and aid in their distribution. Mercuric chlorid in dilution as great as 1:10,000 may inhibit growth but does not kill these bacteria. Indeed, they are rather resistant to this germicide, $1: 1,000$ requiring several hours and even 1:100 needing from five to ten minutes. Absolute alcohol is without effect but 50 per cent. alcohol is quite efficient in ten minutes. Phenol, from 3 to 5 per cent., kills within five minutes. For disinfecting the hands lysol followed by dilute alcohol is recommended.

The staphylococcus is usually found on the skin, the albus most frequently, but the aureus not seldom. It is also present in normal saliva, on the tonsils and walls of the pharynx and in the conjunctival sac. It is frequently present in the normal urethra, both male and female, but rarely in the vagina. It collects on the clothing and makes this a source of infection when carried into wounds. It is often found on cold foods and is a frequent constituent of market milk. The strains showing this wide distribution are generally of low virulence.

Old filtered bouillon cultures of the staphylococcus have certain well-marked effects. They contain a substance which induces degenerative and destructive changes in leukocytes and for this reason is known as leukocidin. This substance has not been isolated and its presence is indicated by its effects. It is inactivated at 60 and is supposed to be a ferment. When leukocytes are subjected to filtered cultures of the staphylococcus, they soon show degenerative changes and finally lose their nuclei. Leukocytes from different animals vary greatly in susceptibility to this agent. Those from the frog are undisturbed; from the mice and guinea-pigs, slightly susceptible; from the dog, more, and from the rabbit, most susceptible. 
The old filtered cultures agglomerate and dissolve red blood cells. Only in dilute or weak solutions is agglutination observable; in strong solutions there is rapid or immediate hemolysis. The hemolytic agent is most in evidence in cultures from six to ten days old. However, this is variable and it may be more abundant in still older cultures. Whether it is the same agent that acts on the white and red corpuscles is not certainly known, but both effects are prevented by heating the filtrate to $60 \mathrm{C}$.

Both antileukocidin and antihemolysin are easily prepared by repeated injections of small doses of filtered cultures of the staphylococcus in animals. This is further evidence that these bodies are toxins and should be classed among the ferments.

Filtered cultures when injected into animals have injurious effects on other cells. Hyalin casts are formed in the uriniferous tubules and necrotic areas appear in the kidney cortex. The subcutaneous tissue about the point of injection becomes indurated, the hairs over it fall out and in some instances necrosis results. Some investigators have observed similar changes in the intestinal mucosa and others report degenerative changes in the central nervous system. It will appear from these statements that the staphylococcus, living or dead, is harmful to body cells. Whether the noxious constituents of filtered cultures are to be considered as secretions of the cocci or as fragments resulting from autolytic cleavage has not been definitely determined, though the prevalent opinion is in favor of the first alternative.

It has long been known that amyloid degeneration results in man after long-continued suppurative processes. This change has been induced in animals by repeated small inoculations of living cultures and by injection of dead cultures.

Bail and his students have used the staphylococcus, as well as other bacteria, in the study of their aggressins. A large amount of an agar culture of a staphylococcus, whose virulence has been greatly increased by passage through animals, is injected into the pleural cavity of a rabbit. The exudate which is formed is drawn off and found to contain cocci, dissolved red corpuscles and degenerated leukocytes. This is freed from bacteria by centrifugation and then it is found that some of the supernatant fluid plus less than a fatal dose of the staphylococcus injected into a half-grown rabbit, kills it 
in a few hours. After death the pleural exudate in this animal is found to be sterile. Therefore, the animal does not die from infection but from intoxication. Bail's explanation is that the exudate is bactericidal and in the second animal quickly splits up the cocci with the liberation of enough poison to kill it. This seems not only rational, but the most probable explanation.

In most of the suppurative affections of man either the streptococcus or the staphylococcus, or both, play some part, either as primary or secondary cause. Other bacteria may be present, but these are the most essential. It is true that there may be an aseptic suppuration and it is also true that other bacteria may incite suppurative processes, but these are rare exceptions. Among the cutaneous and subcutaneous lesions which may be due, either wholly or in part, to the staphylococcus, we may mention acne, erysipelas, impetigo, lymphangitis, boils, abscesses, phlegmons and pemphigus. In the alimentary canal this organism may infect any part from the beginning to the end. Rarely it closely simulates diphtheria in the formation of membrane, and the osseous system seems to furnish favorable conditions for its growth. Abscesses in various parts of the body are most frequently due to this organism alone or in company with the streptococcus. Among our domestic animals it causes the same or similar lesions.

While it is true that the serum of an animal highly immunized to the staphylococcus agglutinates this organism in fairly high dilutions, serodiagnosis of staphylococcic infection has not proved of great value. Fortunately, it is rarely needed.

The contest between the phagocytes and the pus germs is waged on fairly even terms. Each secretes an agent which is destructive to the other. The cocci prepare and use the leukocidin, and the phagocytes employ a bactericidal ferment. The contestants are wary in approach and frequently retreat. When the cocci are only slightly virulent and form but little or no leukocidin, the phagocytes are bold and rapidly devour their enemies. In this case, we say that the chemotaxis is positive. But when the cocci are highly virulent and pour out large amounts of leukocidin, the phagocytes approach with greater caution or retreat. Then, we say that the chemotaxis is negative. Phagocytes feed voraciously on unarmed cocci, but when the latter are prepared, the former seem less hungry. The leukocidin is best prepared for study 
by filtering old highly virulent cultures of the cocci, while the coccidal agent is obtained by forming pleural exudates and separating the remaining cocci by centrifugation. Evidently the phagocytes may be strengthened in this contest in two ways. First, anything which will improve their effectiveness will improve their chances, and second, anything which will lessen the leukocidin of the cocci or render it inert, will help the phagocytes. Vaccination as introduced by Wright is an attempt to help the phagocytes in this contest. Within a limited field, Wright's method of treating disease by vaccination has proved successful. The best results have been secured in the treatment of such pustular diseases as acne and furunculosis. In these diseases the cocci are as it were entrenched and the phagocytes are slow to attack. By injecting cocci into the midst of the leukocytes the latter are stimulated through devouring easily the prey thus thrown to them. The formation of bactericidal ferments by the phagocytes is improved by exercise and this advantage brings victory to them. In the vaccine treatment of disease there is always danger of overdoing the stimulation of the leukocytes. It has worked better with pus bacteria than with others, probably for the reason that the cocci protein is not rich in poison. 



\section{CHAPTER XXII}

\section{DIPHTHERIA}

History.-Under various names this disease is described in the most ancient medical records. Competent authority states that a disease mentioned in the Babylonian Talmud must have been diphtheria. The Greeks held that it came to them from Egypt, to which country they were wont to ascribe most of their ills. The descriptions of Aretaeus are regarded as accurate records of this disease. Galen spoke of false membranes in the larynx and pharynx and said that the former were sometimes removed by coughing, and the latter by hawking. During the dark ages diphtheria was recognized here and there and undoubtedly added much to the high death-rate of that period. During the sixteenth century it was reported from time to time in malignant epidemic form in Spain, France, Holland and Germany. The unusual mortality in Spain in 1613 gave to this year the name of the disease. In the same country and in the same century, Heredia recognized the asthenic and suffocative types and wrote concerning diphtheria paralysis. Before the middle of the seventeenth century it had found its way into the American colonies and we are told that in the year 1659 Samuel Danforth lost four of his eleven children of "a malady of the bladders in the windpipe." As early as 1761, an American physician, Bard, made important contributions to the study of the disease and held that croup is laryngeal diphtheria. However, we owe the beginnings of the modern study of this disease, also its present name, to Bretonneau. He traced an outbreak in a garrison at Tours to common drinking-cups and other table utensils, and demonstrated the infectiousness of the disease. He claimed that croup is laryngeal diphtheria and that the angina of scarlet fever is quite distinct. These views were accepted and emphasized by the great clinician, Trousseau, and were adopted by the profession in France and America, but were ignored in Germany until the development of bacteriology rendered their demonstration possible. 
During the sixties of the past century, many were busy searching for the particulate cause of this disease and several organisms were presented as claimants for this honor, but at that time bacteriologic methods had not been sufficiently developed to enable the most expert to pick out the one responsible for the disease. In $1883 \mathrm{Klebs}$ called attention to a bacillus with well-marked characteristics, frequently found in diphtheritic throats, and a year later Löfler continued this work.

The Bacillus. - The Klebs-Löffler bacillus is a non-motile rod, generally straight, but sometimes slightly bent. Its length is quite variable (from 3 to 5 microns) and its breadth almost one-fourth its length. The most characteristic form of the bacillus is the club shape. All the rods do not have this form, but in every field there are many so characteristically clubbed that the expert has no difficulty in identification at sight. This is true especially of cultures made directly from the throat. Even the presence of other bacteria does not prevent identification. A sterilized cotton swab is drawn over the membrane in the throat and then over the surface of a slant serum tube. After from six to twelve hours in the incubator, a stain is made from the growth on the serum. While the diphtheria bacillus takes most basic stains well, Löffler's alkaline methylene blue is most generally employed. Direct microscopic examination of this stain enables the expert to determine with certainty in the great majority of instances the presence or absence of the specific organism and announce the bacteriologic diagnosis. The bacteriologist does not depend solely on the presence of club-shaped bacilli. The Klebs-Löffler bacillus has a peculiar segmented appearance when colored with the stain mentioned above. This is more easily recognized than described, but it becomes so familiar to one engaged in this work that he is seldom mistaken. The morphologic identification is rendered more easy by the fact that as a rule the only other bacteria on the slide are streptococci. If the observer satisfies himself that only streptococci are present, he makes a negative report. In a few instances, there are diphtheria-like organisms which may leave one in doubt. However, when in doubt the only wise thing to do is to make a positive diagnosis, when the case will be properly isolated and treated with antitoxin. 
Subcultures of the diphtheria bacillus show many and varied involution forms. Many attempts have been made to establish a relationship between morphology and virulence, but these have led to no practical results. The Löfler serum should be carefully prepared and should consist of three parts of serum (horse, ox or sheep) and one part of neutral bouillon containing 1 per cent. each of peptone and grape sugar. The freshly prepared serum should be shaken for some hours with 3 per cent. chloroform before the bouillon is added. On one day the serum is heated for from five to six hours at from 70 to $80 \mathrm{C}$. (158 to $176 \mathrm{~F}$.). On the next day it should be-held at $80 \mathrm{C}$. for one hour and for the same time at 90 (194 F.), ard then for half this time at $100 \mathrm{C}$. (212 F.), and then allowed to harden slowly. On this medium the bacillus will form a good growth in the incubator within six hours.

The optimum growth temperature is about $37 \mathrm{C}$., but growth proceeds anywhere between 20 and $41 \mathrm{C}$. While air is not absolutely essential, growth is most rapid when this is abundantly supplied. In liquid cultures, a scum forms on top, and the subjacent fluid may remain clear. The sides of the tube may be covered with the growth. On ordinary agar the development is slow and scanty. Gelatin colonies are not characteristic and the medium is not liquefied. In the presence of certain carbohydrates there is a slow production of acid, but this does not occur in bouillon when the muscle sugar has been removed. In the absence of carbohydrates from the medium, the alkalinity is increased.

The resistance of this bacillus to untoward conditions depends on whether it is still protected by its membrane or has been freed from the same. The membrane, even when partially dried, may retain its virulence for many months. On the other hand, silk threads dipped in cultures and exposed to direct sunlight soon become inert. Phenol, 5 per cent. and mercury chlorid, 1:1,000, destroy the bacillus within five minutes. Absolute alcohol has but little or no effect, but when the strength is reduced to from 60 to 30 per cent. a few minutes suffice to kill the bacilli. According to Meyer, certain tooth pastes destroy diphtheria bacilli in less than one minute. It must not be inferred from this that a diphtheritic mouth could be easily disinfected by such an agent. The bacilli are protected by the pharyngeal folds and the crypts 
of the tonsils. However, since the healthy carrier plays a large part in the distribution of this disease, more attention to oral hygiene might be of service in this as well as other directions.

Roux and Yersin discovered diphtheria toxin. Cultures several weeks old were filtered through porcelain. The germ-free filtrate in minute doses kills animals. The toxin has not been obtained in a pure state, and we are still in doubt concerning its chemical composition. It resembles in some respects the ferments. It acts slowly and after a period of incubation; it is active in exceedingly small amounts; it is destroyed by heat, and when repeatedly injected into animals in non-fatal, but increasing, doses, the animal becomes immune by elaborating an antibody. In these respects diphtheria toxin resembles the ferments. It differs from many ferments in the fact that a given amount produces only a certain effect and apparently goes no further. Different strains of the bacillus show wide variations in their toxin production, and the highest toxin producers are not always the most virulent bacilli. What is called diphtheria toxin is an old filtered culture, and the strength of this is determined by ascertaining the minimum amount necessary to kill a guinea-pig of from 200 to $250 \mathrm{gm}$. weight within four days. This minimum lethal dose may be as small as 0.0005 c.c., though that usually employed in the production of antitoxin is much less powerful than this.

The effect of this toxin on animals has opened a new field of research, has given a new understanding of disease processes and has led to one of the most beneficent discoveries, that of diphtheria antitoxin. When a fatal dose of this toxin is injected into an animal, there is a period of incubation during which the animal shows no marked departure from the normal. This incubation period varies with the size of the dose, but is never less than about eight hours, even when many times the fatal amount has been used. The significance of this incubation has, in the writer's opinion, been misunderstood. It should not be inferred that nothing happens during this time. The disturbance simply does not rise to the plane of gross clinical observation. The toxin begins to act soon after its introduction. Within an hour or two the temperature begins to rise and proceeds slowly until some hours before death when it begins to fall, and at death it is several degrees below normal. The skin about the point of injection 
becomes edematous and later necrotic. The interval between injection and death is the same as after inoculation. With sublethal doses there is often paralysis, beginning in the posterior extremities and extending over the body. The internal organs are hyperemic with hemorrhages in the adrenals, stomach and intestine. Sometimes a gastric ulcer is found. It is important to note that after the first day there is a fall in the blood pressure. The effects of the toxin on temperature and blood pressure suggest the action of the protein poison. It will probably be found that the toxin is a ferment which slowly disrupts some protein, setting free the poison which in small amount increases and in larger, decreases the temperature and lowers blood pressure. The toxin apparently has special avidity for nervous tissue. Whether this action is primarily central or peripheral has not been determined. When the toxin is injected into a susceptible animal it soon disappears from the blood current and manifests its activity on certain organs and tissues. It has not been found in the urine except when massive doses are given. In insusceptible animals, it remains for a long time in the blood stream and is, of course, without action on the tissues. It is not able to digest the animal's proteins and it is for this reason that the animal is refractory.

We owe the discovery of diphtheria antitoxin, one of the most beneficent discoveries of all ages, to the labors and genius of von Behring. It is true that others had prepared the way, but this detracts in no way from the debt of gratitude the world owes this distinguished German investigator. To the preliminary work America made two important contributions. Mitchell and Reichert showed that the active principles in the venom of serpents are protein bodies or so closely related to proteins that they have not been separated. Sewall immunized pigeons to this venom. Then came the discovery by the Frenchmen, Roux and Yersin, of diphtheria toxin, closely resembling snake venom in its action. Ehrlich immunized animals to the similar vegetable poisons, abrin, ricin and robin, and demonstrated that passive immunity could be established in other animals by the transference to them of the serum of those actively immunized. Von Behring's method of preparing diphtheria antitoxin as now used is as follows: Sound, healthy horses are kept under observation and tested with mallein to insure freedom from glanders. Injections of diphtheria toxin, begin- 
ning with very small doses, are given these animals at intervals of a few days. It is desirable that the first doses should be so small that marked local or general reactions are not induced. Horses differ widely in susceptibility to the toxin. From time to time a small amount of blood is drawn from the horse and its protective power against the toxin is tested on guinea-pigs. The amount of the serum necessary to protect a guinea-pig of $250 \mathrm{gm}$. weight against 100 minimum lethal doses of the toxin is known as an "immunity unit." When the protective value of the serum has risen to the desired point, from 4 to 8 liters of blood are drawn under aseptic precautions into sterilized glass cylinders. These are allowed to stand in a cool, dark place until coagulation is complete, when the serum is treated with some preservative, such as 0.5 per cent. phenol, 0.4 per cent. trikresol or a small amount of camphor, and placed in containers ready to be injected into the sick person. In some countries no preservative is used and the serum is heated to $56 \mathrm{C}$. In all countries antitoxin is made under governmental supervision and the product is tested in some laboratory. All horses do not produce the same grade of antitoxin, and sera from different animals are mixed and the product tested as to its protective value. Some horses continue to produce a high grade antitoxin for years and from 4 to 6 liters of serum may be obtained from such animals monthly. It will be understood that in such cases the injections of toxin must be regularly repeated. Immediately after an injection of toxin the antitoxin content of the blood falls, then it rises and generally reaches its highest point in ten or twelve days, remaining at that point for a variable time. The horse has been immunized by the repeated injections of the toxin. The process of immunization consists in developing in the animal's body an antitoxin, the excess of which is in the blood, and in the serum after coagulation. The antitoxin is capable of neutralizing the toxin both in vitro and in vivo. The diphtheria bacillus is growing in the throat of the child and pouring its toxin into the child's blood. The blood serum of the horse is injected into the child and neutralizes the toxin coming from the throat. The horse has been immunized, and when its blood serum is introduced into the child, the child becomes for the time physiologically a part of the horse and partakes of the horse's immunity just to the extent of the amount and potency of the horse's serum injected. It 
should be understood that the blood serum of the horse containing the antitoxin is not bactericidal. It does not kill the bacilli in the throat, but it neutralizes the toxin in the blood and tissues. It must be evident from this that the earlier in the disease the antitoxin is used, the more beneficial it is. When the toxin poured from the throat into the blood meets with no antibody, it acts on the body cells and destroys them, and to the extent to which this has been done before the antitoxin has been administered, it is without value. Kossel has shown that when the antitoxin is injected on the first sign of the disease, the percentage of recoveries is 100 . In this every hour counts. Out of 2,428 cases reported by Hilbert, the percentage of deaths varied with the day on which the antitoxin was administred, as follows: First day, 2.2; second day, 7.6; third day, 17.1; fourth day, 23.8; fifth day, 33.9; sixth day, 34.1; after the sixth day, 38.2. According to Wernicke the saving of lives during the first year of the use of antitoxin in Germany amounted to 20,000 , and if the agent was properly and promptly used the saving would amount to 45,000 lives annually. The value of this agent, however, is even greater than is indicated by the lowering in the death-rate. For every sick child saved, at least five are saved from being sick. While the curative value of diphtheria antitoxin is great, its preventive value is greater still. The physician called to a family in which one child has diphtheria gives a curative dose to the one and immunizing doses to all others. Even when the sick one has been neglected so long that the curative value of the agent is lost, its preventive value is still potent. Diphtheria antitoxin has lowered not only the mortality rate, but still more the morbidity rate.

Unfortunately, the immunity induced by diphtheria antitoxin is only temporary, lasting only from three to four weeks. From this it frequently happens that a child who has once had an immunizing dose, may a few months or possibly a few years later, need a curative dose. The fear of anaphylactic shock has led many a physician to hesitate about a "reinjection" of horse serum after an interval of ten days or longer, but one may do this with safety. In all cases of "reinjection" after an interval of ten days or longer, a fraction of a cubic centimeter should be injected. If there are or are not untoward symptoms following this, after an hour or two any amount of the serum may be injected with safety. This procedure should be adopted not only in all cases 
of reinjection, but when the patient has ever shown asthmatic symptoms. With these precautions no physician need fear to use diphtheria antitoxin when it is needed. In order to prevent outbreaks, Heubner, for the past twenty years, has had every child in his hospital injected every fourteen days and no serious result has ever followed.

When antitoxin is used early in the disease, the extension of the membrane usually stops in a few hours. For this reason, laryngeal diphtheria is now rarely seen except in neglected cases. Not only does the extension of the membrane stop on the administration of the antitoxin, but as a rule that already formed begins to recede, becomes detached and fades away. It may truly be said that the discovery of antitoxin has largely robbed diphtheria of its terrors, and it might not be amiss to call attention to the fact that without animal experimentation this could not have been done. Hundreds of animals have been sacrificed in order that hundreds of thousands of human lives might be saved from one of the most distressing forms of death man has known.

Notwithstanding the possession of this wonderful and almost miraculous preventative and curative agent, the problem of the eradication of diphtheria remains one of the most difficult problems still confronting scientific medicine. The bacillus seems well-nigh ubiquitous. Thousands of people in health carry these deadly germs in their throats and mouths. If it has breeding places outside the human body they have not been discovered. The disease is acquired for the most part at least, not from those ill, but from those who are in apparent health. All that we can do at present is to emphasize the desirability of more individuality and less promiscuity in manners of life. The common drinking-cup and other methods of contact with lip to lip directly and indirectly must be discouraged and the importance of oral hygiene must be emphasized, especially among children. 
PART II

I M M U I T Y 



\section{CHAPTER XXIII}

\section{INTRODUCTION}

Had the animal body no effective means of resistance to bacterial invasion, man could not have developed, and the whole animal world would have perished long since, so abundant in numbers and so wide in distribution are the various forms of bacterial life, both saprophytic and pathogenic. In life our skin is covered with bacteria and our alimentary tract filled with them. Even in the most perfect states of health we are the hosts and they are our guests. Willingly or unwillingly, and for the most part unconsciously, we supply homes and food to these parasites. With the approaching death of the host, these myriads begin to penetrate every part of our bodies, and by the time the respiration and pulse cease, both saprophytes and parasites are tearing to pieces our mortal frames. It follows from this that the living animal must possess certain agencies which serve to protect it against bacterial invasion, and it is our purpose to inquire into the nature and action of these agencies.

Different species of animals differ widely in their susceptibility to a given pathogenic bacterium. As a rule at least, it is true that the more widely separated the species the more marked is the difference in susceptibility to the same infection. We know of no bacterial infection common to the cold and warm-blooded animals. It is true that we acquire typhoid fever by eating oysters taken from infected water, but the oysters do not have typhoid fever any more than the leaves of lettuce, which may be soiled with typhoid excreta, do. Fish, turtles and possibly other cold-blooded animals have tuberculosis, but this is due to quite a different organism from that which causes this disease in man. Some cold-blooded animals may be infected experimentally with anthrax and plague, but under natural conditions they are not known to develop these diseases. In some instances at least, the immunity of cold-blooded animals to bacteria pathogenic to the warmblooded seems to be solely a matter of temperature. When kept at 
warm-blood temperature, certain cold-blooded animals become susceptible to tetanus and other infections. Likewise, warm-blooded animals are immune to many bacteria because they cannot grow at the temperature of the animal body. This is true of the greater number of the saprophytic bacteria found in drinking-water. A bacterium which cannot grow and multiply at the temperature of the animal body cannot infect the animal. Such an organism may produce a substance outside the body and at its growth temperature, which is poisonous to a warm-blooded animal, but it cannot infect the animal.

Like differences in susceptibility are observed in birds and mammals. So far as we know, under natural conditions, there is no transference of infection between these classes. With larger doses, or under unnatural conditions the infection of mammals may be transferred to birds. Chickens become susceptible to some of these infections, such as anthrax, when the body temperature is kept low. Chickens have tuberculosis, but the bacillus of avian tuberculosis grows at 45 and even at $50 \mathrm{C}$. while that of the human does not grow above 41 C. $(105.8$ F.). While barnyard fowls have frequent opportunity to pick up the sputum of tuberculous men, they do not become infected in that way, nor are men infected with avian bacilli, although the opportunities are quite frequent. It must not be inferred that temperature is the only factor in these differences in susceptibility. It seems to be one factor. The difference in metabolism is probably quite as great a factor, possibly much greater, but its value is not so easily determined. Here also, the poisons produced by avian infective bacteria may prove harmful to mammals. Man may eat birds dead of chicken cholera and by doing so he does not acquire the disease, but he may be more or less severely poisoned by the bacterial products.

Between herbivorous and carnivorous animals the differences are not so great. The latter are, as a rule, much less susceptible but succumb to large inoculations. Anthrax, one of the most universal infections, is not known to appear in epidemic form among carnivorous animals under natural conditions. There are traditions that this has happened, but these are not based on reliable information. In his susceptibility to infection man is more closely related to the herbivora than to the carnivora. Beasts of prey may become infected with 
anthrax or glanders when fed with large quantities of infected material, but this is not comparable with natural infection. Smith reports tuberculosis, due to human bacilli, in a tame bear whose master had the disease. Possibly with closer association such cases would be more frequent. Man seems to possess complete immunity to rinderpest, and apparently none of our domestic animals are susceptible to scarlet fever or measles. The immunity of the lower animals to cholera and typhoid fever may be due to their normal intestinal bacteria.

When we confine our attention to man, variations in susceptibility among the races is not so great as was once believed. Livingstone found no trace of syphilis among the Africans and believed these people to be immune to this infection, but as early as 1867, Fritsch reported it rare but saw occasional cases which he attributed to contact with the white man. More recently, this disease has become common in the Congo and coast colonies, and in Uganda it is said to have become a veritable plague. Mense states that the bearers of culture have carried the gifts of civilization and the scourge of venereal disease to trustful savages. However, venereal diseases are not the only ills which have been disseminated by the white man. Indeed, if the present opinion concerning the introduction of syphilis into Europe be true, it was one of the jewels borne to Spain by the sailors who accompanied Columbus on his first voyage. Smallpox did much to aid the Spaniard in his conquest of Mexico, and measles and tuberculosis have played important rôles in reducing the red man in America. According to Calmette, the white man has done much in spreading tuberculosis to other races and conditions of men.

Hahn points out that in countries occupied by two races or by peoples of different religions, apparent differences in susceptibility are due to material conditions in life. One race lives more hygienically and more intelligently than the other. This is especially true of those infections which afflict principally the poor and ignorant classes. In India and in the Philippines plague and cholera prevail quite exclusively among the natives, while Europeans and Americans live for the most part in safety. In the cholera epidemic in Astrakhan in 1892, the Armenians suffered but little while the Tartars died in great numbers. Much has been written about the comparative freedom of the Jew in Western Europe and in America from tuberculosis and this 
has been attributed to racial immunity, but Hahn thinks it due to more hygienic living and calls attention to the high death-rate from this disease among the poor, ignorant Jews of Poland and Galicia. Another illustration is the unequal distribution of leprosy among the Kabyles and Arabs of Algeria. The former live in better houses, select better locations for their homes, are not so crowded and are personally more clean. The truth is that the death-rate from infectious diseases has become the best measure of intelligence. The more intelligent a people, the lower the death-rate.

It should be understood, however, that the death-rate from the infectious diseases is a measure not of individual, so much as of community, intelligence. In this country the wonderful reduction in the death-rate from infectious diseases in the past fifteen years has been confined largely to the great cities. Smaller cities, villages and rural communities have improved but little. The larger cities are establishing effective health departments. Building regulations prevent the construction of unsanitary houses, either public or private. Schoolchildren are inspected by competent medical men and first cases are detected and isolated. Proper hospitals for the infectious diseases are provided and scientifically administered. The children of the poorest and most ignorant go to sanitary school buildings and when infected, are scientifically treated. The health officer of the smaller city is a joke and that of villages and rural communities exists, for the most part, only in name.

It was formerly believed that the African is naturally immune to malaria, but more recent and more thorough studies show that this disease is highly prevalent and fatal among the children of that race and that the apparent resistance observed in the adult is due to acquired immunity. In parts of Greece and Italy malaria has been constantly prevalent for more than two thousand years. During that time it has spared no generation and in many localities scarcely any individual, and yet no marked immunity has been inherited. The young of recent generations retain their susceptibility. How this compares with that of the first generation subjected to the infection we cannot say. However, it is undoubtedly true, that resistance to certain specific infections increases after many generations of continuous exposure. The most intelligent physicians of Cuba believed, before the discovery of the 
transmission of yellow fever by the mosquito, that the natives are wholly immune to this disease. Now, it is quite evident that all have it lightly in infancy, and the adult is protected by an acquired immunity. When syphilis first appeared in Europe, it manifested a malignancy much greater than that now usually observed in the white man. It is said to be still much less malignant among the Indians of Central America, whose ancestors, far back beyond the Columbian period, probably had the infection. On the other hand, people among whom it has recently been introduced, suffer its full virulence. The increased mortality of smallpox, measles, scarlet fever and tuberculosis, among peoples unaccustomed to these diseases, seems to be well authenticated. We must conclude that increased resistance to specific infection is both inherited and acquired.

Variation in individuals of the same species to a given infection is a most interesting subject and one which cannot at present be wholly explained. As a rule, the more virulent the infection the less marked the variation. When many guinea-pigs are inoculated with a fairly virulent anthrax culture in the same dosage, all die about the same time. When rabbits are treated in the same way with anthrax, some die within one or two days, others live longer and some do not die. When rabbits are inoculated with the bacilli of chicken cholera, there seems to be no resistance. The reaction at the point of inoculation is slight, a general septicemia results and all the animals die. When guinea-pigs are inoculated with the same organism there is a marked local reaction, as a rule there is no general infection and but few die. When guinea-pigs are inoculated with a virulent culture of the human tuberculosis bacillus all die. With rabbits only a small proportion die. The water-supply of a city becomes infected with cholera or typhoid bacilli. From 5 to 20 per cent. of those who drink the water may develop the disease. Why does not this happen to all? Some answer by saying that the bacilli, being particulate, are not uniformly distributed through the water, consequently all who drink the water do not swallow the infective agent. All soldiers who make a charge in the face of continuous musketry discharges are not killed or wounded.

There is much of truth in this explanation, but it is not altogether applicable. Many of those who do swallow the bacilli, as can be demonstrated by their presence in the stools, do not develop the disease. 
Then, of those who do develop the disease, some have it lightly, others more severely and some fatally. The relative insusceptibility of nursing infants to diphtheria and certain other infections is well known, and Schick has shown that the blood of many of them contains antitoxin, possibly acquired through the mother's milk. Certainly, no such marked variations in susceptibility to a chemical poison could be expected. An infection must meet with some resistance to its multiplication and this is not equally effective in all individuals. It seems fair to conclude from this that in all probability the resisting agent is also a living thing or some product or products of living things. 


\section{CHAPTER XXIV}

\section{PHAGOCYTOSIS}

Phagocytes.-We owe our knowledge of the most important facts in the new science of immunology to the labor and genius of Metchnikoff, whose elucidation of biologic processes we will follow in some detail. In many forms of life, from the simplest unicellular to the most complex multicellular, there are certain cells, one of whose functions is to engulf and digest other cells. These eating cells are designated by Metchnikoff as "phagocytes." The fungi which devour fallen wood, dead leaves and other decaying vegetable matter consist of sporangia or clusters filled with innumerable round spores or cells. Under proper conditions these zoospores are set free and develop into naked masses of protoplasm known as plasmodia * which vary in size from small bodies to those several feet in length. In the free state, these plasmodia are motile and they may engulf and digest solid matter. They shun dry, and seek moist, places. Certain substances attract and others repel them. This phenomenon is known among botanists as chemotaxis. Most dead vegetable matter attracts them while solutions of salt and sugar repel them. In other words, they are attracted by substances which supply them with proper food, and are repelled by substances which harm them. The former is known as positive, and the latter as negative, chemotaxis. However, in this respect they are capable within limits of accommodating themselves to their surroundings, and negative chemotaxis may become positive.

These plasmodia can feed on both soluble and insoluble substances. In the latter instance, they project pseudopodia, surround the solid and digest it. This can be demonstrated by springkling on their food some color such as carmine. These plasmodia absorb and digest not only dead, but also living particles. For instance, they feed upon living algae and the process of digestion within the cell can be studied. Within the cells, green algae can be seen to turn brown, then

* This has nothing to do with the plasmodia of malaria. 
become granular and then disappear. They also absorb or engulf motile bacteria which may for a while continue to display their motility. Digestion is performed by means of an acid fluid, as can be demonstrated by feeding them on litmus or on substances colored with neutral red. In some instances at least, digestion proceeds not only in feebly acid, but also in neutral and feebly alkaline solution. For this reason the digestive ferment is regarded as a trypsin rather than a pepsin.

Another phagocyte is the ameba, which by means of its pseudopodia surrounds and digests not only dead particles, but also microscopic plants, animals and bacteria. Intracellular digestion in these unicellular animals has been carefully studied with most interesting results. They take into their bodies both dead and living bacteria, algae and infusoria. It is easy to watch the behavior of living cells after engulfment. Some amebas live exclusively on living cells and some restrict their food to bacteria. Indeed, some are so particular that they prefer one bacterial species, and when supplied with mixed cultures they devour their favorite, leaving others unharmed. Mouton studied a species of amebas which had been fed through many generations wholly on colon bacilli.

It is especially worthy of note that when colon cultures are fed to those amebas, the bacilli may be agglutinated or bunched outside the amebas and entire clumps are engulfed at once. The similarity between this process and the agglutination of typhoid bacilli with the serum of one ill with this disease is striking and significant. One is justified in supposing that in each case the phagocytes (in typhoid fever, the body cells) pour out a secretion which prepares the bacilli for absorption. Of course, in the agglutination of typhoid bacilli with serum, the phagocyte is not present, but remains in the body. However, agglutination is not essential and single bacilli may be absorbed and digested. In absorption, the bacteria are taken into a vacuole and the process of intracellular digestion begins. When the bacilli have been previously stained with neutral red, they are seen to become cherry red in the vacuole, showing that the digestive fluid is acid. The ferment is known as the ameba-enzyme. It may be obtained by dissolving or extracting masses of amebas. It acts in feebly acid, neutral, and feebly alkaline solutions. It readily digests 
gelatin and blood fibrin, less markedly, egg albumin. Its optimum temperature is $25 \mathrm{C}$. ( $77 \mathrm{~F}$.) or slightly above, but it acts slowly as low as $8 \mathrm{C}$. At $60 \mathrm{C}$. it is destroyed. When solutions of this enzyme are treated with bacteria killed with chloroform, the cloudy fluid soon becomes perfectly clear. It must be noted that Mouton did not succeed in dikesting living bacteria with the extracted enzyme, but they are digested in living amebas. 'This suggests that the bacilli are killed by one enzyme and digested by another. The killing enzyme may be poured out into the surrounding fluid from the living cells and when the amebas are killed its formation, quite naturally, stops. The formation of the digestive enzyme also stops when the amebas are killed and the extract contains only the excess already formed.

Most infusoria depend, in part at least, on intracellular digestion. Most of them accomplish this by acid secretions, while some supply feebly alkaline fluids. While protozoa depend largely on intracellular digestion, this function is not wanting in many multicellular organisms. In many invertebrates the digestive cells of the intestinal tract consist wholly of sessile phagocytes. This is largely true of sponges and coelenterates. This is beautifully illustrated in the siphon sponges which are true beasts of prey. They swallow entire crustacea which are taken into the alimentary canal where they are surrounded by, whole groups of entodermal phagocytes, fusing into great protoplasmic masses, and digested. The actinea seize their victims with their tentacles and digest them after absorbing them into their mesodermal cells. Mesnil has succeeded in extracting from these cells an enzyme which digests fibrin and coagulates albumin in feebly acid, neutral and feebly alkaline solutions. The digestion proceeds at from 15 to $20 \mathrm{C}$., the temperature at which actinea live, but in vitro, it is most effective at from 35 to $45 \mathrm{C}$. Higher temperature weakens its activity which is wholly arrested at from 55 to $60 \mathrm{C}$. The actino-enzyme produces peptone and amino-acid. In these animals, digestion seems to be wholly intracellular.

While intracellular digestion is common in the intestinal canal of the lower invertebrates, it is replaced by extracellular intestinal digestion in the higher invertebrates and in the vertebrates. The intestinal epithelium loses its ability to project pseudopodia, engulf food and digest it. These cells become glands which pour out enzymes and 
intestinal digestion becomes extracellular. However, certain mesodermal cells, even in the highest mammals, including man, continue in the possession of ameboid movements and the exercise of intracellular digestion. The burden of digestion for the animal body as a whole rests on certain glands, but as a further protection against invasion by foreign proteins, the white blood cells retain active movements and the ability to engulf and destroy micro-organisms.

Metchnikoff has shown that the metamorphic change through which many insects and other animals pass is brought about by phagocytic action. The tail of the tadpole is eaten away by the white blood corpuscles. Some of the tissue changes both normal and abnormal in man are due to the same agents. The involution of the uterus after childbirth is due to the absorption and intracellular digestion by phagocytes of the unnecessary tissue. The whitening of the hair with advancing age results from the consumption of the pigment by phagocytes. The general deterioration of the brain with advancing senility is due to the activity of the neuronophages. In short, the man who lives to die physiologically is slowly but certainly devoured by his own phagocytes. Sometimes, however, they seemingly are not content to let us live out the allotted time, and they fall on and devour some part of our anatomy prematurely. According to Metchnikoff, progressive muscular atrophy is an illustration of this apparently undue greed on the part of our wandering cells. This must not lead us to a hasty and rash condemnation of our eating cells, for if they did not feed on the micro-organisms which are frequently entering our bodies, our lives would be even shorter and more precarious than they are.

If some of its own blood, or that of another individual of the same species, be injected into the peritoneal cavity of an animal, it is readily absorbed and does no harm. If it be from another species the phagocytes come from all parts of the body and devour the foreign material. This is true not only of blood but of other foreign cells. Indeed, cells whose normal habitat is limited to one organ or tissue become foreign substances when introduced into another part. Spermatic cells injected into the abdominal cavity of the animal from which they are taken become the prey of the white blood cells. When foreign material is injected into the abdominal cavity, at first the white blood cells, already there, seem to be frightened and run away, but soon they 
return in greatly increased numbers and undertake the destruction of the foreign substance. If this substance be sterile no great harm is likely to result. The surgeon leaves catgut sutures in the tissues, but if they be sterile the phagocytes eat them entirely and no harm comes.

Among the several kinds of white blood corpuscles, the large mononuclear cells are most effective in feeding on animal cells, whether native or foreign to the body, and are designated by Metchnikoff as macrophages. The polynuclear leukocytes play a more important rôle in bacterial infection and are denominated microphages. The former are able to engulf and completely digest a large number of cells. If lymph glands, the great omentum or the spleen be crushed, ground in a mortar and extracted with salt solution, a fine emulsion is obtained, and this dissolves the red corpuscles of various vertebrates. This hemolytic action is destroyed by a temperature of $56 \mathrm{C}$. continued for one hour, and at $60 \mathrm{C}$. in a shorter time. This thermolabile ferment is the cytase of Metchnikoff, the alexin of Buchner, and the complement of Ehrlich. It should be stated that the emulsion of macrophages contains other and thermostabile hemolytic agents, such as fatty acids and soaps, but with these we are not concerned at present.

Bordet showed that the ferment obtained from the macrophages is a complex body consisting of two parts. One is thermolabile, the other thermostabile. One combines with red corpuscles even at low temperature, but does not dissolve them until the other enters into the reaction. Bordet calls the thermostabile body the sensitizer. It prepares the red corpuscles for the action of the complement. Ehrlich names the thermostabile substance the amboceptor, combining by one hand with the red corpuscle and by the other with the complement. Bordet's conception is that the action of the sensitizer is a physical one similar to that of a mordant; Ehrlich's is that of a chemical combination. It is needless to go into a discussion of this difference since all agree that the ferment consists of a thermostabile and a thermolabile part and that joint action is necessary to induce hemolysis or other cytolysis. The alexin or complement does not combine with the red corpuscle or foreign cell directly, and does so only through the sensitizer or amboceptor. In his later papers, Metchnikoff retains the term, cytase, for the thermolabile body and adopts the term, fixator, for the thermostabile substance. 
It must be evident from the facts already stated that it is a function of the white blood corpuscles, to fall on invading cells, absorb and digest them. By chemotaxis the phagocytes are called to the point of bacterial invasion. The army of defense is mobilized by the blood and lymph. The individual leukocytes may pass through tissues, including the walls of vessels, and this aids in the movements of concentration. When the foreign protein, which has found its way into the body, is dead, the only question about it is the ability of the phagocytes to digest it. If they are not able to do so at once, they may acquire this function. When the foreign protein consists of living organisms, there is a struggle between defenders and invaders. The destruction of the latter does not depend solely on the ability of the former to engulf and digest their opponents. The digestive ferments may be excreted or poured out into the surrounding fluid by the phagocytes, and at their death and dissolution all the ferment contained within their bodies is disseminated throughout the adjacent tissue and exerts its destructive action on the invaders. It seems that in giving their lives for the protection of the body as a whole, the leukocytes may become most effective. The secretions from the phagocytes are constantly, in health and in disease, passing into the blood, and, besides, these cells are constantly suffering death and dissolution and in this way blood and serum receive a constant supply of germicidal enzymes.

Besides the leukocytes, there are certain fixed cells which may be regarded as phagocytes. Such are connective tissue and endothelial cells. However, some of these are modified leukocytes. For instance, the Kupffer cells of the liver are now regarded by Metchnikoff as large mononuclear leukocytes. This leaves the large cells of the lymph glands, the spleen and bone marrow as fixed phagocytes. These are regarded as playing only a subordinate rôle in immunity when compared with the wandering leukocytes.

Phagocytosis in Natural Immunity.-Metchnikoff's attention was called to the subject of phagocytosis by observations on an infection in a small, fresh-water crustacean, the daphnia, which on account of its transparency offers special opportunity for a study of this kind. This organism is infected by the spores of a certain yeast, which gain access to the body cavity, where, when unhindered, they multiply in great numbers and soon destroy their host. However, the invader 
meets with resistance, and when the numbers are not too great, all the spores are taken into leukocytes and digested. When the spores are too numerous, they develop and pour out a secretion which kills and digests the leukocytes, then fatal infection follows. In the transparent daphnia all stages of this combat can be followed under the microscope. Metchnikoff applied this knowledge to a study of anthrax infection. He found that when animals naturally immune to this organism, such as dogs and frogs, are inoculated, the bacilli are engulfed in leukocytes which speedily gather at the point of inoculation. On the other hand, in highly susceptible animals, such as guineapigs and mice, phagocytosis is wholly wanting or but slightly in evidence. In moderately susceptible animals, such as rats and rabbits, phagocytosis is more marked and may or may not protect, depending on the virulence and number of the bacilli introduced. Further studies in many laboratories have shown that the greater the susceptibility of an animal to anthrax, the less markedly does phagocytosis occur on inoculation, and the more highly immune the animal the more marked is the phagocytosis. It is generally admitted that natural immunity to anthrax is due to phagocytic effectiveness.

In the study of certain anaerobic bacteria, as the bacilli of tetanus, symptomatic anthrax and malignant edema, interesting facts concerning phagocytosis have been ascertained. Paradoxical as it seems, all animals have a natural immunity to tetanus, but this immunity is suppressed when certain non-pathogenic bacteria are introduced into the animal along with the tetanus bacillus. The injection of a large amount of tetanus bacilli or their spores into animals are without effect provided there is no ready-made tetanus toxin injected at the same time. Under this condition, a large number of leukocytes collect at the point of inoculation and soon devour the bacilli and spores. But when the ready-made toxin is present, phagocytosis does not result and a fatal infection follows. The explanation has been found to be due to the fact that the toxin protects the tetanus bacilli by exerting a negative chemotaxic effect on the leukocytes. It holds back or repels the phagocytes until the spores and bacilli develop and produce more toxin. A capillary glass tube filled with tetanus toxin and introduced under the skin of an animal remains for a long time free from leukocytes, while a similar tube filled with bacilli and spores, free from 
toxin, attracts the leukocytes. The bacilli and spores exert a positive chemotaxic effect upon leukocytes. In like manner the presence of certain non-pathogenic bacteria occupies the activity of the phagocytes, giving time for the tetanus bacillus to elaborate its toxin. When this point is reached, the bacilli are protected by their own secretion. Likewise, if a culture containing the spores of symptomatic anthrax be heated high enough ( 80 to 85 C.) to destroy any toxin that may be present, and be injected into an animal, the phagocytes rush to the point of inoculation and devour the spores. If, however, the spores, free from toxin, be rubbed up thoroughly with fine sterilized sand and particles of this mixture be introduced under the skin, the sand protects the spores long enough for them to develop toxin, infection results, and the animal dies. A similar experiment has been made with the spores of malignant edema. If toxin-free spores be mixed with agar and bits of this be placed under the skin, the phagocytes attack the agar, but while they are at work on this the enclosed spores develop, produce toxin and infect the animal. If the bits of agar after being placed under the skin are crushed between the fingers, the phagocytes reach the spores, devour them and the animal is protected. Certain non-pathogenic bacteria, which are frequently present in the soil, protect the spores of malignant edema.

In natural immunity to tuberculosis, phagocytes develop into giant cells, destroy the bacilli and lead to calcification. When the spirilla of relapsing fever are injected into the peritoneal cavity of a guineapig, they are devoured by phagocytes. In animals naturally immune to certain cocci-gonococcus, pneumococcus, streptococcus and staphylococcus-phagocytosis is in evidence. Natural immunity to patho? genic organisms other than bacteria, such yeasts, moulds, trypanosomes and protozoa, is apparently largely due to phagocytic activity.

As has been stated, Metchnikoff holds that the polynuclear leukocytes, which he calls microphages, play the important rôle in the bacterial diseases. The eosinophils also are capable of taking in and digesting bacteria. This teaching is so fully accepted that a marked increase in polynuclear leukocytes is taken as an indication of bacterial infection. Microphages are transported from one part of the body to another in blood and lymph, and by means of their pseudopodia, they have independent movements. Under the microscope they can be 
seen projecting their pseudopodia, surrounding and engulfing bacteria. The bacterium is taken into a vacuole filled with clear fluid. If the bacterium be motile its movements may continue in the vacuole, but soon active movement ceases. Vibrios crumble into granules and finally disappear. Bacilli become pale and transparent, then are seen only in shadow and finally this is lost. Cocci swell up, become transparent and then are lost to sight. However, some bacteria, such as the tubercle and leprosy bacilli, remain in the microphage quite indefinitely without recognizable change. The same is true of certain spores. In these cases, there is no digestion, but the body is protected from the multiplication of the organism. Phagocytes take up litmus granules which show no change in color after inclusion, but bacilli stained with neutral red become cherry red in the vacuole, showing that the fluid is feebly acid. While this is the rule, in some phagocytes, as in the giant cells containing tubercle bacilli, the reaction is plainly alkaline. There can be no question that phagocytes engulf and finally destroy bacteria. A phagocyte, which has recently engulfed a living bacillus, when brought in a hanging drop under the microscope, soon dies itself and the liberated bacterium may begin to multiply, but when the inclusion has continued for a longer time, the liberated bacterium does not grow. There has been some discussion over the question of the identity of the digestive ferments of the mononuclear and the polynuclear phagocytes. $A$ priori we should expect them to be different, and the weight of evidence supports this view. Exudates especially rich in mononuclear leukocytes are active as hemolytic agents but have only feeble germicidal action, while those rich in polynuclear leukocytes have no hemolytic action, but are powerful bactericides. Is this difference in both the complement (alexin or cytase) and the fixator (sensitizer or amboceptor) or in the latter only? This question has given rise to some marked differences of opinion but a positive conclusion is not justified by any undisputed evidence and we will leave it for future investigators to answer.

In concluding this part of our subject, it must be admitted that Metschnikoff and those who have labored in the same field have demonstrated that Fhagocytosis is an important factor in natural immunity. 
Phagocytosis in Acquired Immunity.-Metschnikoff has shown that acquired immunity is largely due to stimulated phagocytosis. This is true whether the immunity be due to one attack of the disease or to vaccination. A rabbit which has been immunized to anthrax shows a more marked phagocytosis on inoculation with a virulent culture than does a fresh animal. In the latter there is only a slight serous exudate at the point of inoculation, while in the former there is an abundant accumulation of leukocytes, which ingest and digest the bacilli. A drop of this exudate injected into an animal highly susceptible to anthrax, a guinea-pig or mouse, usually results in fatal infection, showing that the included bacilli are not immediately killed. Some hours after inoculation of an immunized animal, microscopic examination of the exudate shows no free bacilli. All are included in the leukocytes and some seem normal while others show granulation and others degenerative changes. Similar observations have been made on other animals immunized to anthrax by vaccines. The phagocytes are stimulated by the introduction of the attenuated bacilli of the vaccines, and finally become strong enough to contend successfully with those of full virulence.

Pfeiffer has shown that if guinea-pigs be highly immunized to the cholera vibrio by repeated intraperitoneal injections, the clear peritoneal fluid dissolves these organisms much as water dissolves sugar or salt. There is no phagocytosis in evidence. In fact, the peritoneal fluid is quite free from leukocytes. This is known as Pfeiffer's phenomenon, and it has been held by many that it overthrew Metschnikoff's theory of the importance of phagocytosis in acquired immunity. In fact, this phenomenon has divided immunologists into two camps, the holders of the humoral, and those of the cellular theory. Metschnikoff explains Pfeiffer's phenomenon as follows: The repeated injections of the vibrio into the peritoneal cavity have accumulated in that viscus many phagocytes which have been injured and have given up their contents, including their digestive enzyme, to the surrounding fluid. In fact, Metschnikoff has demonstrated masses of these dead leukocytes on the peritoneal walls and the omentum. This destruction and dissolution of the phagocytes he designates phagolysis. The agent in the fluid which dissolves the vibrios is the enzyme from the injured leukocytes. The solvent action proceeds extracellularly, but the sol- 
vent agent is of intracellular origin. Furthermore, he has shown that the phagolysis can be prevented, and when this is done the peritoneal fluid remains rich in leukocytes and phagocytic action is easily demonstrated under the microscope. Still further, Levaditi has shown that phagolysis may occur in other parts of the body. If the cholera vibrio be injected into the circulation of a highly immunized guineapig, the phagocytes practically disappear from the peripheral blood. On sectioning the lungs they are found in clumps and evidently injured. About them are seen masses of the vibrio undergoing digestive changes. Positive chemotaxis still manifests its influence and brings the phagocytes and bacilli together at the place where the former, in undergoing dissolution, pour out a secretion which is fatal to the latter.

If cholera vibrios be injected into the anterior chamber of the eye of a highly immunized guinea-pig, a place where there has been no phagolysis, the phagocytes concentrate here and phagocytosis may be demonstrated.

Further elucidation of this subject seems unnecessary. It is evident that in acquired immunity there is increased activity and effectiveness on the part of the phagocytes in the destruction of the invading organism, which may be destroyed by intracellular or extracellular digestion. In either case the destructive agent is supplied by the phagocytes. Metschnikoff holds that in the body intracellular digestion is the rule and that extracellular destruction plays only a subordinate rôle.

Phagocytosis in Injuries and Disease.-In this section we continue to follow the teachings of Metschnikoff. In inflammation there is an accumulation of phagocytes at the point of injury. When the injury is aseptic, the functions of the phagocytes are to remove the injured body cells and to repair the tissue. In septic wounds the additional duty of destroying the foreign cells falls on the phagocytes. In the lower animals which possess neither nerves nor blood vessels, the motile connective-tissue cells devour the invading organisms. In the higher animals the process is more complicated. Through nerve stimulation, the blood vessels of the injured part are dilated, phagocytes from distant parts of the body are brought to the locality and pass 
through the walls of the vessels. Inflammatory transudates which contain but few leukocytes are the exceptions. They occur only when the injury is so slight that great activity is not needed or at the other extreme when it is so great or the infection is so virulent that repair and resistance are impossible. The mononuclear cells, the macrophages, may become fixed connective tissue and form scar-tissue. The polynuclear cells, the microphages, do not serve this purpose.

There are inflammations which are due to soluble irritants without cellular elements. In these instances the phagocytes assemble and feed on the fluid. Strictly speaking, there are probably but few wounds absolutely free from bacteria, but when these are few in number and non-virulent, they are soon destroyed by the phagocytes and healing by first intention results.

Fehleisen has studied phagocytosis in erysipelas. In the initial stage the streptococci are, for the most part, free; in the second, many are included in phagocytes; in gangrenous areas there are but few leukocytes and these show degenerative changes; in healed areas there are but few free cocci, many in leukocytes, also many macrophages. Beyond the inflammatory area the cocci are free; on the edge many cocci are included in phagocytes; in the third zone the cocci are wanting and there is marked small-cell infiltration. In pneumonia the favorable progress of the disease is indicated by an increase in the sputum of phagocytes containing pneumococci. Immediately after a slight leakage from a diseased appendix all the bacteria are free, with time more and more are found in leukocytes, and in case of recovery, all are disposed of in this way.

Phagocytosis is in evidence in certain systemic infections, for instance, relapsing fever. This has been studied in apes. The first febrile stage lasts a few days and generally ends in permanent recovery. Several apes were killed at different hours in the febrile stage. Before the fever, the spirilla may be abundant in the blood, but with the rise in temperature they can no longer be detected in the peripheral circulation. At the crisis, the polynuclear cells of the spleen are filled with the spirilla, some of which seem quite normal while others show degenerative changes. A fresh ape inoculated with these cells develops the disease, showing that at least some of the included spirilla are still alive and virulent. An examination of the spleen after recovery shows 
all the spirilla markedly changed and inoculation with this material does not induce the disease. It is true that the serum of one in the febrile stage of relapsing fever is markedly bactericidal to the spirillum, but this is due to the destruction of the leukocytes and the passing of the enzyme into solution. There seems no doubt that recovery from relapsing fever is due to phagocytic activity.

Uhlenhuth found that phagocytosis is responsible for the spontaneous healing of experimental syphilis in rabbits. Like success is not in evidence in this disease in man, although here also phagocytosis seems to deserve credit for the healing of specific lesions so far as they spontaneously occur.

The fact that the plasmodia of malaria are engulfed by the phagocytes of the blood, spleen and liver is well known. Many of them are undoubtedly destroyed in this process, but unfortunately many escape to multiply and continue to induce their deleterious effects.

Rindfleisch holds that phagocytes are more or less effective in the removal of gouty deposits. 



\section{CHAPTER XXV}

\section{SPECIFIC PRECIPITINS}

History.-In 1897 Kraus discovered that the blood serum of animals immunized to a given bacterium gives a precipitate when mixed with a germ-free filtrate of a culture of that organism. Further study showed that this reaction is specific. Cholera serum precipitates only cholera filtrates; typhoid serum only typhoid filtrates, etc. Two years later Tchistowitsch and Bordet ascertained that this is a general protein reaction. A rabbit which has had several injections of horse serum yields a serum which precipitates horse serum and no other. One treated with cow's milk furnishes a serum which precipitates cow's milk and no other. One treated with the white of the hen's egg precipitates egg albumin and no other protein. This test is now used practically in the identification of blood stains, in the detection of mixed meats and in the study of the blood relationship of animals.

If a blood stain be dissolved in salt solution and then mixed with the blood serum of a rabbit which has been repeatedly treated with human blood, a precipitate will form if the stain is human blood. If a Hamburger steak be extracted with water, the clear filtrate will be precipitated with the blood of an animal which has been treated with horse's blood provided the steak contains horse meat. The meat of any other animal in the steak can be detected in the same way. If the steak contains beef and horse meat, its extract will precipitate the serum of an animal treated with extract of horse meat also the serum of one which has been treated with an extract of beef. The serum of a rabbit treated with human blood will give a marked precipitate even in a high dilution of human and a slighter one in undiluted chimpanzee's blood serum. This supplies a method of detecting and identifying different proteins in quantities too small to be detected in any other way.

The Precipitinogen.- The substance which is injected into the animal is known as the precipitinogen (producer of the precipitin). Precipitinogens are bacterial, vegetable, and animal. A culture of the 
typhoid bacillus, preferably one several weeks old, is filtered through porcelain, in order to free it from the bacterial cells, then every third or fourth day some of the filtrate is injected into a rabbit. Some days after the last injection, serum obtained from this rabbit precipitates the typhoid filtrate and that of no other bacterium. Other precipitinogens are used in like manner with like result. The thing in the bacterial culture or other fluid, which produces this effect, has never been isolated. We only know that all precipitinogens are albuminous substances, or derivatives of these, and that no fat, carbohydrate or crystalloid has such action. Some precipitinogens contain only simple proteins and these in small amounts, as is shown by the application of tests for proteins.

The Precipitins.-The substance in the immune serum is known as a precipitin. In the sera of certain animals, which have had no treatment, there are natural precipitins. The serum of the untreated ox, undiluted, precipitates many bacterial filtrates. Normal goat's serum gives precipitates with the sera of rabbits and dogs. These normal precipitins do not interfere with our tests because (1) they are not specific and (2) they do not give the precipitates in high dilutions. Not every animal produces precipitins. The best laboratory animal for the production of precipitins is the rabbit. It is best in case of blood tests not to select an animal closely related with that from which the precipitinogen comes. The blood of one animal will not develop a precipitin in another of the same species. The precipitinogen may be administered intra-abdominally, subcutaneously or intravenously. Administration by the mouth produces a precipitin only when for some reason the precipitinogen is absorbed undigested. This may result from overfeeding and easily happens in the young. Puppies, kittens, and rabbits, up to ten days old, frequently absorb unchanged proteins from the alimentary canal and this leads to the production of precipitins. It has been found in a few instances that the serum of infants precipitates cow's milk. This indicates that the casein of the food has been absorbed undigested. It is possible that this is a factor in the causation of cholera infantum. Especially is milk partly changed by peptonizing bacteria likely to be absorbed without digestion. 
The tissue in which the precipitin is formed is evidently not the same in all cases. It depends on the nature of the precipitinogen and the avenue of its introduction. When a foreign protein is introduced parenterally, it has a predilection for certain tissues and this is different for different proteins. We only know at present that precipitins are formed in organs rich in leukocytes. The mononuclear cell is believed to be active in this function. It is probable that the endothelial cells of the blood vessels also have this function.

The precipitin can be thrown down in serum by one-third saturation with ammonium sulphate and seems to be contained in the euglobulin fraction. Attempts to obtain a protein-free precipitin have failed; indeed, I think it highly probable that the precipitin is a protein. When heated to 70 degrees the serum no longer reacts with the precipitinogen.

The Precipitate.-This results from a reaction between the precipitinogen and the precipitin. In case of bacterial filtrates, the precipitate does not form directly on adding the precipitin to the precipitinogen and it is customary to allow the mixture to stand at incubator temperature for from two to twenty-four hours. The rapidity and abundance of the formation of the precipitate depend on the richness of the fluids in their respective active constituents. With animal precipitinogens the precipitate may appear immediately on the mixture of the fluids. Precipitation takes place in neutral, feebly alkaline and feebly acid solutions. When the acidity is due to organic acid or acid salt, the action is promoted. In the complete absence of inorganic salts the reaction fails. The precipitate consists essentially of protein. It contains no carbohydrate group, is insoluble in mineral acid and alkali, and is highly resistant to the digestive ferments. There seems no doubt that the bulk of the precipitate is derived from the precipitin. Pick employed a precipitinogen which did not give the biuret reaction and with this obtained a voluminous albuminous precipitate. Welch and Chapman obtained with a precipitinogen which contained only $1 \mathrm{mg}$. of protein, a precipitate which contained 25.1 mg. of protein. Evidently, in these cases, the bulk of the precipitate must come from the serum. However, this is not always true since the bulk of the precipitate produced with lactosera consists of casein. It is probable that in many instances substances other than the 
precipitinogen and the precipitin are carried down mechanically. When a new dose of precipitinogen is injected into an animal whose blood already contains the corresponding precipitin, the amount of the latter is for a time markedly decreased. This leads to the inference that the union between precipitinogen and precipitin takes place in the body, but there is no evidence that a precipitate is formed in vivo.

That both factors enter into the formation of the precipitate quantitatively is known, but it is not known whether or not the whole of each factor exists in the product, nor is it known whether the reaction is a physical or a chemical one. Evidently the presence of electrolytes is essential to the reaction. Quantitatively the reaction is specific. The serum of animals immunized to one strain of the colon bacillus precipitates the filtrate from this strain in higher dilution than it does the filtrate from other strains, and there may be strains of the colon bacillus whose filtrates it will not precipitate at all. It is quite certain that the precipitation of filtrates agrees with the agglutination of the living bacilli. It is difficult not to believe that the specificity of both these reactions, precipitation and agglutination, is due to the chemical structure of the protein molecule and that both are due to definite cleavage of this molecule in the process of parenteral digestion. 


\section{CHAPTER XXVI}

\section{AGGLUTINATION}

History.-In 1889 Charin and Roger in studying the action of the serum of sick and immunized animals on homologous bacteria, observed that the Bacillus pyocyaneus behaved peculiarly when placed in the serum of an animal immunized to this organism. In the serum of a normal rabbit, this bacillus grows as it does in beef-tea, forming an opaque culture, while in the serum of an animal immunized to it, it forms floccules which soon subside leaving a clear supernatant fluid. Two years later, Metschnikoff noticed that the vibrio which bears his name behaves in a similar manner. He recorded this observation as follows:

In the blood and serum of non-vaccinated guinea-pigs, the vibrio develops as it does in ordinary liquid media, the individual organisms retaining their motility and remaining distinct, one from the other. On the other hand, in the blood and serum of vaccinated animals the vibrios become immobile, and form smaller or larger floccules which float in the liquid.

In 1893 Issaeff, and later he and Ivanoff observed the same phenomenon and described it as follows:

In the blood serum of healthy, non-immunized guinea-pigs the vibrio develops rapidly, and after from four to five hours at $37^{\circ}$ there is a uniform cloudiness throughout the fluid, while the surface is covered with a scum; but in immune serum, the microbes sink to the bottom of the tube, while the supernatant fluid remains clear. This condition continues for from eight to nine days, and it is not until the tenth day that the culture becomes cloudy and a scum appears on the surface.

These observations attracted no attention and in all probability their significance was not appreciated by the observers themselves. In 1896, Gruber and Durham ascertained that this reaction is specific. Each bacterium is clumped by the serum of animals which have been inoculated with it and not by other sera. They suggested that the phenomenon be designated as "agglutination" and that it would prove 
serviceable in the identification of bacteria. A given bacterium is the typhoid bacillus if it is agglutinated by the properly diluted serum of an animal immunized to this organism. If an unknown culture is not agglutinated by the serum of an animal immunized to the cholera bacillus, the culture does not contain this organism. I have carefully read the original paper of Gruber and Durham and fail to find therein any reason for concluding that these investigators at that time had any idea that the phenomenon which they were investigating was soon to become one of the most certain and easily applicable methods for the diagnosis of typhoid fever. It is true that they speak of the serum test as a diagnostic measure, but from the context it is plainly evident that by the term diagnosis they mean the specific and positive identification of a suspected bacterium. A few months after the publication of this paper of Gruber and Durham, Widal demonstrated the value of this reaction in the diagnosis of typhoid fever.

Factors.-It is evident that in such a reaction as that observed in agglutination there must be two factors. One of these, designated the agglutinin, is found in the serum, and the other, known as the agglutinable substance, exists in the bacterial culture. The product of the reaction is known as the agglutinate. The serum of certain normal animals has a slight agglutinating action on certain bacteria, notably typhoid and colon bacilli. The normal serum of the horse, dog, donkey, and rabbit, in an undiluted state, agglutinates typhoid cultures. Some effect may be observed when the serum is diluted $1: 30$. The serum of a man, who has never had typhoid fever, may agglutinate typhoid cultures when the dilution is not higher than $1: 30$. The period in the progress of typhoid fever when marked agglutination manifests itself varies widely. Usually it is not before the seventh day, but it may occur as early as the second day, and it may be delayed until the second week and in rare cases even later. Likewise the disappearance of the reaction after recovery is variable. It may fail within ten days after the loss of the fever, and it has been known to continue for years. In intensity the reaction is variable and bears no indication of the severity or seriousness of the disease. There are many ways in which the phenomenon may be observed and measured. One recommended by Widal and Sicard and much employed is the following: 
A number of small diameter tubes each containing $1,2,3,4$, or 5 c.c. of bouillon, are kept on hand. When a test is to be made, one adds a drop of the serum to each of these tubes and then inoculates each with a typhoid culture. The tubes are then kept at incubator temperature for from four to six hours. At the expiration of this time it may be seen at a glance in which tubes agglutination has taken place, since these will be unclouded and the floccules will be seen on the bottom. The first tube has a dilution of $1: 20$; the second, $1: 40$, etc.

Johnston was the first to show that a drop of blood allowed to dry on non-absorbent paper, may be transported any distance and kept indefinitely and still be capable after solution in water of giving the agglutination test. However, accuracy in dilution is not reached. The reaction may be observed in a hanging drop under the microscope when only one drop of blood is available.

Agglutinins exist not only in the blood, but in other fluids of the body. The agglutinating power of the urine in the same individual is variable not only from day to day, but from hour to hour, and is always feeble compared with that of the serum. Serum obtained by blisters has a relatively high agglutinating value. That of the bile is marked. Pus from typhoid abscesses markedly agglutinates. Agglutinins may pass from the mother to the fetus and to the nursing child. Typhoid serum may be treated with formaldehyd in 40 per cent. solution and kept quite indefinitely without loss of its agglutinating property. However, the use of antiseptics is not necessary to preserve agglutinating sera. A highly active serum will retain its agglutinative action after it has become putrid from bacterial contamination. Dilute mineral acids decrease the agglutinating property of typhoid sera, but when the contact has not been prolonged, full activity may be restored by neutralization. Alkalies act similarly. App arently the agglutinins are not altered by either pepsin or trypsin. In experimental animals, sera can be obtained which will agglutinate typhoid bacilli in dilutions as high as $1: 1,000,000$ and colon bacilli, $1: 2,000,000$.

Quantitatively the agglutinins are specific, but in order to be so considered they must be active in high dilutions. A positive diagnosis of typhoid fever should not be made unless the serum acts decidedly in a dilution not less than $1: 50$, and even in this dilution there is a rare chance of mistake. A paratyphoid serum may agglutinate typhoid 
bacilli in a dilution of $1: 1,000$; or a typhoid serum may act in like dilution on a paratyphoid bacillus. In making a clinical diagnosis such a mistake would be of little or no importance, but in the identification of a bacterium it would be important. According to Paltauf the following dilutions are necessary for the positive identification of the named bacteria: plague bacillus, $1: 1,000$; typhoid and cholera bacilli, $1: 10,000$. The active substance in the serum, the agglutinin, is undoubtedly a globulin. It is inactivated at temperatures which range from 75 to $90 \mathrm{C}$. in different sera.

The active constituent of the culture, the agglutinable substance, is not, in my opinion, an essential constituent of the bacterial cells, but consists of one or more proteins closely associated with the bacterial cells. It may be a protein already split off from the bacterial pabulum in the culture medium preparatory to absorption, or it may be an excretory product. The reasons for this belief may be briefly stated as follows:

1. Agglutination does not destroy the viability or virulence of bacteria; therefore, the reaction does not disrupt the living bacterial cell.

2. Thoroughly washed typhoid bacilli are not agglutinable.

3. When typhoid bacilli are thoroughly shaken in salt solution so as to remove the flagellae and the bacilli are deposited in a centrifuge, the emulsion of flagellae is agglutinable.

4. Cholera bacilli, as shown by Neufeld, when shaken with 1 per cent. alkali, which does not dissolve the cells but washes away the adherent matter, the cleansed cells are not inagglutinable, but when injected into animals they produce no agglutinin.

Agglutination and precipitation are like phenomena. When a bacterial culture is filtered, some of the proteins adherent to the bacterial cells pass into solution and constitute the precipitinogen, some of the same class of near-cell proteins remain in close connection with the cells and constitute the agglutinable substance or the agglutinogen. Inorganic salts are essential to agglutination. The reaction is that of a colloid and the specificity is due to the chemical structure of the proteins entering into the reaction. The agglutinable substance is 
shaped and its chemical structure determined by the ferments of specific bacteria, consequently it is specific.

As Widal concluded years ago, agglutination is not a reaction of immunity, but a reaction of infection. Both agglutination and precipitation are evidences of parenteral digestion. 



\section{CHAPTER XXVII}

\section{OPSONINS}

Metschnikoff ascribes both natural and acquired immunity to the activity of the phagocytes. In the former the leukocytes fall on the invading bacteria and devour them. In acquired immunity the phagocytes are stimulated by the attenuated cultures, or vaccines, and learn how to cope with the invaders. The phagocytes constitute the mobile army of defense. Without previous training they are able to destroy certain bacteria; this constitutes natural immunity. By first bringing them in combat with attenuated cultures, which they satisfactorily dispose of, they are so trained that they become able successfully to combat virulent forms; this explains acquired immunity. Both depend on the efficiency and aggressiveness of the phagocytes. In the main, Metschnikoff's facts have been corroborated, even by those who have desired to controvert them. Phagocytosis is more marked in an immunized animal than in a fresh one of the same species. Is this due to increased efficiency on the part of the phagocytes or to impairment of the bacteria? This is the question now before us.

The fundamental facts essential to the solution of this problem were discovered by Denys and Leclef in 1895 . They showed that phagocytes can be obtained and mixed with bacteria in vitro and that phagocytosis may be observed under conditions controlled by the investigator. They established the following: 1. Phagocytosis proceeds in vitro the same as in vivo. 2 . When the phagocytes are collected from an animal immunized and from one not immunized and these are washed free from all serum and mixed with the immunizing bacteria suspended in either salt solution or normal serum there is no phagocytic action in either tube. The phagocytes from the immunized animal and those from the non-immunized animal are alike impotent. 3. When the two kinds of phagocytes are mixed with the bacteria and suspended in the serum of an immunized animal, phagocytic action begins promptly and is equally marked in the two tubes. 
These facts show that the agent which develops and stimulates phagocytosis is in solution in the blood of the immunized animal, is not present in the blood of the non-immunized animal, and is apart from the leukocytes.

The work of Denys and Leclef seems to have been ignored for some years, and quite ignorant of it, Leishman in 1902 showed that phagocytic action can be demonstrated in a drop of human blood freshly taken. He determined the degree of phagocytic action by counting the included bacteria in a number of phagocytes and showed that these were greater in the blood of one vaccinated with staphylococci than in normal man. In this way, Leishman opened the way for "vaccine therapy," which has since been widely employed. Wright and Douglas developed this treatment and proposed that the substances in the blood which favor phagocytic activity should be designated "opsonins" (from the Greek, $\delta \phi \sigma \omega \nu \nu^{\prime} \omega$, meaning, "I prepare the food"). They showed that the opsonins in normal blood vary in narrow limits and that they are greatly increased by the subcutaneous injection of dead bacterial cultures, known as vaccines. It is only fair to state that many years earlier Wright had used heated typhoid bacteria in vaccination against this disease. It is not my purpose to discuss here either the methods of employment or the value of bacterial "vaccines."

The normal blood of man and other animals contains opsonins or substances which favor phagocytic action with numerous bacteria, and these are increased by proper vaccination. When the normal blood contains no opsonin for a given bacterium, one can be developed by vaccination, that is, by repeated parenteral administration of that bacterium either in numbers too small to endanger life or attenuated or killed by heat. In some instances the bacterium while in the body forms a capsule. This is strikingly true of anthrax and plague bacilli. The apparent purpose of this is self-protection. Not all bacteria which are taken into phagocytes are killed. However, even in these cases phagocytosis is protective to the body. When bacteria undergo complete disruption outside a phagocyte, its poisonous content is set free and exerts its deleterious effects. The inclusion of dead bacteria is protective for the same reason. When there is no phagocytosis and the bacteria are rapidly split up by a bactericidal serum, the greater 
is the danger to life. It follows from this that a large opsonin blood content is more protective than a powerful bactericidal blood.

Certain bacteria are readily devoured by phagocytes in normal salt solution or in inactivated normal serum. In other words, with these bacteria opsonins are not essential to phagocytosis. Naturally these are avirulent organisms. It must not be inferred, however, that all avirulent bacteria are phagocitized without the aid of opsonins. The phagocytic-favoring substances are of two kinds. The first, known as tropins, are evidently of relatively simple structure, are not inactivated by heat, and consequently are present in heated serum. The true opsonins are more complicated, consisting of a thermolabile part, known as alexin or complement, and a thermostabile part, known as fixator or amboceptor. Since both parts are essential to complete action, serum is inactivated by heat. Neither tropins or opsonins induce recognizable alterations in the bacteria which they prepare for phagocytosis. In the study of phagocytosis in vitro, Metschnikoff's finding that bacteria are devoured by the polynuclear leukocytes has been confirmed. The large mononuclear cells are not wholly indifferent in the disposal of bacteria but in this they play a very subordinate rôle. On the other hand, the macrophages are the chief consumers of animal cells, such as red corpuscles, spermatozoa, etc.

It was shown early in these studies that dead, highly virulent bacteria are not readily taken up by leukocytes except in the presence of immune serum. This indicates that dead, as well as living bacteria, especially if of virulent strains, are prepared by the opsonins as food for the leukocytes. From this we infer that in whatever reaction there may be between the opsonins and the bacterial cells, the later show no vital activity.

It was shown by Neufeld and Händel that when rabbits have been treated with injections of milk or egg white, their serum causes leukocytes to engulf milk globules and albumin emulsified with oil. The engulfment is not due to the oil but to the casein or albuminous envelopes.

It is well to show that the opsonins do not act by stimulating the leukocytes. When leukocytes are kept in contact with immune serum for twenty minutes at $37 \mathrm{C}$., then removed and washed wholly free from the serum and then brought into contact with the bacteria there 
is no phagocytosis. On the other hand, when the bacteria are kept in contact with the immune serum, then washed and brought in contact with the leukocytes, active phagocytosis begins. This shows that the serum of an animal immunized to a streptococcus, for instance, does not stimulate the leukocytes but in some way makes the streptococci more inviting as a food.

Parenthetically it should be stated that there are substances which stimulate phagocytes, such as nuclein, peptone, quinin, potassium iodid, etc., but these have nothing to do with opsonins. Anesthetics inhibit phagocytic action and the same is true of narcotics.

The study of phagocytosis in vitro has shown that the immune serum and the leukocytes need not come from the same animal, not even from the same species. Hektoen has shown that immune sera from horses, dogs, rabbits, guinea-pigs, etc., prepare streptococci so that they are readily devoured by leukocytes from man. This list of animals has been extended by Hektoen's students so that it includes certain cold-blooded ones. Streptococci sensitized with immune sera from warm-blooded animals are readily devoured by phagocytes from cold-blooded ones. This makes it all the more certain that the reaction is between the serum and the bacteria. When the latter are prepared by the former, a phagocyte from any kind of an animal will eat them.

The opsonins do not kill the bacteria; indeed, they do not stop their growth nor lessen their virulence. When bacteria have been in contact with homologous immune sera long enough to be sensitized and are then placed in ordinary culture media, they multiply, and their progeny are not found to be sensitized. We infer that the union between cell substance and opsonin has no destructive or radical effect on the former. In fact, Hektoen has shown that anthrax bacilli, streptococci and pneumococci grow abundantly in homologous immune sera.

Phagocytosis proceeds in the same way in vitro and vivo. The serum from a rabbit immunized to streptococcus, will sensitize the streptococcus in a test-tube or in the abdominal cavity of a guineapig, and a healthy phagocyte from any source will eat the prepared food in either place. Indeed many bacteria are more readily disposed of by the phagocytes in test-tubes than in the body, because in the latter they develop in the second and subsequent generations, protec- 
tive capsules. Some show other alterations which evidently have the same purpose. We distinguish between "animal" and "culture" bacteria inasmuch as the former are more resistant especially to the destructive secretions of the body cells.

Observation shows that most of the bacteria taken into the leukocytes are completely digested. The bacterial cells become pale, then granular, and finally disappear altogether. Occasionally a phagocyte takes in more bacteria than it can digest and injures itself, in some cases, fatally. The digestive phenomena are identical in the test-tube and in the body. The tubercle bacillus, although readily engulfed by phagocytes, is not digested. These bacilli probably owe their protection to the abundant deposits of wax and fat which they contain. The intracellular ferment of the phagocytes is studied by collecting a large number of leukocytes and dissolving them in very dilute acid or alkali or breaking them down by alternating freezing and thawing.. This ferment is not destroyed by a temperature of $65 \mathrm{C}$. It is able to digest many bacteria, such as streptococci and pneumococci, which are not affected by extracellular ferments. Levaditi found that the intracellular ferment of the polynuclear cells acts on bacteria but is without effect on red corpuscles, trypanosomes and spirochetes, while that of the large mononuclear cells acts on the latter group and has but little or no action on bacteria. Opie found the ferment from the polynuclear cells, which he calls leukoprotease, acts in neutral or feebly alkaline solution, while that from the large mononuclear cells, which he calls lymphoprotease, acts only in acid solution. When leukoprotease is set free in the body by the disruption of the polynuclear leukocytes, its action is inhibited by soluble substances in the plasma. When lymphoprotease is set free in the blood, its action is inhibited by the alkalinity of the fluid. It appears from this that, physiologically, both of these ferments are active only within the cells which elaborate them. It is by virtue of these intracellular ferments that the phagocytes kill and digest the bacterial and other cells which they engulf.

Whether the action of opsonins on bacteria is wholly physical, wholly chemical, or both, we do not know. Neufeld states that this action is not chemotaxic, because unsensitized bacteria, in suspension with phagocytes, collect about the latter quite as plainly as sensitized bacteria do; but with the former there is no phagocytosis. It seems 
justifiable with our present knowledge to conclude that the opsonins rob the bacteria of some defensive weapon and thus make them easy prey for the phagocytes. To go farther than this at present would result in unprofitable speculation. 


\section{CHAPTER XXVIII}

\section{GERMICIDAL SERA}

Normal Sera.-As early as 1872 Lewis and Cunningham demonstrated the fact that bacteria injected into the circulation rapidly disappear. In the blood of twelve animals which had been given such injections, bacteria could be found after six hours in only seven. In a second series of thirty, bacteria were found after twenty-four hours in the blood of only fourteen, and in a third experiment with seventeen animals, bacteria were found in only two when the examination was made within from two to seven days.

In 1874, Traube and Gscheidlen found that arterial blood taken, under aseptic precautions, from the jugular vein of rabbits into which a small amount of a putrifying fluid had been injected forty-eight hours previously, failed to undergo decomposition for months. They attributed the germicidal properties of blood to the ozonized oxygen. Grohmann found that anthrax bacilli decrease in virulence on being kept in plasma.

In 1887, Fodor found that anthrax bacilli rapidly decrease in numbers when injected into the circulation. He then took blood from the heart with a sterile pipette, inoculated it with anthrax, kept it at incubator temperature and plated it out at intervals. He found that the number decreased for some hours and then multiplied abundantly.

In 1888 Nuttall found that defibrinated blood from various species of animals, sheep, rabbits, mice and pigeons, destroys both pathogenic and non-pathogenic bacteria. He also confirmed the finding of Fodor that after a time the blood loses its germicidal action and becomes a suitable culture-medium in which the bacteria multiply abundantly. In his studies, Nissen reached the following conclusions: 1 . The addition of small quantities of salt solution or bouillon to the blood does not destroy its germicidal properties. 2. Cholera and typhoid bacilli are easily destroyed by fresh blood. 3. In a given volume of blood there is a maximum number of bacilli, which can be destroyed. 4 . Blood, the coagulability of which has been destroyed by the injection of peptone, 
is still germicidal. 5. Blood in which coagulation is prevented by the addition of 25 per cent. of magnesium sulphate, has its germicidal properties decreased. 6. Filtered blood plasma from the horse is germicidal.

At one time, Behring attributed the action of the blood of the white rat on anthrax bacilli to its alkalinity. He made titrations which showed that the blood serum of the rat is more alkaline than that of certain susceptible animals, as the cow, rabbit and guinea-pig. However, there are other and more important points in which these animals differ from the rat than in slightly less blood alkalinity. Had he shown that the blood of the adult rat, which is highly resistant to anthrax, is more alkaline than that of the young rat, which is more susceptible, his argument would have been more reasonable; but even then it would not be convincing evidence.

In 1890, Buchner made valuable contributions to our knowledge of the germicidal properties of blood and stated his conclusions as follows: 1 . The germicidal action of blood serum is not due to phagocytes, because it is not influenced by the alternate freezing and thawing of the blood, by which the leukocytes are destroyed. 2. The germicidal properties of the cell-free serum must be due to its soluble constituents. 3. Neither neutralization of the serum, nor the addition of pepsin, nor the removal of carbon dioxid gas, nor treatment with oxygen, has any effect on the germicidal properties of the blood. 4. Dialysis of the serum against water destroys its activity, while dialysis against 0.75 per cent. salt solution does not. In the diffusate there is no germicidal substance. The loss by dialysis with water must be due to the withdrawal of the inorganic salts of the serum. 5. The same is shown to be the case when the serum is diluted with water and when it is diluted with salt solution; in the former instance the germicidal action is destroyed while in the latter it is not. 6. The inorganic salts have in and of themselves no germicidal action. They are active only in so far as they affect the normal properties of the albuminates of the serum. The germicidal properties of the serum reside in its albumin constituents. 7. The difference in the effects of active serum and that which has been heated to $55 \mathrm{C}$. is due to the altered condition of the albuminate. The difference may possibly be a chemical one (due to changes within the molecule) or it may be due to alterations in 
mycelial structure. The albuminous bodies act on the bacteria only when the former are in an active state.

Vaughan pointed out an inconsistency between Buchner's experimental results and his conclusions. Experimentally he ascertained that peptic digestion of blood serum does not destroy its germicidal properties and yet he concludes that the active principle is serum albumin. Since serum albumin is converted into peptone by peptic digestion and since peptone forms an excellent medium for bacterial growth, Buchner's conclusion that serum albumin is the germicidal constituent of blood serum cannot be true. This criticism has held.

In 1893 Vaughan and McClintock, after reviewing the literature up to that time, reported their work on the germicidal constituents of blood serum as follows: 1 . Serum albumin is not the germicidal constituent. 2. The germicidal substance must belong to the proteins. Otherwise, it would be difficult to explain the fact that a temperature of $85 \mathrm{C}$. renders blood serum inactive. 3. The only protein likely to be present in blood and which is not destroyed by peptic digestion is nuclein.

Having reached these conclusions, the following questions naturally presented: 1 . Is there a nuclein in blood serum? 2. Has this nuclein, if there be any, germicidal properties? Their work answered both these questions in the affirmative. The existence of nuclein in blood serum was confirmed by Lilienfeld and by Kossel, and its germicidal action by the latter. Furthermore, it was demonstrated that injections of nucleinic acid, prepared from yeast and spleen cells, increased both the number of leukocytes in the blood and the germicidal action of the serum. However, Buchner very properly declined to accept nucleinic acid as the chief germicidal constituent of serum, since the latter is inactivated at from 56 to $58 \mathrm{C}$., while aqueous solutions of nucleinic acid are not altered by much higher temperatures.

It should be stated, parenthetically, that the relation of nucleinic acid to the intracellular ferment of the polynuclear leukocytes has never been satisfactorily worked out. The researches of Schattenfroth and others have shown marked differences between the extracellular and intracellular constituents of the blood. The latter has no hemolytic action on the red corpuscles of other species while the former may have. The intracellular germicide is not affected by the salt 
content of the medium, while the extracellular substance is inactivated by the removal of salt from the serum by dialysis. Daubler came to the conclusion that the germicidal constituent of the serum and that of the leukocytes are not identical, the latter remaining active after being heated to $60 \mathrm{C}$. He also found that the germicidal substances obtained from the leukocytes of different species differ in measurable degree when tested on the same bacteria. Many other investigators produced evidence of the fact that the intracellular and extracellular germicidal constituents are not identical.

Petterson designates the intracellular bactericidal constituents of leukocytes and other cells as "endolysis" and his pupil, Kling, summarizes our knowledge on this subject as follows: 1. The germicidal substances (endolysins) of the polynuclear leukocytes may be obtained by the following methods (a) By digesting the cells for half an hour at $50 \mathrm{C}$. in bouillon; $(b)$ by extracting the cells with weak acid or alkali; $(c)$ by alternate freezing and thawing of the cells. They cannot be obtained by digesting with bouillon at $37 \mathrm{C}$., nor with salt solution, nor with 5 per cent. inactivated serum. 2. As tested on Bacillus subtilis, the endolysin bears a temperature of $65 \mathrm{C}$. without recognizable effect on its germicidal action, and it is not until the temperature is increased to $75 \mathrm{C}$. that any such effect is noticed. The endolysins can in daylight at room temperature, and in the dark at 37 C., be evaporated to dryness, and in this state they may be heated for half an hour at $100 \mathrm{C}$. without being destroyed. The serum germicides may be obtained in the dry state in the same manner, but when heated to this temperature they are inactivated. 'The endolysis, as tested on the subtilis, does not pass through a Pukall filter, while the serum germicide does. The endolysins, as tested on the subtilis, the anthrax and the typhoid bacillus are destroyed by the Roentgen ray, while the serum germicide is not. The endolysins can be extracted with ether, while the serum lysins are destroyed by ether. 3. The activity of an inactivated extract of the leukocytes of the rabbit, as tested on the subtilis, may be restored by the addition of a small quantity of the serum extract in a fresh state. Likewise, an inactivated normal serum of the rabbit or the inactive serum of the guineapig may be complemented by the addition of a small amount of the leukocytic extract from the rabbit or guinea-pig, respectively. Fur- 
thermore, an inactivated leukocytic extract from a guinea-pig can be activated by the addition of a small amount of the normal serum of a rabbit. 4. Extracts from the polynuclear leukocytes of rabbits, guinea-pigs, and cats destroy in vitro the timothy, grass and butter bacilli. The extracts from rabbits' leukocytes have a bactericidal action on the bacillus tuberculosis of man. Extracts of rabbit, guinea-pig and cat macrophages (mononuclear cells) do not destroy these acidfast bacilli in vitro. The same is true of the extracts from the thymus glands of rabbits. Living polynuclear leukocytes injected into guineapigs decrease the virulence of the bacillus tuberculosis of man. The leukocytes of the guinea-pig do not have this effect. This must suffice to show that the intracellular and extracellular germicidal constituents of the blood are not the same and we will now return to a consideration of the germicidal action of blood serum.

Buchner named the germicidal constituents of serum, "alexins" (defenders). These are inactivated at from 56 to $58 \mathrm{C}$. At first he believed alexins to be protein bodies, but later he regarded them as proteolytic ferments or enzymes. He did not succeed in isolating the alexins, but he believed that they are secretions of the polynuclear leukocytes and he proposed that these should be designated "alexocytes," which, however, has not been adopted. Metschnikoff holds that the alexins from the polynuclear cells (microphages) are bactericidal, while those from the large mononuclear cells (macrophages) destroy red corpuscles and other animal cells. He designates all alexins as cytases and divides these according to the cells supposed to secrete them into microcytases and macrocytases. However, it has not been demonstrated that the production of alexins is limited to the leukocytes, both mononuclear and polynuclear. Furthermore, Metschnikoff did believe that alexins are intracellular ferments and that their presence in blood serum is due to the dissolution of the leukocytes and that there are no free alexins in blood plasma, except possibly a trace due to the physiologic dissolution of the leukocytes. As has been seen, this view is no longer tenable.

It was shown by the work of Metschnikoff and Bordet that a germicidal serum which has been inactivated by heating to from 56 to $58 \mathrm{C}$. may be reactivated on the addition of fresh serum. Further work has shown that the bacteriolytic substances, present in both nor- 
mal and immune sera consists of two parts, one of which is thermolabile and the other is thermostabile. This is probably true of most, if not all, enzymes. The thermolabile part is now known as alexin or complement; the thermostabile part is known as fixator, sensitizer or amboceptor. The former is present in all sera and the weight of evidence is that it is non-specific. The amboceptor is the specific part. According to Ehrlich's theory the amboceptor, which he has, at different times, designated as intermediary and immune body, but which is now generally known as amboceptor, combines on the one hand with the bacterial or other cell and on the other with the complement. The union between the amboceptor and cell may take place at low temperature (even at $0 \mathrm{C}$., $32 \mathrm{~F}$.), but the complement enters into the reaction only at temperatures not far above or below that of the animal body. The complement is destroyed by a temperature of from 56 to $58 \mathrm{C}$., but the amboceptor is not injured at this temperature. When a serum is heated to this temperature it is inactivated; its bacteriolytic or cytolytic action is interrupted because the complement is destroyed, but the ambocepter is not impaired and the serum is reactivated by the addition of fresh complement which exists in both normal and immune, unheated serum. This applies to all cytolytic sera, whether they manifest their activity on bacteria, red blood cells, spermatic cells or other kind of cell. According to Ehrlich's teachings the union of amboceptor with cell on one hand and with the complement by the other is chemical, while Bordet believes the amboceptor, which he calls a sensitizer, acts as a mordant in coloring and the complement may be regarded as a dye. In other words, Bordet's explanation supposes the action of physical rather than chemical forces.

To conclude this part of our subject, we may say that normal blood, and the serum obtained from it, contains non-specific bactericidal ferments or enzymes. These vary in amount, kind and efficiency in different species. In a general way, the blood is a germicidal fluid and it owes this function to the presence of proteolytic enzymes. In normal blood these enzymes are not specific and they display marked, destructive action on certain bacteria, and are wholly without effect on others. Living cholera cultures, in doses that might infect by way of the intestines, can be. injected into man subcutaneously or intravenously without ill effect. Cattle bear large injections of the organ- 
isms of symptomatic anthrax provided all goes into the blood current directly and the subcutaneous tissue is not infected.

Immune Sera.-The words, immune sera, are likely to be misleading in this connection. Immunity due to bactericidal constituents of the blood, whether it be natural or acquired, is always relative. Even the immunity secured by one attack of the disease may be overcome, in most instances at least, by the administration of an overwhelming dose of the virus in virulent form. The man who has once had smallpox may have it again when brought into intimate and long-continued contact with the virus. The immunity induced by one attack of yellow fever is probably the most complete and persistent form known among the diseases to which man is susceptible. The only way in which a man who has had this disease may be exposed again is through the bite of an infected mosquito, and the virus introduced in this way is always limited and fairly constant in amount. We do not know what would happen to a yellow fever immune should 100 or 1,000 infected mosquitos bite him in the same hour. Experimentally the injection of a large number of bacteria into the peritoneal cavity of highly immune animals kills quickly, and the more marked the immunity, provided it be due to germicidal substances in the blood and lymph, the more promptly and more certainly does it kill. The explanation of this fact is that the fluids of the body promptly split up the bacterial cells, setting the protein poison free in large amount. Nothing exactly similar to this occurs in nature, but the experiment is of great value in demonstrating the phenomena of bacteriolysis. A highly germicidal blood is of great value in preventing infection, because the first few organisms that find their way into the body are promptly killed before they can multiply and while the amount of poison set free is too small to produce any marked effect. On the other hand, it would be highly disastrous for the blood to become suddenly and highly germicidal when the body is filled with bacteria. This would mean sure and speedy death. Phagocytes not only serve the body in feeding on bacteria, but they protect the body from the poison which results from the extracellular cleavage of the bacteria.

The essential difference between the germicidal constituent of normal serum and that of immune serum is that the latter is specific 
while the former is not. Whether the general enzyme is so changed as to have specific action or a wholly new enzyme has been developed, no one can say with certainty. Pfeiffer found that when a mixed culture of the vibrio of cholera and another vibrio was injected into the peritoneal cavity of a guinea-pig immunized to cholera, all the cholera vibrios were dissolved and all the others were left whole. When the same mixed culture was injected into the abdomen of a guinea-pig immunized with the Nordhafen vibrio, all these were dissolved and the cholera vibrios left unharmed. The great majority of bacteria are harmless because they are speedily destroyed by the digestive secretions of the animal body. The germicidal constituent of man's blood is easily made specific by vaccination with cholera or typhoid bacilli. So far no specific bacteriolytic substance has been developed in the blood of any animal with anthrax bacilli or streptococci. It is true that Pasteur developed highly efficient vaccines against anthrax, but these increase phagocytic activity, probably through the formation of opsonins, and do not develop immune sera. It will be understood that we are not now concerned with toxin immunity. We are confining ourselves to the study of specific bacteriolysins.

It has been positively shown that the proteolytic enzyme which destroys the bacteria is not an albuminous substance. Pfeiffer and Proskauer precipitated a highly active cholera serum with alcohol and allowed it to stand for three months with frequent change of the alcohol. From the hard mass which formed, they extracted with distilled water a highly active body which responded to none of the protein reactions. Some serum preserved by the addition of 0.5 per cent. phenol stood for ten years in Pfeiffer's laboratory and was found to be active at the end of that time. The enzyme is not always so susceptible to heat as was first supposed and some samples at least require a temperature of $70 \mathrm{C}$. for one hour for complete inactivation.

When a highly immune serum is injected into an animal it increases its resistance to its homologous bacterium. Animals are actively immunized by repeated treatments with the bacteria, either in attenuated form or in small doses of the virulent form. Animals thus actively immunized furnish an immune serum with which other animals may be passively immunized. It is generally believed that living bacteria give a better active immunization than dead cultures. Many years 
ago Feran used living cholera bacilli subcutaneously as a vaccine against this disease. Wright introduced typhoid vaccination with heated cultures and this has proved highly successful and is now widely used, not only among soldiers but among civilians. Strong recommends highly attenuated typhoid cultures. Besredka combines active and passive immunity in vaccination against typhoid. The growth from a forty-eight hour agar-culture is mixed with a small amount of salt solution. To this is added a homologous immune serum and the mixture allowed to stand for twelve hours. This results in agglutination. The bacteria are washed in salt solution, heated to $56 \mathrm{C}$. for one hour and then injected. Vaccines thus prepared cause no inflammation. The bacteria are sensitized or combined with the amboceptor in the immune serum and probably are more easily split up when introduced into the body. Dead and avirulent plague bacilli have been employed as a vaccine against this disease. The serum of men and animals actively immunized shows a higher bacteriolytic titer than normal serum, but we are not sure that the increased resistance is due solely to this. It must be evident that this method of securing increased resistance to a given infection is in principle the same as that secured by a light attack of the disease. The body cells learn how to combat the infection. They learn how to elaborate a specific enzyme which will destroy the specific bacteria if they should subsequently find their way into the body. For instance, the blood of a man contains no specific enzyme capable of destroying the cholera bacillus. A small amount of this organism is injected under his skin, and the cells of his body under this new irritant learn how to elaborate a specific enzyme which destroys the cholera bacillus. Later, if he drinks water containing this organism, it must be plain that he has a distinct advantage over the unvaccinated man in resisting the infection. The world is indebted to the Spanish physician, Feran, who first had the intelligence and courage to employ this method in combating cholera. He was wiser than his time and from his work has come vaccination against typhoid and plague in man.

Pfeiffer and Mark have endeavored to ascertain in what part of the body this specific immunizing enzyme is formed. For this purpose they inoculated rabbits and killing one from time to time tested extracts from the various organs. They found that the bacteriolytic 
enzyme appears in the spleen first, and within twenty-four hours after the inoculation. The bacteriolytic titer of the spleen extract increased before that of the circulating blood. However, it must not be inferred that the spleen is the only organ in which the specific enzyme is formed. It is possible that many of the cells of the body are capable of performing this function and that an organ specially active in resisting one infection may play a subordinate rôle in another. Heck made a comparative study of the persistence of the typhoid bacilli in various organs of normal and immunized animals after intravenous injections. In the normal animals, they were not found in the circulating blood after six hours; were present in the kidneys and lungs up to the third day; in the liver after the fifth day; in the spleen after the twentieth day and in the bone marrow up to the sixtieth day. In immunized animals, they disappeared first from the spleen and bone marrow, and all organs were sterile on the third day.

The constitution of the specific bacteriolysins is similar to that of the non-specific in normal blood. They consist of alexin or complement and fixator or amboceptor. Their specificity lies in the amboceptor and it is this which combines with, or acts on, the bacterial cells. Pfeiffer describes the action of a highly immune serum on its homologous bacterium as follows: "The micro-organisms first lose their motion, then swell and finally contract into balls, in which some motion may be still seen, showing that living bacilli are being dissolved. For a time the granules seem like micrococci and can be stained. They gradually grow smaller and smaller and finally dissolve in the fluid just as sugar or salt dissolves in water." 


\section{CHAPTER XXIX}

\section{THE GENERAL PRINCIPLES AND MECHANISM OF INFECTION AND IMMUNITY}

Each and every living thing must feed, assimilate and eliminate. Living matter cannot continue in active life without performing these functions. There are certain resting forms in which these functions are, for the time, held in abeyance. Such are, eggs, spores, seeds and reproductive cells. These organisms possess only potential life; they are not in active life. A grain of corn or wheat, or any vegetable seed, contains a germ cell, a store of food and an enzyme. When placed in the ground, under suitable conditions of temperature and moisture, the enzyme begins to split up the stored food, the germ cells begin to utilize the split products and potential life awakens into active life. The revivified germ cell is now able to feed on the constituents of the soil, the stalk grows and the grair or seed is reproduced. The spores of anthrax are only potentially alive and active life begins anew only in the presence of proper nutriment. The granules into which certain other bacteria are changed in the absence of food are further examples of resting forms. Ova, whether those of lower or higher animals, after stimulation by the spermatic cells, and under proper conditions, begin to develop into active life. In all cases life in one form or another is potentially, at least, continuous.

No thing in active life remains in a condition of equilibrium. It absorbs, assimilates and eliminates. Metabolism is a life runction and there can be no active life without it. Indeed, it is metabolism, active and latent, that distinguishes between living and dead matter. When matter becomes endowed with this function, it is no longer dead, but is alive. Nothing in active life can be conceived of as existing alone. It must have food or die.

The morphologic unit of life is the cell, although the physiologic unit is the molecule or the group of molecules essential to the cell. All living things are essentially proteins. The cell may contain carbo- 
hydrates, fats and extractives, but the functions of life reside in its protein molecules. Each kind of life must consist of its own specific proteins and there are as many kinds of proteins as there are kinds of cells. It follows that proteins are specific. Those of the colon bacillus are not identical with those of the typhoid and differ more widely still from those of the tubercle bacillus. Relationship between varieties and species depends on similarity in the chemical constitution of the molecules. The essential proteins of wheat and barley are not identical, but are more closely related in chemical structure than are those of barley and those of pumpkin seed.

All cells, so long as they are in active life, must feed. Otherwise, they cannot grow and multiply. This is equally true of cells which have an individual existence and constitute unicellular forms of life, and of those which have a communal life and exist in the organs of multicellular beings, such as man. A living cell can feed only on that with which it comes in contact. Some of the cells of man's body, such as the leukocytes, can go in quest of food, while others are fixed and must depend on what is brought to them.

Each cell feeds by means of its enzymes which split up the pabulum into blocks which can be fitted into its molecular structures. Each kind of cell must have its own specific ferment or ferments and there are as many kinds of ferments or enzymes as there are kinds of cells. There are enzymes which split up carbohydrates, known as diastases, and those which split up fats, known as lipases, but in our studies of infection and immunity, we are especially concerned with those that split up proteins, known as proteases or proteolytic enzymes or ferments. These enzymes are specific in two senses; first they are products of specific cells and second, they can act only on proteins of certain chemical structure. It must be evident that a cell can feed only on that material which is digestible by its enzymes. This is true of single cells and of multiple cells. Horn contains proteins and other nitrogenous substances, but man cannot live on it because the enzymes of his alimentary canal cannot digest it. Only that which its enzymes can properly prepare for assimiliation is food for the organism, whether it be unicellular or multicellular. With this understanding of the conditions under which cells grow and multiply, we are ready 
to study some of the phenomena of infection. In doing this we will confine ourselves to bacteria.

Bacteria.-There are some widely prevalent views concerning bacteria which in my opinion are quite erroneous. It is generally stated that bacteria are low forms of plant life. This belief is founded on an early observation that they are not readily soluble in dilute acids or alkalies. Is this enough to justify their classification as plants? Hair, skin and horn are not readily soluble in dilute acid or alkali and still they can hardly be called plants. Plant cells, generally, at least, contain cellulose; bacteria do not. Plants, under normal conditions, take in carbonic acid and give off oxygen; bacteria absorb oxygen and give off carbonic acid. Many think that bacteria contain no nuclei, because there is no differentiation in staining, but it should be remembered that their staining properties show that they are practically wholly composed of nuclein. Some think that they are of simple chemical structure, because morphologically they are simple. I and my students have shown that, chemically, bacteria are quite as complicated and as highly developed as are the cells of man's body. Functionally, they are highly developed. It is important to hold this in mind in studying the contests between bacterial and body cells, which so often end in the discomfiture of the latter.

Bacteria live and multiply through the activity of their enzymes. Their extracellular enzymes split the pabulum within their reach into proper blocks and their intracellular enzymes fit these blocks into the bacterial molecule. It must be plain that a bacterium, whose enzymes cannot act on body proteins, cannot infect that animal. Such a bacterium may grow outside the animal body, feed on dead material and elaborate a poison which may harm the animal. Such a bacterium is the Bacillus botulinus. The peptonizing bacteria of milk so change the milk proteins that they are absorbed through the intestinal walls of infants and are further digested in the blood and tissues with the formation of poisons which cause the symptoms and lesions of cholera infantum and the other diarrheal diseases of infancy. During intrauterine life, all the processes of digestion are parenteral, that is, they do not occur in the intestine but in the blood and tissues. In infancy, the walls of the intestine are easily permeable and parenteral digestion 
continues, especially when the food proteins are altered by bacterial growth. In rare cases of summer diarrhea, casein, but little altered, has been detected in the biood by biologic tests. Bacteria which cause disease by the elaboration of toxins or poisons in foods before they are taken into the body are known as toxicogenic organisms. This term was proposed by me many years ago.

Body Cells.-These live, like the bacterial cells, by means of their enzymes which also are extracellular and intracellular. The former cleave the pabulum properly and the latter fit the blocks into the molecules. The feeding cells are not confined to the leukocytes. All the living cells of the body, so long as they are alive, feed. They eat, assimilate and eliminate. In the higher animals, including man, the gross digestion for the whole is done in the alimentary canal. This is known as enteral digestion. The special preparation of food for the cells of the different organs, however, is done by their own specific enzymes and this process is known as parenteral digestion. Moreover, occasionally, proteins in small amounts pass from the alimentary canal into the lymph and blood without complete digestion. Fine bits of organic matter are inhaled and find their way into the system without being subjected to any form of enteral digestion. Finally, and of the greatest importance in the present study, living proteins, known as bacteria, find their way into the tissues. These not only have escaped enteral digestion, but they are capable of growth and multiplication, and if their development in the body be prevented it must be through parenteral digestion. Whether they are engulfed by phagocytes or destroyed by the fluids, it is in either case parenteral digestion. It must be evident that parenteral digestion is the big and deciding factor in most cases of infection. If it fails or if it is slow in procedure, the invading bacteria may multiply. If it proceeds promptly and efficiently the invaders, which under natural conditions are few in number, are destroyed before they can multiply and the body is protected. Now, we have the great problem of infection and immunity fairly before us. It is a contest between bacterial and body cells and, as we have seen, they are armed with similar weapons. The bacterial cells have their enzymes, poisons and toxins. The body cells have their enzymes, bactericidal and bacteriolytic agents, opsonins, and phagocytes. The phagocytes constitute the mobile army of defense 
and the fixed cells elaborate destructive weapons. Which of these bears the brunt of the defense depends on the armament of the invader.

Whether a given bacterium is pathogenic to a given animal or not, depends essentially on two things. First, can it feed on the proteins of that animal's body? If it cannot, it can do no harm. Secondly, can the cells of the body destroy the invading cells before they can multiply?

The Phenomena of Infection.-It should be clearly understood that only a living thing can infect. It must not only be alive, but it must be able to multiply in the animal body. It is true that the injection of diphtheria or tetanus toxin into an animal may cause all the symptoms and lesions of disease, but this is an artificial procedure, and, besides, the toxin is the product of bacterial growth. An infectious disease arises when foreign cells find their way into the body and multiply to the detriment of the body cells. Simply carrying virulent bacteria on the surface or in the cavities of the body does not constitute infection. It is not rare to find tubercle bacilli on the hands of those who care for others ill of this disease. According to Flügge, 70 per cent. of those in houses where there is a case of epidemic meningitis carry the organisms. In a schoolroom in which a child has developed diphtheria, 30 per cent. of all the children may have the diphtheria bacillus in their throats and are not infected. In order to develop infection, the bacterium must feed on the body. Carriers of infection are of importance to the epidemiologist, but they are not necessarily infected. The bacterium must not only feed on the animal tissue, but it must multiply. The essential difference between saprophytic and pathogenic bacteria is that the latter can multiply in the animal body, while the former cannot. Saprophytic bacteria contain in their cellular substance just as much protein poison as the pathogenic organisms do and it is easy to kill an animal by injecting a relatively large amount of them into the abdominal cavity, but this is not infection. A bacterium is not pathogenic to a given animal unless it can convert that animal's proteins into its own proteins.

Saprophytic bacteria are speedily digested by the enzymes in the blood and tissues of the body, and if they be injected in large amount the protein poison set free may be sufficient to quickly kill the animal. 
So great is the bacteriolytic action of the blood that even some pathogenic bacteria do not infect when injected directly and wholly into the blood. This is true of the bacillus of symptomatic anthrax. A dose which infects when administered subcutaneously, fails when given intravenously. The cholera bacillus is harmless when introduced subcutaneously in doses which would infect by the intestine. In the first instance, it is speedily killed by the bactericidal constituents of the tissues; in the second it grows and multiplies in the intestine in which it does not come in contact with the germicidal agents.

There are many conditions which influence the capability of bacterial growth in the animal body. A given bacterium may be pathogenic to one species of animal and without effect on another. Some are active in mixed cultures, one bacterium being of assistance to another. Some grow in certain tissues of the body and not in others. The number of bacteria introduced into the animal is an important factor. One anthrax bacillus may kill a mouse and one tubercle bacillus may have a like effect on a guinea-pig, but these are exceptions, and whether or not an infection results depends, in most instances, in part, on the number and virulence of the organisms introduced.

While the blood has a marked bactericidal action on some bacteria, it forms an excellent culture-medium for others. Virulent streptococci, plague and tubercle bacilli grow abundantly in the blood and kill the more promptly the sooner they find their way into the circulation. Quite naturally, many bacteria grow most vigorously in injured and necrotic tissue on account of the lessened resistance. The readiness with which streptococci take possession of tissues already weakened by cancer, tuberculosis or syphilis is an illustration.

Incubation.-The period of incubation of an infectious disease is the time interval between the introduction of the infecting agent and the first appearance of the symptoms of the disease. This varies greatly in different diseases and for the same diseases in different animals. With the same disease in the same species there are also variations, but not so marked. For instance, one swallows typhoid bacilli, he does not develop fever the same day or the next, but as a rule between the sixth and tenth day. In some individuals the period of incubation for this disease may be longer. During this period 
there is no recognizable disturbance in the health of the individual, either subjectively or objectively. He considers himself well and attends to his usual duties, and yet this is an important and critical time in the development of the infection. The bacilli are growing and multiplying enormously in the man's body. They are converting body proteins into bacterial proteins, native into foreign proteins, and this goes on without the host being conscious of it. The ferments of the bacterial cells are fitting the body proteins into the cellular molecules of the bacteria. During the period of incubation, the bacterial cells supply the enzymes, the body proteins constitute the substrate, the process is synthetic and constructive, no poison is set free and consequently no symptoms are manifest. It follows that the multiplication of the typhoid bacillus in man's body is not the direct cause of the symptoms of the disease. There is no evidence that the growth and multiplication of the bacilli proceed at the expense of, or directly cause injury to, body cells. The bacilli feed on the simple, soluble proteins of the body. A tubercle bacillus passes through the intestinal wall and leaves no lesion. A plague bacillus may penetrate the skin of an animal and make no visible alteration. The rate at which the virus multiplies during the period of incubation is an important factor in determining the final outcome. The more virulent the virus, the more rapidly does it multiply, and this means a larger amount of body protein converted into bacterial protein. The phenomena of the period of incubation may be studied in a guinea-pig into the abdominal cavity of which a fatal dose of a virulent culture of the colon bacillus has been injected. In this experiment the incubation period is from eight to twelve hours, during which time the infected animal is in its behavior undistinguishable from its untreated fellows. However, if a drop of the abdominal fluid be taken out from hour to hour it will be seen that the bacilli are multiplying rapidly.

The Disease.-In some cases the period of incubation passes abruptly, in others more gradually, into that of the active disease. Symptoms, both subjective and objective, develop and indicate a more or less marked departure from health. In some diseases there is a chill, which may vary greatly in severity, and this is followed by fever. Evidently something has happened which disturbs physiologic 
processes. The body cells have begun the contest against the invaders. Since the invasion began they have been preparing for the war and now the battle has begun. The bacilli have gained entrance and multiplied at the expense of the soluble proteins of the body because the animal cells were not at first prepared to combat them. Now they have developed bactericidal and bacteriolytic ferments and opsonins, possibly antitoxins, and with these the further development of the bacteria is to be contested. When the infecting organism is a toxin producer, like the diphtheria or tetanus bacillus, it is not the cellular substance of the bacteria which directly and immediately endangers the body cells, so . much as its soluble product, the toxin. In this case, the contest is decided by the ability of the body cells to elaborate and make available enough antitoxin to neutralize the bacterial toxin. In this case, the therapeutic administration of antitoxin has secured to curative medicine its greatest triumph, and success or failure depends on the early administration of this magical cure in sufficient amount. The cells of the horse have been trained to produce this body and now it is poured into the blood current of the child to save its cells from destruction. The diphtheria bacilli contain a cellular poison, quite different from the toxin, but since the bacilli, except in small numbers, are not in the child's blood and tissue, but in its throat, the cellular poison may be neglected, for as a rule the few in the body do not contain enough poison to endanger the life of the child. Cure, then, depends on the neutralization of the toxin before it has done irreparable harm.

When the infecting bacterium is one best combated by phagocytes, the body cells supply opsonins which, in some way yet unknown, render the invaders less resistant to the leukocytes. In these cases, the result depends on the effectiveness with which both the fixed and mobile cells of the body perform their functions. One of the important factors is the number as well as the virulence of the invading bacteria at the time when the contest begins. The greater the number, the more must the phagocytes devour, and feeding is a limited function. The more virulent they are, the less effective will be the opsonins. Rosenow has shown that the opsonins are not effective against the more virulent strains of streptococci and that infection with these generally proves fatal. It is worthy of note that bacteria devoured by phagocytes do not endanger the life of their host to the extent and in the same way 
as do those which suffer extracellular digestion. In the latter instance, the cellular poison of the bacteria is set free and in its death it becomes most dangerous to its host.

By far the larger number of bacteria which infect man do not elaborate soluble toxins and for these we can have no antitoxin. Of the other pathogenic bacteria there are many which, in first infections at least, are not to any large extent devoured by phagocytes. The members of this large class, which cannot be met with antitoxins or disposed of by stimulated phagocytosis, must be dealt with by bactericidal and bacteriolytic enzymes. The potent poison which they contain is set free and exerts its deleterious effect, which is determined by the rapidity with which the bacterial cells are disrupted. It must be evident that the development of powerful bacteriolytic enzymes at a time when the body is filled with bacteria would be most disastrous. The faster the invaders are destroyed, the more danger is there to the host. This is well illustrated in typhoid fever, in which the bacillus produces no soluble toxin and consequently there can be no antitoxin developed and in which there is no increase in the phagocytes. The greatest misfortune that happens in the progress of typhoid fever is the rapid development of a powerful bacteriolytic enzyme and the speedy destruction of the invading bacteria in large numbers. This is true of plague and typhus, as well as of typhoid fever. It does not apply to diseases due to soluble toxins, such as diphtheria and tetanus, and probably not to those combated exclusively by phagocytes, if there be such.

The assertion has been made that the infectious diseases have benefited the race by the destruction of the unfit. This idea I have combated most vigorously since our study of typhoid fever in the army in 1898. My colleagues and I found that out of 9,481 soldiers who had previously been on the sick report and could not be regarded as possessing standard health, 648 , or 6.8 per cent., contracted typhoid fever; whereas, out of 46,383 men who had no preceding illness, 7,197, or 15.3 per cent., developed typhoid fever. More than 90 per cent. of the men who developed typhoid had no preceding intestinal disorder.

Under ordinary conditions the strong, busy man, especially the one whose activities demand wide excursions from his home, is more likely to become infected than the one whose sphere of action is more 
limited on account of infirmity. The reason for this is too obvious to need statement, and it follows that more men than women and more adults than children have typhoid fever. Moreover, the case mortality is greater among the strong, because death in this class of infectious diseases is often due to the rapidity with which the invading organism is broken up by the secretions of the body cells and the protein poison made effective. From this I have concluded that contagion, like war, destroys the very flower of the race. This view is sustained by the historians of the pestilences of former times.

Thucydides, in his description of the plague at Athens, says: "Moreover, no constitution, whether in respect of strength or weakness, was found able to cope with it; nay, it swept away all alike, even those attended to with the most careful management." Procopius, in his account of the Justinian epidemic, states that youth was the most perilous season, and females were less susceptible than males. Cogan, in describing an outbreak of typhus at Oxford in 1577, writes: "The same kind of ague raged in a manner over all England and took away very many of the strongest sort, and in their lustiest age, and for the most part, men, and not women and children, culling them out here and there, even as you would choose the best sheep of a flock." In his account of the plague of 1665 in London, Boghurst makes the following statement:

Of all the common hackney prostitutes of Luteners-lane, dog-yard, crosslane, Baldwins-gardens, Hatton-gardens and other places, the common criers of oranges, oysters, fruits, etc., all the impudent drunken, drubbing bayles and fellows and many others of the rouge route, there is but few missing - verifying the testimony of Diemerbroech that the plague left the rotten bodies and took the sound.

Like testimony comes from an account of the plague at Moscow: "Drunkards and persons of feeble temperament were less subject to attack." Davidson observed that typhus fever was more frequent among the robust than the weak. He states that out of 429 cases, the spare and unhealthy taken together made only about 17 per cent. He adds that the death-rate among the poor was one in twenty-three, while among the well to do, it was one in four. The greater mortality of typhus among the higher classes has been noted by Barber and Cheyne and by Braken. Hurty, nearly a century ago, wrote: "A fever which 
consigns thousands to the grave, consigns tens of thousands to a worse fate-to hopeless poverty, for fever spares the children and cuts off the parents, leaving the wretched offspring to fill the future ranks of prostitution, mendicancy and crime." Creighton says:

The best illustrations of the greater severity and fatality of typhus among the well to do come from Ireland in times of famine, and will be found in another chapter. But it may be said here, so that this point in the natural history of typhus may not be suspected of exaggeration, that the enormously greater fatality of typhus (of course, in a smaller number of cases) among the richer classes of the Irish families, who had exposed themselves in the work of administration, of justice, or of charity, rests on the unimpeachable authority of such men as Graves, and on the concurrent evidence of many.

In the active stage of disease due to bacterial invasion of the body, the body cells supply the ferment, the bacterial cells constitute the substrate; the process is essentially destructive and analytic; complex cellular proteins are split into simple soluble bodies; the protein poison is set free, exerts its deleterious effects on the body cells and disturbs the health; the evidence of infection rises to the plane of clinical observation; the symptoms of the disease become manifest and the contest between bacterial and animal cells continues until one or the other holds possession.

It should not be understood that there is always a sharp line of demarcation between the period of incubation and the appearance of active disease. The bacterial growth may be extending into new parts of the body coincidently with its destruction in other regions.

Fever.-All bacteria are capable of inducing fever, and this is a most constant accompaniment of infection. Fever is not directly due to the growth of bacteria in the body. It is not in evidence during the period of incubation when bacterial growth is most abundant. The early progress of tuberculosis is without fever, because at this time the number of bacilli in the body is few and most of these are living. It is not until the body becomes sensitized against the invading organism and begins to digest and destroy it that fever makes its appearance. The face may be covered with acne pustules, each of which contains streptococci, and still there is no elevation of temperature, because the cocci are not reached and digested by the bacteriolytic enzymes of the blood and lymph. The fever of infection results from the parenteral digestion of the bacterial proteins. 
Many years ago Gamaleia showed that fever follows the parenteral introduction of dead as well as living bacteria, either pathogenic or non-pathogenic. He concluded that fever is not a phenomenon of bacterial growth in the body. Furthermore, he found that the less virulent the organism, the higher and more persistent is the fever. A rabbit inoculated with the anthrax bacillus suffers a fever for only a few hours, when the temperature falls and death results, while one inoculated with a highly attenuated anthrax culture (the second vaccine) shows fever for three days and then recovers. With a highly virulent culture, there may be but litte or no elevation of temperature and death comes within from five to seven hours after inoculation. The febrile process is not a result of the activity of the bacteria, but, on the contrary, is due to a reaction of the body against their presence and marks their destruction.

More recently it was shown by experiments in my laboratory that fever can be induced in animals by the subcutaneous injection of proteins of diverse origin and structure, and that by modifying the size and frequency of the dose, the type of fever can be determined at will. By injecting egg-white into rabbits and by regulating the size and interval between doses, one may induce an intermittent, remittent, continued or acute fever. In the last mentioned, the temperature can be carried to $107 \mathrm{~F}$. with a fatal termination. Not only fever but its accompaniments also may be developed. In the continued fever thus induced, there is the morning fall and the evening rise so constantly seen in typhoid. There is loss of appetite with lassitude, gradual emaciation, decreased urinary output and increased nitrogen elimination. Protein fever, which includes all infective and practically all clinical fevers, results from parenteral digestion. In this process the animals' cells supply the ferment and the foreign protein constitutes the substrate. The foreign protein may enter the body living or dead, with or without form. It may be detached and dead tissue from the animal's body, as after burns. It may be absorbed from some mucous surface, as in hay fever. It may be artificially introduced, as in serum disease. It is usually a living protein, as in the infectious diseases.

There are other causes of fever, but that of the infectious diseases results from the parenteral digestion of the infecting agent by specific 
secretions elaborated by the body cells. It is a phenomenon of the disposal of foreign and harmful material and it must be recognized as beneficent. However, there is a point above which it becomes a danger per se. In parenteral digestion, the following sources of heat production must be evident: 1 . The unaccustomed stimulation and consequent increased activity of the cells which supply the enzyme must be the source of no inconsiderable increase in heat production. 2. The cleavage of the foreign protein increases the heat liberation. 3. The reaction between the digestive products and the tissues leads to increased heat production. I regard the first and third as the important sources of the overproduction of heat in the infectious diseases.

There are many conditions affecting the course of a fever and some of these may be mentioned. Some viruses sensitize more quickly and thoroughly than others. It is possible that the living bacterial cells, so long as they are living, do not sensitize. Some of the bacterial protein must pass into solution before cell penetration, which seems essential to thorough sensitization, can occur. A living colon bacillus of not more than twenty-four hours' growth, when injected intraabdominally in a guinea-pig, requires about ten hours to sensitize. With dead bacilli the time is reduced to half, while with old autolyzed cultures, in which the sensitizing group is already in solution, the time is further shortened. Some pathogenic bacteria, like the tubercle bacillus, have been so long parasitic that they have learned to protect themselves by deposits of fats and waxes. Others form capsules which serve a like purpose. In this way they are probably protected to some extent against the destructive enzymes elaborated by the body cells. In all the infectious diseases, the destruction of the invading organism is modified and delayed by the altered relation between ferments and substrate and the accumulation of fermentative products. The blood is a highly active digestive fluid with a finely adjusted balance between ferment and antiferment, which will soon be better understood and the solution of this problem will add another triumph to scientific medicine. When the ferment in the blood is suddenly activated, immediate death results, as is seen in anaphylactic shock. When properly regulated, this delicate mechanism protects against harmful bodies, both those introduced from without and those generated within. 



\section{N D E X}

Agglutination $\ldots \ldots \ldots \ldots \ldots \ldots \ldots \ldots \ldots . \ldots 201$

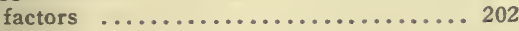

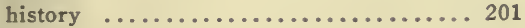

Agglutinin $\ldots \ldots \ldots \ldots \ldots \ldots \ldots \ldots \ldots . \ldots 202$

Alexins ........................ 217

Amboceptor ................... 218

Anthrax ...................... 77

avenues of infection.............. 85

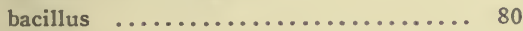

history $\ldots \ldots \ldots \ldots \ldots \ldots \ldots \ldots \ldots \ldots, 77$

symptomatic ................... 127

symptomatic, bacillus............. 127

symptomatic, history.............. 127

Bacteria .....................27, 225

antagonism between ............. 28

capsules of ................... 16

flagella of ................... 30

metabolism .................. 32

morphology of ................. 27

multiplication $\ldots \ldots \ldots \ldots \ldots \ldots \ldots \ldots . .28$

oxygen need of ................. 30

pathogenicity ................. 33

spore formation............... 27

structure .................... 31

symbiosis of ................. 29

Body cells.................... 226

Botulism ......................... 137

bacillus $\ldots \ldots \ldots \ldots \ldots \ldots \ldots \ldots \ldots . \ldots 138$

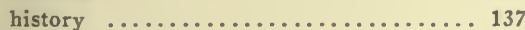

Cells, body.................... 226

Cholera, Asiatic................ 57

bacillus $\ldots \ldots \ldots \ldots \ldots \ldots \ldots \ldots \ldots . \ldots \ldots$

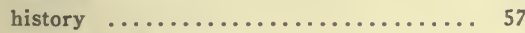

sources of infection............. 62

Death-rates from infectious diseases..... 14

Disease, theories concerning........... 19

Diphtheria ...................... 167

antitoxin ...................... 170

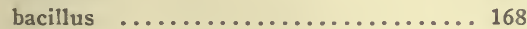

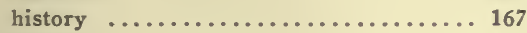

Dysentery $\ldots \ldots \ldots \ldots \ldots \ldots \ldots \ldots \ldots \ldots . \quad 87$

Flexner bacillus................ 89

history $\ldots \ldots \ldots \ldots \ldots \ldots \ldots \ldots \ldots \ldots . \ldots \ldots$

Shiga bacillus................ 88

sources of infection.............. 91

Edema, malignant................ 131

bacillus $\ldots \ldots \ldots \ldots \ldots \ldots \ldots \ldots \ldots \ldots 131$

history $\ldots \ldots \ldots \ldots \ldots \ldots \ldots \ldots \ldots \ldots . \ldots \ldots$

Endolysis ........................ 216

Eye as portal of entrance for bacteria.... 35

Fever of infection................ 233

Gas phlegmon................... 132
Germ theory $\ldots \ldots \ldots \ldots \ldots \ldots \ldots \ldots \ldots .23$

Germicidal sera................. 213

Glanders ....................... 133

avenues of infection............... 134

bacillus ......................... 134

history ....................... 133

Immune sera.................... 219

Immunity $\ldots \ldots \ldots \ldots \ldots \ldots \ldots \ldots . \ldots . \ldots 177$

acquired, phagocytosis in........... 192

and infection, mechanism of......... 223

natural, phagocytosis in ............ 188

Incubation period of infection......... 228

Infection and immunity, mechanism of... 223

avenues of ................... 35

fever of ..................... 233

phenomena of ................ 227

Infectious diseases, death-rates from..... 14

disease, incubation period........... 228

Intestines as portal of entrance for bacteria ....................... 37

Koch, work of .................. 25

Leprosy ....................... 51

avenues of infection.............. 54

bacillus ..................... 53

history of ................... 51

present distribution.............. 52

Lungs as portal of entrance for bacteria.. 36

Malta fever...................... 139

history ........................ 139

organism ...................... 139

Miasm, theory of................ 22

Mouth as portal of entrance for bacteria.. 35

Normal sera.................. 213

Nose as portal of entrance for bacteria... 35

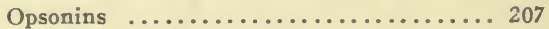

Pasteur, work of ................. 24

Phagocytosis ..................... 183

in acquired immunity ............ 192

in injuries and disease............ 193

in natural immunity.............. 188

Plague ...................... 111

bacillus .................... 117

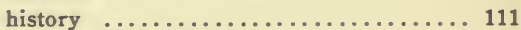

mode of infection................ 121

Pneumonia ..................... 143

bacillus ..................... 144

history $\ldots \ldots \ldots \ldots \ldots \ldots \ldots \ldots \ldots \ldots 143$

Precipitate .................... 199

Precipitinogen ................. 197

Precipitins ....................... 198

specific ....................... 197

specific, history ................ 197 
Pseudotuberculosis .............. 49

Sausage Poisoning: see Botulism........ 137

Sera, germicidal................ 213

immune ..................... 213

normal .................... 213

Skin as portal of entrance for bacteria... 35

Staphylococcic infection............ 161

infection, organism............. 161

Stomach as portal of entrance for bacteria. 37

Streptococcic infection............. 153

infection, history.............. 153

infection, organism.............. 154

Tetanus ......................... 149

bacillus ........................ 149

history .................... 149
Tuberculosis $\ldots \ldots \ldots \ldots \ldots \ldots \ldots \ldots \ldots . . \ldots$

avenues of infection............ 47

avian type of ................. 44

bacillus $\ldots \ldots \ldots \ldots \ldots \ldots \ldots \ldots \ldots, 40$

bovine bacillus ................ 42

history ...................... 39

piscidian variety of $\ldots \ldots \ldots \ldots \ldots \ldots \ldots 45$

pseudotuberculosis................ 49

sources of infection.............. 48

Typhoid fever................... 65

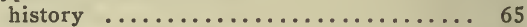

sources of infection............. 70

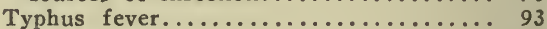

history $\ldots \ldots \ldots \ldots \ldots \ldots \ldots \ldots \ldots, 93$

organism ........................ 108

transmission $\ldots \ldots \ldots \ldots \ldots \ldots \ldots \ldots 106$ 


\section{DATE DUE SLIP}

UNIVERSITY OF CALIFORNIA MEDICAL SCHOOL LIBRARY

THIS BOOK IS DUE ON THE LAST DATE STAMPED BELOW 


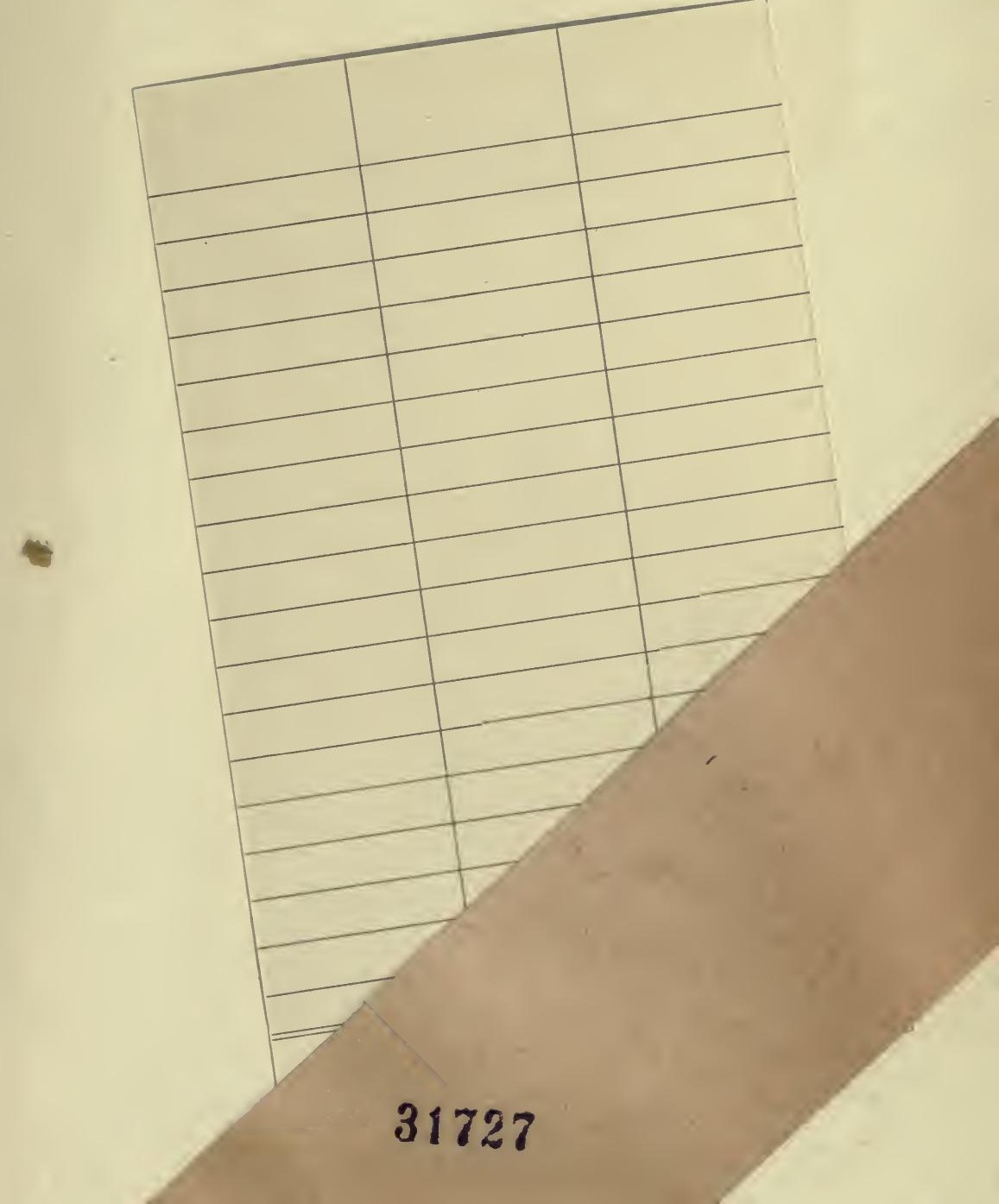




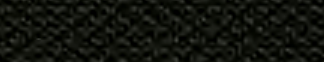

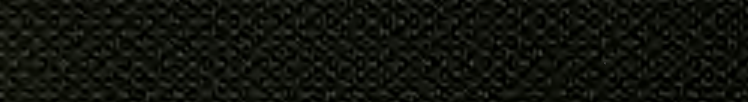

Sors.

(2)

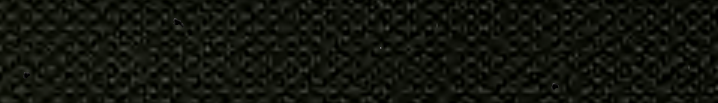

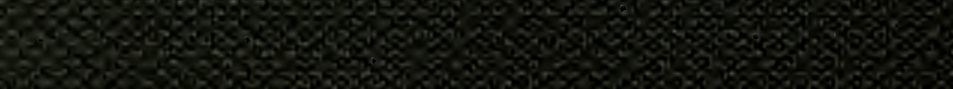

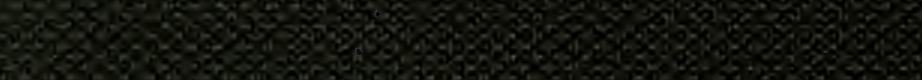

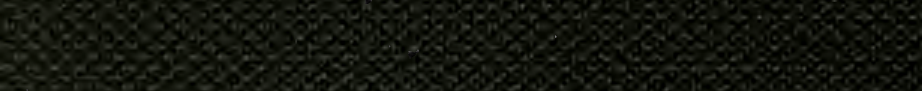

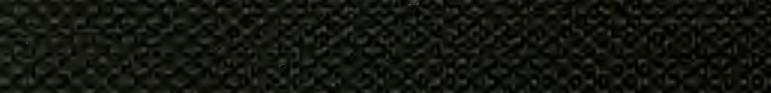

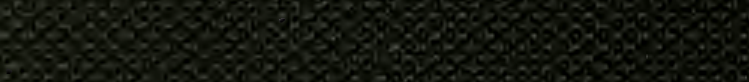

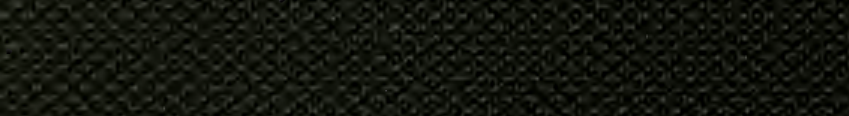

$\frac{1}{8}$

40300 .

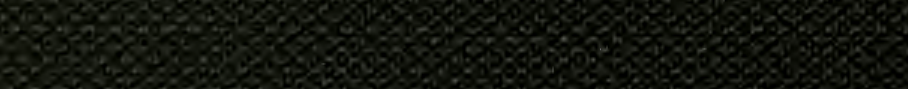

35 .

3.

\% 0.0 